\title{
Rezente und fossile Böden auf niederrheinischen Terrassen und deren Deckschichten
}

\author{
Von Wilhelm PaAs, Bonn
}

Mit 32 Abbildungen im Text

$\mathrm{Z}$ us a m m e n f as su ng. Im Rahmen dieser Arbeit wurden im Niederrheingebiet die fossilen Böden auf den Terrassen und in den Deckschichten untersucht. Die Untersuchungen im Gelände wurden im Laboratorium durch Korngrößenanalysen, röntgenographische Analysen der Tonsubstanz und durch mikromorphologische Studien ergänzt.

Durch bodenkundlichen Vergleich, palaeolithische Funde und C14-Bestimmungen ergab sich im Arbeitsgebiet folgende stratigraphische Gliederung der Deckschichten (vgl. Abb. 32): Drenthe-Löß, der während der Drenthe/Warthe-Warmzeit zu einem braunlehmartigen gelblichroten Boden (Wegberger Bodenbildung) verwitterte, ist nur im Profil Wegberg aufgeschlossen. Der Warthe-Löß wird durch eine Parabraunerde, die Rheindahlener Bodenbildung, in zwei Teile gegliedert. Der EemBoden ist durch eine z. T. stark pseudovergleyte Parabraunerde, die Erkelenzer Bodenbildung, vertreten.

Der Altere Weichsel-Löß stellt sich in zwei verschiedenen Fazies vor. Im nördlichen Niederrheingebiet ist er meist geschichtet und zu einer z. T. erodierten Braunerde verwittert. Die Schichtung ist durch wiederholte Solifluktion, Bodenbildung und Lößbildung entstanden. Im südlichen Teil des Arbeitsgebiets ist dieser L.öß durch sandigere Einlagerungen nur noch schwach gestreift, durch eine kalkhaltige Braunerde nur noch einmal untergliedert und schwach zu einer kalkhaltigen Braunerde verwittert. Der Jüngere Weichsel-Löß besitzt im unteren Teil einen Naßboden, im mittleren Teil häufig Flugsandeinlagerungen und ist im Spätglazial und Holozän zu einer Parabraunerde verwittert.

Mit Hilfe der Deckschichten und der im folgenden kurz beschriebenen Merkmale der fossilen Böden auf den Terrassenkiesen wurde eine Gliederung der Rheinterrassen versucht. Die Kiese und Sande der Hauptterrasse (HT) und der Oberen Mittelterrasse (oMT) sind durch intensive Bodenbildung während mehrerer Interglaziale $\mathrm{zu}$ einem braunlehmartigen gelblichroten Interglazialboden verwittert. Charakteristische Merkmale dieser Böden sind Dichte, leuchtend gelblichrote Färbung und mächtige Profilentwicklung. Der Tongehalt beträgt durchschnittlich 19\%; die Skelettkörner sind im Dünnschliff in eine stark verwürgte, strähnige und dichte Grundmasse aus doppelbrechendem Braunlehmteilplasma eingebettet. Die Tonmineralgarnitur besteht ausschließlich aus Kaolinit und Illit mit sehr breiter Basisinterferenz. In den Deckschichten konnten Drenthe-, Wartheund Weichsel-Lösse nachgewiesen werden.

Der ähnlich ausgebildete braunlehmartige gelblichrote Interglazialboden der Drenthe/WartheWarmzeit auf der Unteren Mittelterrasse (uMT) und auf den glazialen Schottern und Sanden der Rißvereisung ist schwächer entwickelt. Verlehmung (durchschnittlich $14 \%$ Ton) und Profilentwicklung sind weniger mächtig. Neben Illit und Kaolinit ist ein deutlicher Gehalt an Vermikulit in der Tonfraktion enthalten.

Die kräftige Verwitterung der uMT während der Drenthe/Warthe-Warmzeit, die Frechener Bodenbildung, fehlt auf der Krefelder Terrasse (KT). In der Warthe-Eiszeit wurde über der Terrasse schon der jüngere Warthe-Löß abgesetzt. Daraus folgt, daß die KT während eines frühen Warthe-Stadiums entstanden ist. In den Terrassenkiesen werden häufig rötlichbraune Tonanreicherungsbänder beobachtet, die durch Toneinschlämmung aus den überlagernden fossilen und rezenten I'arabraunerden aus Löß entstanden sind und daher ähnlich ausgebildet sind wie die in der Niederterrasse (NT).

Die NT setzt sich aus zwei verschiedenen Schotterkörpern zusammen: Die jüngere, Laacher Bims führende Stufe, die während der Jüngeren Dryaszeit entstanden ist, lagert bei Bonn in einigen Gruben in geringer Mächtigkeit auf der frostgestörten bimsfreien älteren Stufe oder auf einem bimshaltigen allochthonen braunen Kalkauenboden des Alleröds. So war also die Aufschotterung der älteren Stufe zu Beginn des Alleröds abgeschlossen. Die Kiese und Sande der NT sind von einem zu einer Parabraunerde verwitterten Hochflutlehm oder von einem zu einer SandParabraunerde verwitterten Flugsand bedeckt. Bei völliger Entkalkung der Deckschichten wurde die Tonsubstanz z. T. in die Terrassenschotter durchgeschlämmt und in rötlichbraunen Tonanreicherungsbändern wieder abgesetzt. Neben Illit und Kaolinit setzt sich die Tonsubstanz, die in den Bändern durchschnittlich $8 \%$ ausmacht, aus Montmorillonit, Hydrobiotit und Vermikulit zusammen. Im Schliffbild sind die Skelettkörper nur noch von dünnen, bei $+\mathrm{N}$ doppelbrechenden P!as- 
mahäutchen umgeben. Auf Plasmabrücken ist die Bindigkeit des Bodenmaterials zurückzuführen. Das Hochflutbett des Rheins wurde während des Praeboreals angelegt. Der allochthone braune Kalkauenboden ist hier der herrschende Bodentyp.

$\mathrm{Su} \mathrm{m} \mathrm{m}$ a r $\mathrm{y}$. This paper deals with the examination of fossil soils and their cover beds in the Lower Rhine District. In addition to the field work, analyses of grain sizes, X-ray analyses of the argillaceous material, as well as micro-morphological studies have been made.

Based upon pedological comparison of soils, paleolithic findings, and the C14 method, the following stratigraphic sequence of the cover beds could be established in the area (cf. fig. 32): Drenthe loess which, during the Drenthe/Warthe interglacial period, weathered to a soil similar to the Red-Yellow Podsolic soil, but with low content of kaolinite, (braunlehmartiger gelblichroter Boden) is found only in the Wegberg section. The loess of the Warthe is divided in two parts by a Grey-Brown Podsolic soil (Parabraunerde). The Eem soil is represented first by a GreyBrown Podsolic soil which, in parts, has been intensely changed to a Pseudogley.

There are two facies of the older Weichsel loess. In the north of the Lower Rhine District it is bedded in most cases and weathered to a Brown Earth (Braunerde). The bedding originates from repeated solifluction, pedogenesis as well as loess deposition during this period. In the southern part of the area this loess is striped only slightly by more sandy intercalations. It is subdivided only once by a Calcareous Brown Earth (kalkhaltige Braunerde) and weathered slightly to a Calcareous Brown Earth. The younger Weichsel loess has in its lower parts a Tundra-Gley (Naßboden), whereas its intermediate part shows frequent intercalations of drifted sand. During the Late Glacial and Holocene the younger Weichsel loess weathered to a Grey-Brown Podsolic soil.

Using the terrace covers and the characteristics of fossil soils, described briefly in the following, a division of the Rhine terraces was tried. Caused by intensive pedogenesis during several warm periods, the pebbles and sands of the Main Terrace (Hauptterrasse) and the Upper Middle Terrace (Obere Mittelterrasse) weathered to a kind of Red-Yellow Podsolic soil (braunlehmartiger gelblichroter Boden). Density, a strikingly yellowish red colour and large thickness are characteristics of this soil.

The Red-Yellow Podsolic soil of the Drenthe/Warthe interglacial above the Lower Middle Terrace (Untere Mittelterrasse) and above the glacial gravel of the Drenthe glacial period is less thick. The intensive pedogenesis of the Drenthe/Warthe interglacial period is missing on the Krefeld Terrace. During the Warthe the younger Warthe loess was deposited on this terrace. Therefore, the deposition of the Krefeld Terrace must have taken place during an early Warthe period.

The two gravel bodies of the Lower Terrace are as follows: The younger stage contains Laacher See pumice and dates back to the younger Dryas time. It is found in several gravel pits in the Bonn area and thinly covers the older part which is free of pumice, yet disturbed by frost cracks. It may also cover an Allochthonous Brown Calcareous Flood Plain soil (allochthoner brauner Kalkauenboden) of the Alleröd period which also contains pumice. The gravel fill of the older stage was finished, therefore, at the beginning of the Alleröd. The pebbles and sands of the Lower Terrace are covered by high tide loam, weathered to Grey-Brown Podsolic soil, or by drifted sands, weathered to a Sandy Grey-Brown Podsolic soil (Sand-Parabraunerde). The high tide bed of the Rhine river was formed during the Preboreal time. In this area the Allochthonous Brown Calcareous Flood Plain soil is the dominating type.

In hal t s verzeichnis

A. Einleitung

B. Untersuchungen im Gelände

1. Das Hochflutbett

2. Die Niederterrasse

3. Die Krefelder Terrasse

4. Die Untere Mittelterrasse und die glazialen Schotter und Sande der Rißvereisung

5. Die Obere Mittelterrasse

6. Die Jüngere Hauptterrasse

C. Untersuchungen im Laboratorium

1. Korngrößenanalyse

2. Untersuchung der Tonsubstanz mit Hilfe der Röntgenanalyse

3. Untersuchung der Eisenoxyde und Eisenoxydhydrate mit Hilfe der Röntgenanalyse

4. Mikromorphologische Untersuchung der Böden auf den Terrassen. 

D. Schlußfolgerungen
1. Die stratigraphische Gliederung der Lößprofile
2. Der Ablauf des Jungpleistozäns im Niederrheingebiet auf Grund der Löß-
3. Vergleich des niederrheinischen Lösses mit den Lössen Nordfrankreichs und Belgiens
4. Stratigraphische Gliederung der Terrassen im Niederrheingebiet mit Hilfe ihrer Böden und Deckschichten.
E. Angeführte Schriften.

\section{A. Einleitung}

Das Niederrheingebiet läßt sich an der Linie Bergheim, Mönchen-Gladbach, Viersen und Straelen in zwei Teile gliedern. Der westliche Teil senkte sich bis zum Abschluß der Sedimentation der Hauptterrassenschotter. Hier sind so die stratigraphisch älteren Stufen unter den jüngeren begraben. In der Folgezeit setzte eine geringe Hebung ein, die nur lokal eine undeutliche jüngere Terrassenbildung zuließ. Die von einem verschieden mächtigen Löß und Lößlehm bedeckten Schotter und Sande der Jüngeren und Alteren Hauptterrasse sind daher fast über das ganze westliche Gebiet verbreitet. Dieses wurde durch schon während des Tertiärs angelegte Verwerfungen in einzelne Schollen zerlegt, wie die Erft-Scholle, die Rur-Scholle und der Venloer Graben.

Das Gebiet östlich der bezeichneten Linie hob sich während des Pleistozäns mit dem östlich angrenzenden Gebirge, so daß der Rhein sein Bett immer tiefer graben mußte und dadurch Terrassen ausbildete. So ist dieser Teil besonders geeignet, terrassenmorphologische und bodenkundliche Studien an den jüngeren Terrassen durchzuführen. Am unteren Niederrhein von Krefeld bis Xanten und Kleve sind die Stauchmoränen und Sander der Rißvereisung trotz starker Ausräumung durch den Rhein noch gut erhalten.

Grundlage für die meisten Untersuchungen waren bisher die morphologischen Merkmale. Durch das Studium der Lagerungsverhältnisse ergaben sich wichtige Hinweise auf die Altersbeziehungen zwischen den einzelnen Stufen (E. KaIser 1903, 1908; G. STEINmanN 1906, 1924; A. Quaas 1911; A. Steeger 1913, 1925, 1952; F. Jungbluth 1917; H. Breddin 1929; H. W. Quitzow 1956; K. Thome 1958, 1959).

Mit großem Erfolg wurden erst in neuerer Zeit Geröllzählungen und Schwermineralanalysen zur Parallelisierung von Terrassen herangezogen (G. C MAarLeveld 1956; J. D. De Jong 1956; J. I. S. Zonneveld 1956; W. Monreal 1958; R. Vinken 1959). Zwischen der Hauptterrasse, der Oberen Mittelterrasse und der Unteren Mittelterrasse konnten dabei deutliche Unterschiede herausgearbeitet werden. Bei den jüngeren Terrassen war das Ergebnis jedoch unbefriedigend.

Die interglazialen, pollenführenden, tonigen Einlagerungen in den Schottern der Hauptterrasse, auf der Krefelder Platte und in den Stauchmoränen sind ebenfalls zur stratigraphischen Gliederung der Terrassen herangezogen worden (A. SteEgER 1952, G. von der Brelie \& U. Rein 1956).

Die einzelnen angeführten Methoden haben manche Fragen beantworten können; viele Probleme harren jedoch noch der Klärung, insbesondere ist die Stellung der Krefelder Terrasse immer noch umstritten. Große Fortschritte in der Gliederung quartärer Ablagerungen konnten besonders in Süddeutschland und O'sterreich durch die Untersuchung fossiler Böden erzielt werden (E. SchöNhals 1951 und andere Arbeiten; J. Fink 1956; F. Brandtner 1954, 1956; K. Brunnacker 1956; H. Freising 1951). Unter dem Einfluß der bodengestaltenden Kräfte Klima, Vegetation, Wasser, Gestein, Relief (Bodenabtrag), Mensch und Zeit (E. MücKenhausen 1957) bilden sich bestimmte Bodentypen heraus. Aus dem Studium der fossilen Böden lassen sich daher Rückschlüsse auf die Bildungsbedingungen ziehen. Die Terrassen besitzen ein verschiedenes Alter. Während der Interglazial- und Interstadialzeiten wurde jede Stufe verwittert und zwar um so stärker, je 


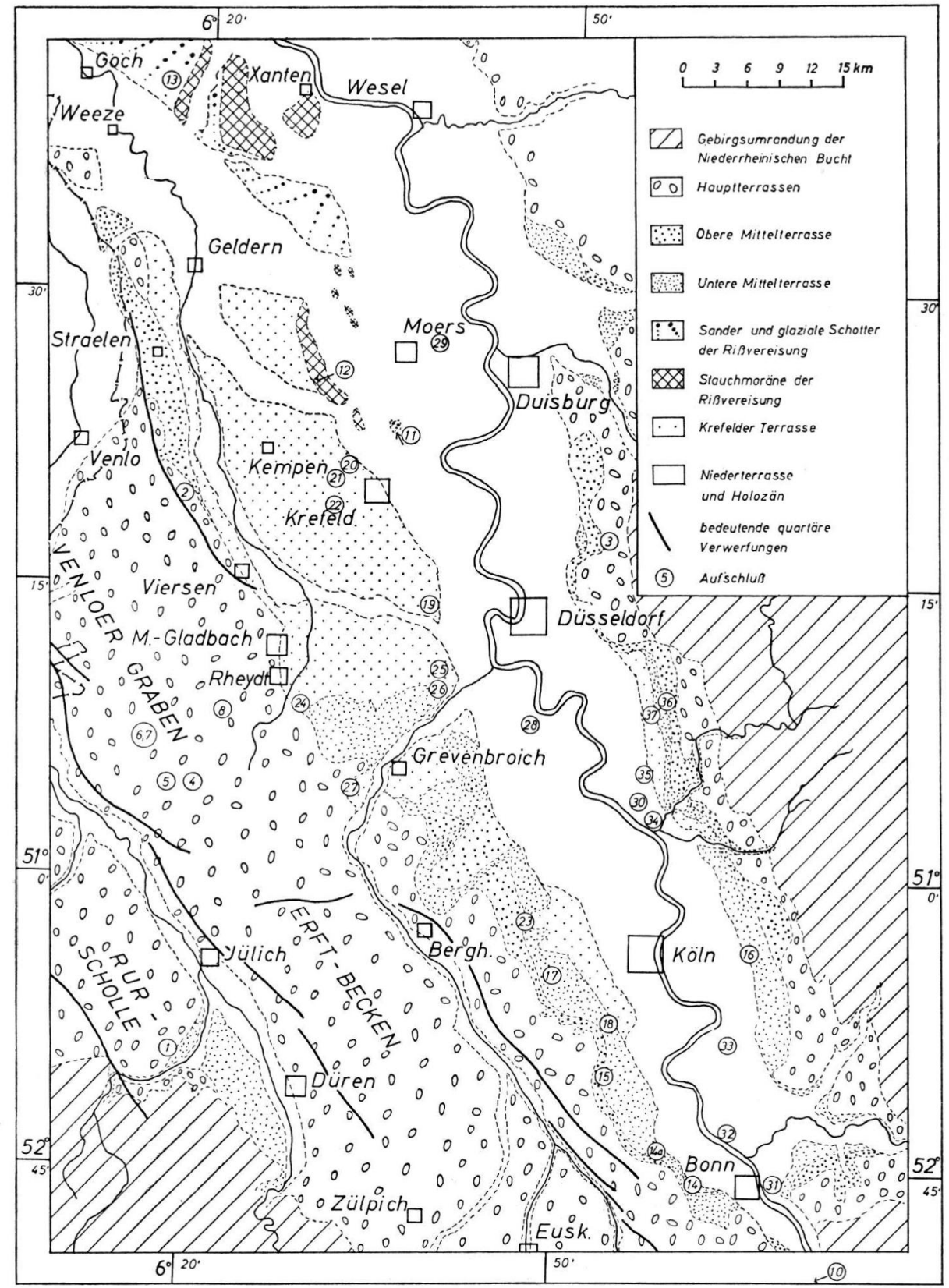

Abb. 1. Geologisch-morphologische Übersicht der Flußterrassen im Niederrheinischen Tiefland. Nach A. Steeger (1928), H. W. Quitzow (1956), W. MonreaL (1958) und eigenen Untersuchungen.

mehr Interglazialzeiten einwirken konnten. Das Studium möglichst vieler Aufschlüsse gibt damit die Möglichkeit, mit Hilfe der fossilen Böden wenigstens die zeitliche Stellung der Terrassen zueinander festzulegen. Ferner läßt sich das Alter einer Terrasse durch eine stratigraphische Gliederung der Deckschichten näher bestimmen. Hier sind eingeschaltete 
fossile Böden mit charakteristischem Profilaufbau und typischer Struktur und Farbe wertvolle Leithorizonte.

Die vorliegende Arbeit entstand als Dissertation am Geologischen Institut in Bonn unter dem Titel: „Gliederung der Terrassen im Niederrheingebiet mit Hilfe ihrer Verwitterungsdecken und Deckschichten“. Sie wurde angeregt von meinem hochverehrten Lehrer, Prof. Dr. P. WoLdSTEDT, dem ich für viele Anregungen und fördernde Kritik zu großem Dank verpflichtet bin. Prof. Dr. Dr. E. MüCKenHAusEn verdanke ich das bodenkundliche Rüstzeug, das diese Arbeit erst ermöglichte, Prof. Dr. R. Brinkmann meine geologische Ausbildung. Dr. H. Remy förderte durch manche Diskussion den Fortgang der Arbeit, Dr. W. KerPen half mir bei der Auswertung von Bodendünnschliffen. Prof. Dr. DE WAARD, Groningen, führte die C14-Bestimmungen durch. Die bodenkundlichen Analysen wurden im Institut für Bodenkunde, Bonn, ausgeführt. Die Deutsche Forschungsgemeinschaft unterstützte die Arbeiten im Gelände und im Laboratorium durch finanzielle Beihilfen. Ihnen allen und auch den Ungenannten, die mit zum Gelingen der Arbeit beigetragen haben, danke ich von Herzen.

\section{B. Untersuchungen im Gelände}

Die bodenkundliche Untersuchung der fossilen Böden im Gelände wird dadurch erschwert, daß in nur wenigen Fällen noch völlig erhaltene Bodenprofile erhalten sind. Die Einflüsse verschiedener Zeiten der Bodenbildung können sich in einem Profil überlagern; steigendes Grundwasser überprägt das ursprüngliche Bild, und eine früher vorhandene und nun erodierte Lößbedeckung kann die Ausbildung eines Bodens auf Terrassenschottern verhindert haben. Daher ist die Grundlage für diese Arbeit eine eingehende Untersuchung möglichst vieler Aufschlüsse. So ist in jedem Aufschluß immer wieder zu klären, welche Erscheinung auf echte Verwitterung, auf Grundwasser, auf spätere Pseudovergleyung, auf den Absatz von Verwitterungslösungen oder auf Umlagerung von Bodenmaterial zurückzuführen ist. Die für die einzelnen Stufen charakteristischen Bodentypen ergeben sich so aus dem Vergleich vieler Profilaufnahmen.

Die typologische Ansprache der rezenten Böden geschah nach der von E. MückeNHAUSEN (1957) herausgegebenen Systematik der wichtigsten Böden der Bundesrepublik Deutschland. Bei der Untersuchung der fossilen Böden wurden die Arbeiten von W. L. KuBIËNA $(1953,1956)$ herangezogen. Die Bestimmung der Bodenfarbe erfolgte mit Hilfe der Munsell'schen Farbskala. Aus charakteristischen Horizonten wurden Proben entnommen für Korngrößen- und Röntgenanalysen, Dünnschliffuntersuchungen und $\mathrm{C}^{14}$ Bestimmungen.

\section{Das Hochflutbett des Rheins}

Mit einer scharfen Geländekante ist das Hochflutbett des Rheins von der Niederterrasse (NT) abgesetzt; der Höhenunterschied beträgt 5-10 m. Es wird, soweit es nicht durch Deiche vor dem Rheinhochwasser geschützt ist, nur noch bei Hochflut vom Rhein überspült. Im südlichen Teil der Niederrheinischen Bucht ist das Hochflutbett nur in kleinen Flächen zwischen den Rheinschlingen ausgebildet, nördlich von Düsseldorf wird es allmählich breiter und erreicht nördlich von Kleve eine Breite von ca. $10 \mathrm{~km}$.

Das Hochflutbett ist eine Erosionsform in der NT; es ist entstanden nach Abschluß der Aufschotterung dieser jüngsten Terrasse. Durch alte Rheinarme ist es gegliedert. Bei Hochwasser hinterläßt der Rhein auch heute noch in dem nicht abgedeichten Gebiet seine Schlickabsätze; dabei wird der Boden durch das kalkhaltige Rheinwasser aufgekalkt. Im Hochflutbett des Rheins sind so sehr junge Böden verbreitet. Der typische Boden des Überflutungsgebiets ist der weitverbreitete "allochthone braune Kalkauenboden“:

Profil Rheindorf (34)

Aufschluß an der Trasse der Nord-West-Ölleitung südlich Rheindorf bei Leverkusen, $230 \mathrm{~m}$ vom Rhein entfernt, M.-Bl. Leverkusen (4907), 39,8 m über NN., eben.

A $\quad 0-40 \mathrm{~cm}$ schwärzlichbrauner, kalkhaltiger, stark humoser feinsandiger Lehm, Brökkel- bis Krümelgefüge, viele Regenwurmröhren vorhanden, stark porös; 
$\begin{array}{ccl}M_{1} & 40-100 \mathrm{~cm} & \begin{array}{l}\text { dunkelbrauner feinsandiger Lehm, Bröckel- bis Krümelgefüge, viele Re- } \\ \text { genwurmröhren vorhanden, stark porös; kalkhaltig; } \\ \text { kräftigsepiabrauner feinsandiger Lehm, kalkhaltig, Bröckelgefüge, stark } \\ \text { porös. }\end{array}\end{array}$

Charakteristische Merkmale der jungen braunen Kalkauenböden sind der aus der periodischen Durchtränkung mit Rheinwasser herrührende Kalkgehalt und die im nicht abgedeichten Gebiet noch fortdauernde Sedimentation des vom Rhein transportierten Materials. In Gebieten, die durch Deiche vom Rheinhochwasser abgeschirmt werden, oder die schon ständig oberhalb des Hochwassers liegen, wandelt sich der Kalkauenboden langsam zur Braunerde, so daß hier heute Übergangsbildungen vom Auenboden zur Braunerde vorliegen (E. Mückenhausen \& H. Wortmann 1958).

\section{Die Niederterrasse (NT)}

Verbreitung und Morphologie: Mit dem Eintritt des Rheins in die Niederrheinische Bucht erweitert sich die NT schon unmittelbar nördlich von Bonn zu einer ca. $12 \mathrm{~km}$ breiten, von zahlreichen Altwasserrinnen durchzogenen Ebene, die sich nach $\mathrm{N}$ immer mehr verbreitert. In mehreren Rinnen im Bereich der Krefelder Terrasse (KT) und der Stauchmoränen verbindet sie den Rhein über die Niers mit der Maas. Im Mittelrheingebiet läßt sich die NT' noch morphologisch in eine obere, etwas Wehrer Bims führende (Altere Niederterrasse, äNT) und eine untere, reichlich Laacher Bims führende Stufe (Jüngere Niederterrasse, jNT) gliedern (J. Frechen 1959). Der Wehrer Bims der äNT stammt aus dem Wehrer Kessel und führt im Gegensatz zum Laacher Bims keinen Hauyn. Im Niederrheingebiet ist diese Gliederung nach der Morphologie nicht mehr durchzuführen. Nach A. SteEger (1954) enthalten die Kiese der NT im Zentralgebiet in allen untersuchten Aufschlüssen Bimsmaterial des Laacher See-Ausbruchs. Die ältere Stufe liegt unmittelbar nördlich von Bonn schon $2-3 \mathrm{~m}$ unter der jüngeren begraben. Die Terrassenkreuzung hat also für die Niederterrassen schon auf der Höhe von Bonn stattgefunden.

Rezente Böden a uf der jNT und ihren Deckschichten

Die Kiese und Sande der jNT sind im Niederrheingebiet zum größten Teil von Hochflutlehm bedeckt. Weit weniger häufig sind Terrassenaufschlüsse mit Flugsandüberlagerung. Auf dem Material der jNT, dem Flugsand und dem Hochflutlehm sind eine Vielzahl von Bodentypen entwickelt, die in dieser Arbeit nicht alle beschrieben werden können. Insbesondere wird auf die Beschreibung der rezenten Grundwasserböden verzichtet, da hier mögliche fossile Böden durch jüngere Bodenbildung überprägt und daher nicht mehr zu beobachten sind. Die Böden in den untersuchten Kies- und Sandgruben lassen sich bei einem tiefen Grundwasserstand fast immer auf zwei Grundtypen zurückführen, die bestimmt werden durch die Zusammensetzung des Ausgangsgesteins.

a) Die Bodenbildung a us Hochflutlehm

Der Hochflutlehm, dessen Bodenart vom schwach lehmigen Sand bis zum Lehm reicht, ist im Durchschnitt 1 bis $1,5 \mathrm{~m}$ mächtig und geht in einigen Gruben allmählich in die Terrassensande über; meist besteht jedoch eine scharfe Grenze zwischen Hochflutlehm und Niederterrassenschottern. Ein typisches Bild der vom Hochflutlehm bedeckten NT zeigt das

Profil Nievenheim (28) (s. Abb. 2)

Kiesgrube nördlich Nievenheim-Delrath zwischen Köln und Neuß, M.-Bl. Neuß (4806), $41 \mathrm{~m}$ über NN; aufgenommen im März 1959.

Profil I

Ap $\quad 0-25 \mathrm{~cm}$

$\mathrm{A}_{3} \quad 25-55 \mathrm{~cm}$

$\mathrm{B}_{1} \quad 55-85 \mathrm{~cm}$

humoser lehmiger Sand;

lehmiger Sand, kräftigbraun (7,5 YR 4/4-5/6);

lehmiger Sand, rötlichbraun (5 YR 4/4), Polyedergefüge, Tonhäutchen auf den Gefügeelementen, schwach fahlgrau gefleckt; 
B $\quad 85-100 \mathrm{~cm}$ sehr schwach lehmiger Sand, grau, mit wenigen dünnen rötlichbraunen Tonanreicherungsbändern (5 YR 4/4);

$B_{3} \quad 100-120 \mathrm{~cm}$ lehmiger Sand, braun, in Bändern schwach lehmig und rötlichbraun gefärbt;

DB $120-400 \mathrm{~cm}$ lichtgrauer (10 YR 7/2) Sand und kiesiger Sand mit dünnen rötlichbraunen (5 YR 4/4) schwach lehmigen Bändern (Tonanreicherungsbänder);

D $\quad 400-600 \mathrm{~cm}+$ Sand und kiesiger Sand in Wechsellagerung, lichtgrau (10 YR 7/2).

Aus dem Hochflutlehm hat sich eine Parabraunerde gebildet. Charakteristisch für viele Niederterrassenaufschlüsse ist die rötlichbraune Bänderung der unverwitterten Schotter und Sande, die sehr oft bis zu $10 \mathrm{~m}$ Tiefe reicht. Die Bände besitzen meist 7-9\% Ton und verlaufen parallel der Schichtung oder Schrägschichtung; sehr oft kommt es aber zu einer Tonanreicherung in unregelmäßigen, vertikal verlaufenden Zonen. Die Bänder sind also nach der Aufschotterung entstanden und das Ergebnis einer Bodenbildung.

Die Entscheidung, ob hier der Rest eines fossilen, später erodierten Bodens vorliegt, oder ob diese Tonanreicherung mit der rezenten Bodenbildung aus dem Hochflutlehm stattgefunden hat, ist in sehr vielen Fällen schwierig. Das Profil II wurde in $2 \mathrm{~m}$ Entfernung von Profil I aufgenommen. Auch hier ist aus dem Hochflutlehm eine Parabraunerde gebildet worden. Im Gegensatz zu Profil I fehlen jedoch im Profil II in den Kiesen und Sanden der NT die Tonanreicherungsbänder, und die rezente Bodenbildung hat noch nicht die ganze Deckschicht erfaßt:

Profil II

Ap $\quad 0-20 \mathrm{~cm}$ humoser lehmiger Sand;

$\mathrm{A}_{3} \quad 20-55 \mathrm{~cm}$ lehmiger Sand, kräftigbraun (7,5 YR 4/4-5/6);

$\mathrm{B}_{1} \quad 55-95 \mathrm{~cm} \quad$ lehmiger Sand, rötlichbraun (5 YR 4/4), Polyedergefüge, Tonhäutchen auf den Gefügeflächen:

(B) $\quad 95-110 \mathrm{~cm}$ lehmiger Sand, braun, Bröckelgefüge;

C $\quad 110-120 \mathrm{~cm}$ kalkhaltiger lehmiger Sand, weißlichgrau;

D $120-500 \mathrm{~cm}+$ Sand und kiesiger Sand in Wechsellagerung, lichtgrau (10 YR 7/2).

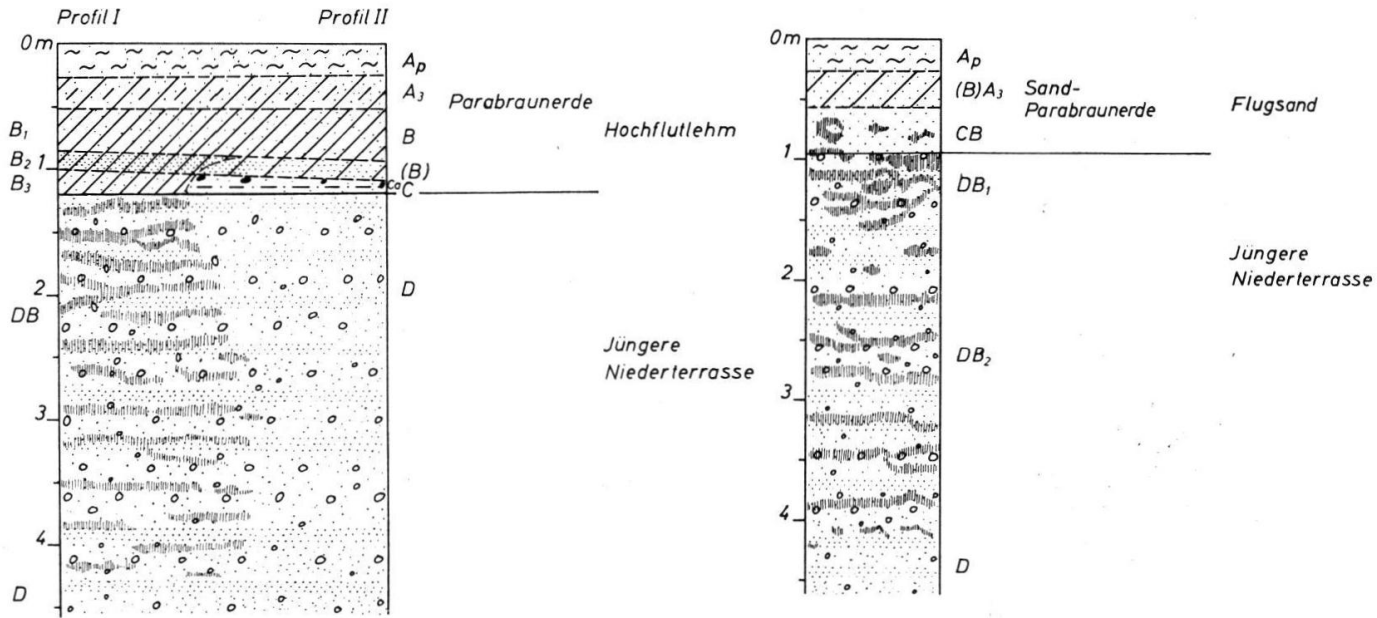

Abb. 2 (links). Profil Nievenheim. - Abb. 3 (rechts). Profil Moers.

Der Hochflutlehm ist im unteren Teil noch kalkhaltig. Dieser Kalkgehalt mit seinem hohen $\mathrm{pH}$-Wert führt zu einer Flockung der Tonsubstanz, die bei der Parabraunerdebildung mechanisch auf Schwundrissen und Regenwurmröhren aus dem Ap und $\mathrm{A}_{\mathbf{3}}$-Horizont nach unten in den verdichteten B-Horizont durchgeschlämmt wird. Dadurch wird eine weitere Wanderung der Tonsubstanz in das Terrassenmaterial hinein, wie sie im Profil I stattfindet, verhindert. 
Die Korngröße des Bodenmaterials ist entscheidend für die Art des Absatzes der Tonsubstanz. In einem feinkörnigen, schweren Material findet die Wanderung und der Absatz auf Schwundrissen und Regenwurmröhren statt. In dem groben Filtergerüst der Terrassensande und -kiese können die Tonteilchen gleichmäßig zwischen den Körnern wandern und setzen sich schließlich rhythmisch wieder ab: Der B-Horizont löst sich in eine Folge dünner Bänder auf. Diese Auflösung ist besonders gut dort zu beobachten, wo der Hochflutlehm allmählich in die Terrassensande übergeht. Die rötlichbraunen Bänder in den bimsführenden Kiesen und Sanden der NT sind also keine fossile Bildung, sondern entstanden bei der Parabraunerdebildung aus dem Hochflutlehm.

b) Die Bodenbildung aus Flugsand

Verschieden mächtige Flugsande überlagern bei Moers, sowie in kleineren Sanddünen zwischen Neuß und Köln die NT. Auch hier unter Flugsand ist die Anreicherung der Tonsubstanz in Bändern sehr verbreitet.

Profil Moers (29) (s. Abb. 3)

Kiesgrube im Baerler Busch bei Moers, an der Römerstraße, M.-Bl. Moers (4505), $29 \mathrm{~m}$ über NN, eben, aufgenommen im März 1959.

Ap $\quad 0-25 \mathrm{~cm}$ humoser Sand mit gebleichten Quarzkörnern;

(B) $\mathrm{A}_{3} \quad 25-60 \mathrm{~cm}$ sehr schwach lehmiger Sand, gelblichbraun (10 YR 5/4);

$\mathrm{CB} \quad 60-95 \mathrm{~cm}$ Sand, lichtgelblichbraun (10 YR 6/4), mit wenigen unregelmäßigen Ton-

anreicherungsbïndern, rötlichbraun (5 YR 4/4);

$\mathrm{DB}_{1} \quad 95-140 \mathrm{~cm}$ Sand mit wenigen kiesigen Einlagerungen, bis $30 \mathrm{~cm}$ mächtige Tonanrei-

cherungsbänder vorhanden;

$\mathrm{DB}_{2} \quad 140-400 \mathrm{~cm} \quad$ Sand, nach unten kiesiger werdend, mit unregelmäßigen, $10 \mathrm{~cm}$ mächtigen

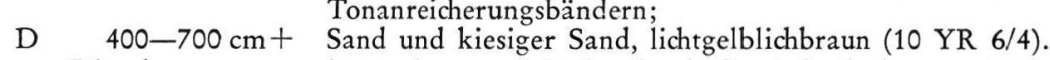

Die oberen $25 \mathrm{~cm}$ des Bodens sind leider durch die Ackerkultur verändert. Einen Boden mit ähnlicher Profilentwicklung bezeichnet W. LAATsCH (1957, S. 244) als podsolige Braunerde, der in Nordwestdeutschland die typische Bodenbildung unter Eichen-Birkenwald darstellt.

Bei der Deutung des Profils Moers als podsolige Braunerde ergeben sich Schwierigkeiten in der Horizontbezeichnung. Unter dem Ap-Horizont folgt eine $35 \mathrm{~cm}$ mächtige Verlehmungszone, die nach unten in den unverwitterten Flugsand und Terrassensand übergeht. Damit ist sie als ein (B)-Horizont einer Braunerde aufzufassen. Gleichzeitig wird aus dieser Verlehmungszone und dem Ap-Horizont Tonsubstanz nach unten in die liegenden Kiese und Sande verlagert, wo sich eine in viele dünne Bänder aufgelöste Tonanreicherungszone (CB- und DB-Horizont) bildet.

Die Korngröße, der Tonmineralgehalt und das mikromorphologische Bild der Bänder stimmt mit den Tonanreicherungsbändern der Parabraunerden aus Hochflutlehm überein. Aus der Verlehmungszone wird also gleichzeitig ein Verarmungshorizont, der (B) $\mathrm{A}_{3}-$ Horizont.

Hauptmerkmale des Profils sind das sandige Substrat, die Verlehmung in den Apund (B) $\mathrm{A}_{3}$-Horizonten und die mechanische Tondurchschlämmung. Ein Boden mit diesen Kennzeichen wird entsprechend einem Vorschlag von E. MücKenHausen (mündliche Mitteilung) als Sand-Parabraunerde bezeichnet.

$$
\text { Fossile Böden auf der Alteren Niederterrasse }
$$

a) Frostböden

Hochflutlehm oder Flugsand lagern im Niederrheingebiet meistens auf ungestörten, Laacher Bims führenden Kiesen und Sanden der jNT. A. SteEger (1954) sieht so in dem Fehlen von Kryoturbationen neben der Bimsführung einen Hinweis auf die spätglaziale Entstehung der NT im Niederrheingebiet.

Die Kiesgrube Beuel bei Bonn liegt im Grenzgebiet von Mittelrhein und Niederrheinischer Bucht. Bims ist in den Kiesen und Sanden unterhalb des in $3 \mathrm{~m}$ Tiefe beginnenden 
Taschenbodens nicht enthalten, vereinzelt wohl in den im unteren Teil sehr sandigen und kiesigen Deckschichten. Es handelt sich hier wahrscheinlich um Laacher Bims. Bimsmaterial vom Wehrer Kessel ist sehr selten und tritt im Mittelrheingebiet im unteren Teil der Kiese und Sande der äNT auf. Damit ist der Schottersockel wahrscheinlich ein Rest der äNT, während die Deckschichten oberhalb des Taschenbodens schon die jNT vertreten. Nach J. Frechen \& G. v. D. Bоom (1959) gehört der Aufschluß insgesamt zur oNT. Die schwach bimsführenden Kiese und Sande gehen nach oben in einen sehr sandigen Hochflutlehm über, aus dem eine Parabraunerde gebildet ist.

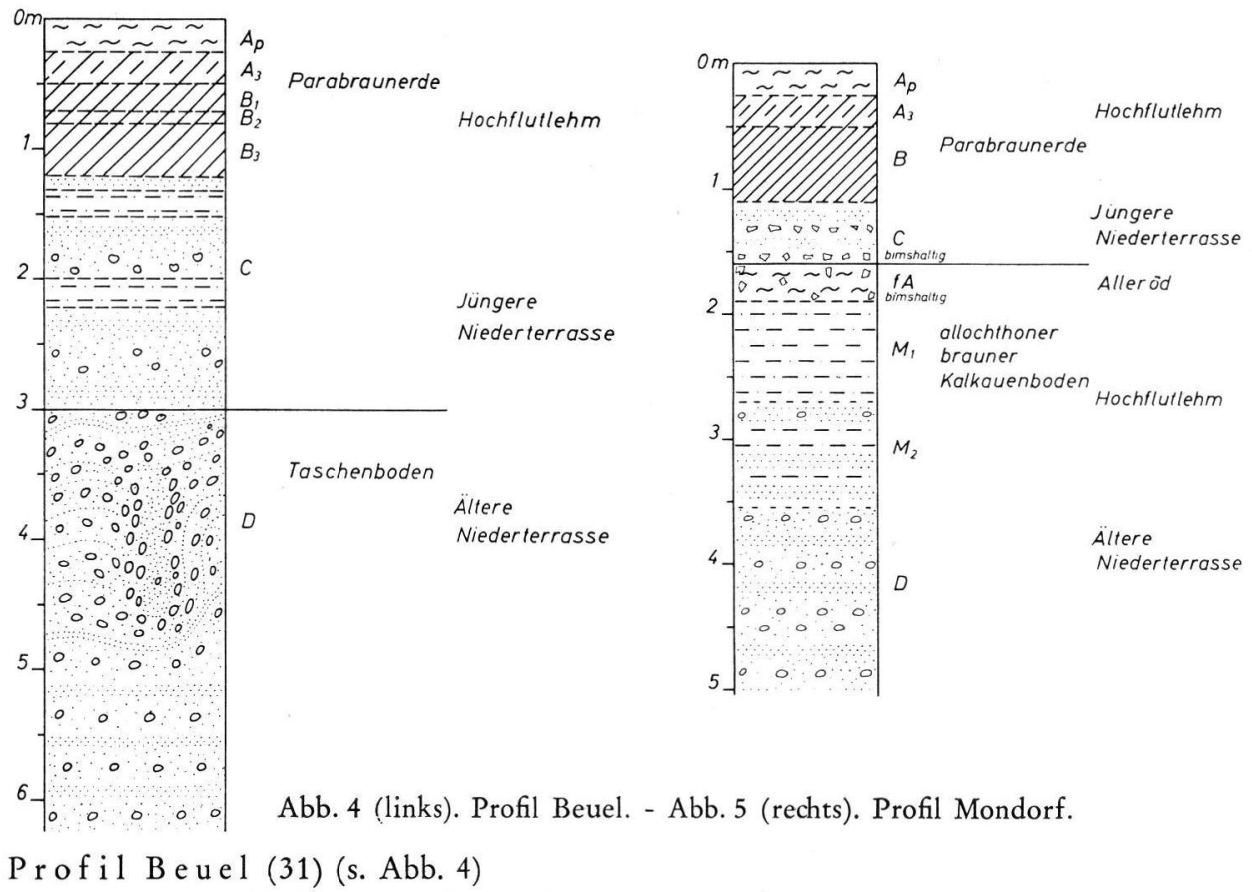

Kiesgrube Beuel bei Bonn, an der Straße nach Siegburg, M.B1. Bonn (5208), 59,5 m über NN, eben, aufgenommen im Juni 1959.

Ap $0-25 \mathrm{~cm}$ humoser lehmiger Sand;

$\mathrm{A}_{3} \quad 25-50 \mathrm{~cm} \quad$ lehmiger Sand, Bröckel- bis Polydergefüge;

$\mathrm{B}_{1} \quad 50-70 \mathrm{~cm}$ lehmiger Sand, rötlichbraun (5 YR 4/4), Polyedergefüge, Tonhäutchen auf

$\mathrm{B}_{2} \quad 70-80 \mathrm{~cm} \quad \begin{aligned} & \text { den Gefügeelementen; } \\ & \text { lehmiger kiesiger Sand, rötlichbraun (5 YR 4/4); }\end{aligned}$

$\mathrm{B}_{3} \quad 80-120 \mathrm{~cm}$ lehmiger Sand, rötlichbraun (5 YR 4/4);

C $120-300 \mathrm{~cm}$ kalkhaltiger Sand und lehmiger Sand in Wechsellagerung, nach unten zunehmend bis $20 \mathrm{~cm}$ mächtige Kieslinsen enthaltend, Kalkmyzelien vorhanden, wenige Bimsgerölle eingelagert, dunkelbraun (7,5 YR 4/4) und sehr fahlbraun (10 YR 7/4);

D $\quad 300-350 \mathrm{~cm}$ kalkhaltiger kiesiger Sand, schwach kryoturbat gestört, wahrscheinlich sehr schwach verlehmt;

$350-500 \mathrm{~cm}$ kiesiger Sand, in Frosttaschen und Tropfen ist kalkhaltiger Feinsand eingearbeitet;

$500-1000 \mathrm{~cm}+$ ungestörter kalkhaltiger kiesiger Sand.

Die Trennung von äNT und jNT bietet sich schon mit dem Auftreten des Taschenbodens auf den bimsfreien Kiesen und Sanden an. Strukturböden wurden bei der Geländearbeit sehr selten auf den bimsführenden Sanden und Kiesen der NT beobachtet. Dazu scheint eine sehr schwache Bodenbildung auf der älteren Stufe stattgefunden zu haben, da das Material in den oberen $50 \mathrm{~cm}$ schwach verbraunt ist. 
Weitere Strukturböden wurden in folgenden Gruben gefunden: Kräftige Durchbewegung der Terrassenschotter in der Kiesgrube Kriegsdorf bei Troisdorf (M.-Bl. Wahn, 5108), Frostkeile in der Kiesgrube Zündorf (33), Taschenböden und gestörte Grundwasserhorizonte in der Kiesgrube Kapellen (M.-Bl. Mörs, 4505) und nach E. MüCKenHausen (1954) ein Strukturboden in der Kiesgrube Friesdorf (M.-B1. Bonn, 5208). In dem frostgestörten Terrassenmaterial konnte in keiner Grube Bims beobachtet werden.

Das Vorkommen von Strukturböden kann so im Niederrheingebiet im Aufschluß eine Trennung in äNT und jNT ermöglichen.

b) Fossile Bodenbildung aus Hochflutlehm

Die äNT ist ebenfalls in den Kiesgruben bei Mondorf (Siegkreis) aufgeschlossen. Laacher Bims konnte hier in den Kiesen und Sanden nicht nachgewiesen werden.

Profil Mondorf (32) (s. Abb. 5)

Mondorf in Richtung Rheidt, nördlichste Grube, Siegkreis, M.-Bl. Bonn (5208), $55 \mathrm{~m}$ über NN, an einer Geländekante gelegen, aufgenommen im Juli 1960.

Ap $\quad 0-25 \mathrm{~cm}$ humoser lehmiger Sand;

$\mathrm{A}_{3} \quad 25-50 \mathrm{~cm}$ lehmiger Sand, dunkelgelblichbraun (10 YR 4/4);

B $\quad 50-110 \mathrm{~cm}$ lehmiger Sand, braun (7,5 YR 4/4), einzelne kiesige Einlagerungen vorhanden, Polyedergefüge, Tonhäutchen auf den Gefügeelementen, stellenweise Laacher Bims eingelagert, nach unten allmählicher Übergang;

C $\quad 110-160 \mathrm{~cm}$ kalkhaltiger Sand und Feinsand mit Laacher Bimseinlagerungen, starke sekundäre Kalkanreicherung;

fA $\quad 160-190 \mathrm{~cm}$ kalkhaltiger humoser feinsandiger Lehm, dunkelbraun (7,5 YR 4/2), gröBere Laacher Bimsbrocken enthalten;

$\mathrm{M}_{1} \quad 190-270 \mathrm{~cm}$ kalkhaltiger, feinsandiger Lehm, braun (7,5 YR 5/4), Schneckengehäuse enthalten;

$\mathrm{M}_{2} \quad 270-355 \mathrm{~cm}$ kalkhaltiger sandiger Lehm, braun (7,5 YR 5/4), einzelne kiesige Einlagerungen vorhanden, nach unten allmählicher Ubergang zu Sand;

D $\quad 355-700 \mathrm{~cm} \quad$ kiesiger Sand und Sand, lichtgelblichbraun (10 YR 6/4).

Aus dem Material der äNT geht nach oben allmählich ein kalkhaltiger Hochflutlehm hervor, der oben mit einem humosen Horizont abschließt. Wohlerhaltene Schneckenschalen treten bis unmittelbar unter dem fA-Horizont auf und zeigen, daß noch primärer Kalk enthalten ist. Daher wird dieser fossile Boden als ein allochthoner brauner Kalkauenboden bezeichnet. Braune, schwach verwitterte, bis $2 \mathrm{~cm}$ Durchmesser große Bimsgerölle sind in dem fossilen Humushorizont (fA) regelmäßig verteilt enthalten. In dem kalkhaltigen Material darunter konnte kein Bims mehr nachgewiesen werden. Sicherlich han. delt es sich bei dieser starken Häufung des vulkanischen Materials um Laacher Bims.

In Schnüren und Bändern angereichert, tritt Laacher Bims in unverwitterter weißlichgrauer Form in Hangenden des humosen Horizonts, in dem kalkhaltigen, schwach kiesigen Sand (D-Horizont) und im unteren Teil des rezenten Bodens (B-Horizont) auf. Aus dem Hochflutlehm hat sich, wie in den übrigen Niederterrassenaufschlüssen des Niederrheingebiets, eine Parabraunerde entwickelt.

Das Bimsmaterial im $\mathrm{fA}$-Horizont ist erst während der Bildung des braunen allochthonen Kalkauenbodens angelandet worden. Während des Absatzes der fM-Horizonte führte der Rhein offensichtlich kein vulkanisches Material. So liegt die Vermutung nahe, daß der Rhein vor der fossilen Bodenbildung den Laacher Bims noch nicht führte, und diese somit gleich alt ist mit dem Auswurf der trachytischen Laacher Bimsmassen.

Nach W. Ahrens (1930) hat sich der Rhein zur Zeit des großen mittelrheinischen Bimssteinausbruchs bereits sehr tief, wahrscheinlich tiefer als heute, in die äNT eingeschnitten. Trotzdem hat eine zeitweilige Überflutung der äNT in der Umgebung von Bonn stattgefunden, wie die mit dem allochthonen Kalkauenboden vergesellschafteten Bimsgerölle zeigen.

Gleichfalls muß mit der Möglichkeit gerechnet werden, daß Bimsmaterial in der Luft bis nach Bonn gelangte, so daß dieses sich bei Mondorf auf primärer Lagerstätte befinden kann. 
Nach vorliegenden Altersbestimmungen mit Hilfe der $\mathrm{C}^{14}$-Methode ergibt sich ( $\mathrm{J}$. Frechen 1952, F. Firbas 1953) ein Alter von etwa 11000 Jahren für den Laacher SeeAusbruch und damit für den gleichalten fossilen allochthonen Kalkauenboden auf der äNT.

Zur äNT gehören ebenfalls die Kiese und Sande in der Kiesgrube an der Straße Zündorf-Wahn (M.-Bl. Wahn, 5108). Das Terrassenmaterial ist oben durch eine kräftige Bodenbildung stark verlehmt. Die zeitliche Einordnung dieser Bodenbildung ist nicht möglich. Die Verwitterung während der kurzen Alleröd-Schwankung reicht nicht aus, um ein so mächtiges Bodenprofil zu schaffen. Auch mit der Braunerde auf der Krefelder Terrasse (KT) ist dieser Boden nicht zu vergleichen. Der fossile Boden ist unter $1,70 \mathrm{~m}$ mächtigem Hochflutlehm begraben, der während des Holozäns zu einer Parabraunerde verwittert ist und im Untergrund noch kalkhaltig ist.

\section{Die Krefelder Terrasse (KT)}

Verbreitung und Morphologie: Die KT hat ihre Hauptverbreitung zwischen den Städten Krefeld, Mönchen-Gladbach und Neuß; kleinere Vorkommen finden sich rechtsrheinisch zwischen Düsseldorf und Leverkusen (s. Abb. 1 und 18) und linksrheinisch zwischen Köln und Bonn. Während der vertikale Abstand der KT zur Unteren Mittelterrasse (uMT) im rechts- wie im linksrhienischen Gebiet auf der Höhe von Düsseldorf noch $10 \mathrm{~m}$ beträgt gegenüber nur $8 \mathrm{~m}$ zur NT, konvergieren nach Süden die KT und die uMT allmählich und bilden schließlich südlich von Köln eine morphologisch einheitliche Terrasse, die Talwegterrasse (=uMT) (vgl. Abb. 6).

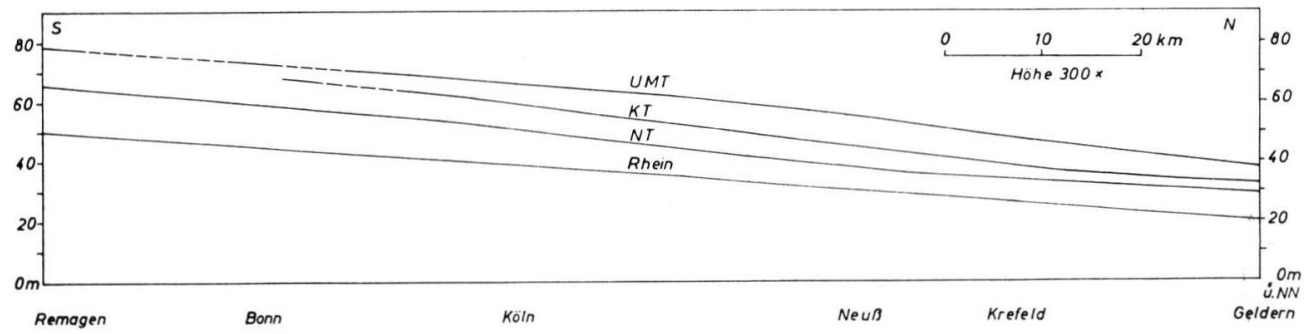

Abb. 6. Schematisches Längsprofil der Terrassen im Niederrheingebiet.

Es entsteht nun die Frage: Ist die KT lediglich eine Erosionsform in der uMT, wobei dann die südliche Fortsetzung durch die ältere Stufe gebildet wird? Oder ist die KT eine eigene Aufschüttungsterrasse, die südlich von Köln gerade das Niveau der älteren Stufe erreicht hat? Oder haben die jüngeren Schotter südlich von Köln sogar die älteren, verwitterten Schotter überdeckt? Eine Antwort auf diese Frage soll durch eingehende geologische und bodenkundliche Untersuchung der Terrassenaufschlüsse gesucht werden.

Charakteristisch für die KT ist die tischebene Oberfläche, die nur durch flache Rinnen und gelegentlich durch kleine, seichte Senken schwach gegliedert ist. Die Bezeichnungen Krefelder und Aldekerker Platte sind Ausdruck dieser starken Verebnung. K. THоме $(1958,1959)$ sieht daher in der KT eine Erosionsform, die durch den nach Westen abgelenkten Rhein beim Zurückweichen des Drenthe-Eises entstanden ist.

$$
\text { Die fossilen Böden auf der Krefelder Terrasse }
$$

Die Schotter und Sande der KT sind in zahlreichen Kies- und Sandgruben westlich von Krefeld, nordöstlich von Neuß und westlich von Köln gut aufgeschlossen. Fast immer überlagert in diesen Aufschlüssen ein geringmächtiger, einheitlicher Lößlehm die frischen oder bis $50 \mathrm{~cm}$ Tiefe schwach verlehmten Schotter der KT. Das Profil der Kiesgrube Buscherhöfe bei Kaarst/Neuß kann als ein Normalprofil für viele Gruben gelten:

Profil Ka arst (19) (s. Abb. 7) 
Kiesgrube westlich der Buscherhöfe, Kaarst bei Neuß, M.-Bl. Willich (4705), $37 \mathrm{~m}$ über NN., eben, aufgenommen im April 1959.

Ap $\quad 0-25 \mathrm{~cm}$ humoser feinsandiger Lehm, dunkelgelblichbraun (10 YR 4/4) (Lößlehm);

$\mathrm{A}_{3} \quad 25-50 \mathrm{~cm}$ feinsandiger Lehm mit einzelnen Kieselsteinen braun, (7,5 YR 4/4);

$\mathrm{B}_{1} \quad 50-85 \mathrm{~cm}$ feinsandiger Lehm, Tonhäutchen auf den Gefügeelementen, kräftigbraun

$\begin{array}{lll} & & (7,5 \mathrm{YR} 5 / 6) ; \\ \mathrm{B}_{2} & 85-95 \mathrm{~cm} \quad \text { feinsandiger Lehm, kräftigbraun (7,5 YR 5/6); }\end{array}$

$\mathrm{B}_{3} \quad 95-110 \mathrm{~cm}$ lehmiger Sand, kräftigbraun (7,5 YR 5/6) und schwach lehmiger Sand, sehr fahlbraun (10 YR 7/4), in Wechsellagerung; in den sandigen Lagen Anreicherung von Tonsubstanz in dünnen Bändern (rötlichbraun 5 YR $4-5 / 4)$;

$\mathrm{f}(\mathrm{B}) \mathrm{DB}$ 110-145 cm schichtungsloser, schwach kiesiger Sand, deutlich verlehmt, rötlichgelb (7,5 YR 6/6), im oberen Teil bis zu $5 \mathrm{~cm}$ mit dem hangenden Lößlehm vermischt, an der Oberkante Steinsohle, wenige Tonanreicherungsbänder vorhanden, nach unten allmählicher Übergang;

DB $\quad 145-350 \mathrm{~cm}$ ungestörter Sand und kiesiger Sand, Tonanreicherungsbänder vorhanden, stellenweise bis $5 \mathrm{~m}$ Tiefe;

D $\quad 350-500 \mathrm{~cm}+$ kiesiger Sand und Sand, im oberen Teil stellenweise fossiler Grundwasserhorizont vorhanden ( $\mathrm{fGo}$ ).

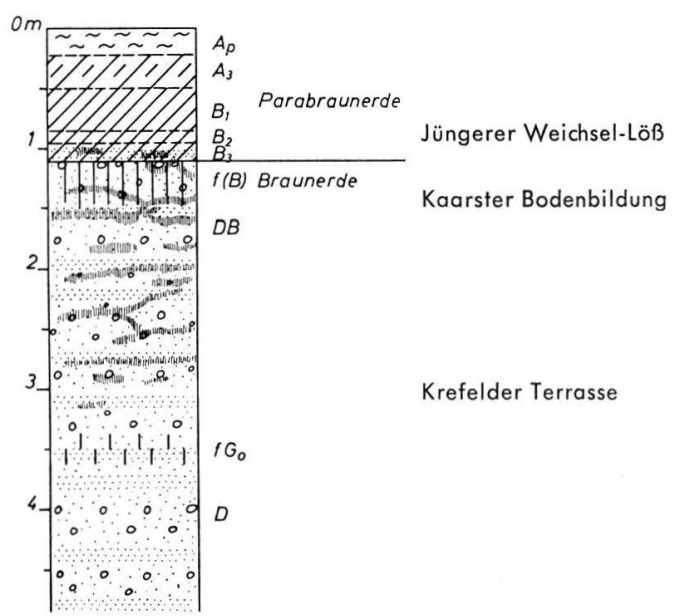

Abb. 7. Profil Kaarst.

Der die Terrassenschotter überlagernde Löß is $\mathrm{zu}$ einer Parabraunerde verwittert. Dabei entstehen infolge Tondurchschlämmung im Lößlehm ein einheitlicher Tonanreicherungshorizont (B-Horizont), in den Terrassenkiesen viele dünne Tonanreicherungsbänder (vgl. jNT). Aus diesem Profil ist nicht zu entscheiden, ob eine fossile, später erodierte Parabraunerde an der Bildung der Tonanreicherungsbänder beteiligt war. Aus einem Vergleich mit dem Profil Brauweiler ergibt sich, daß die Bänderung in sehr vielen Fällen z. T. auf einen fossilen, später erodierten Boden zurückzuführen ist.

Sehr oft ist die ca. $50 \mathrm{~cm}$ mächtige Verwitterung auf den Kiesen der KT, die nur von dem geringmächtigen jüngsten Löß bedeckt sind, nicht mehr nachweisbar. Diese Bodenbildung auf den Kiesen ( $\mathrm{f}(\mathrm{B})$-Horizont) hat vor der Ablagerung des jüngsten Lösses, der im unteren Teil unverwitterte oder nur schwach verwitterte Sandbänder enthält $\left(B_{3^{-}}\right.$ Horizont), stattgef unden. Typologisch ist der z. T. erodierte fossile Boden als eine Braunerde anzusprechen. In Verbindung mit dem $f(B)$-Horizont treten zwar meistens Tonanreicherungsbänder auf, stellenweise fehlen sie jedoch in und unterhalb dieses Horizonts. Sie sind also nicht an den $\mathrm{f}(\mathrm{B})$-Horizont gebunden. Der in 3,5 $\mathrm{m}$ Tiefe vorkommende Grundwasserhorizont läßt sich im Aufschluß keiner bestimmten Bodenbildung zuordnen. Nähere Hinweise auf die zeitliche Aufeinanderfolge von Tondurchschlämmung, fossiler 
Braunerdebildung, Kryoturbation und Bildung von fossilen Grundwasserhorizonten bieten die Aufschlïsse westlich von Krefeld:

Profil Krefeld-Coenen (20) (s. Abb. 8)

Nordwestecke der Kiesgrube Coenen in Krefeld-Benrad, M.-Bl. Krefeld (4605), 39 m über NN, eben, aufgenommen im April 1959.

ca. $1,10 \mathrm{~m}$ Lößlehm ist abgetragen;

$\mathrm{f}_{1}(\mathrm{~B}) / \mathrm{DB} \quad 0-15 \mathrm{~cm} \quad$ Schwach verlehmter Sand und schwach kiesiger Sand, kryoturbat gestört, bräunlichgelb (10 YR 6/6), mit wenigen rötlichbraunen (5 YR $4-5 / 4)$ Tonanreicherungsbändern, im sandigen Material wird der Horizont bis $40 \mathrm{~cm}$ mächtig;

$\mathrm{DB} \quad 15-40 \mathrm{~cm}$

kiesiger Sand, lichtgrau (10 YR 7/2), kryoturbat gestört, mit wenigen von der Frostbewegung ungestörten Tonanreicherungsbändern;

$\mathrm{f}_{2} \mathrm{G}_{0} \quad 40-60 \mathrm{~cm}$

D $\quad 60-120 \mathrm{~cm}+$ kiesiger Sand, kräftigbraun (7,5 YR 5/6), kryoturbat gestört;

kiesiger Sand und Sand, normal, Kryoturbation verliert sich allmählich nach unten.

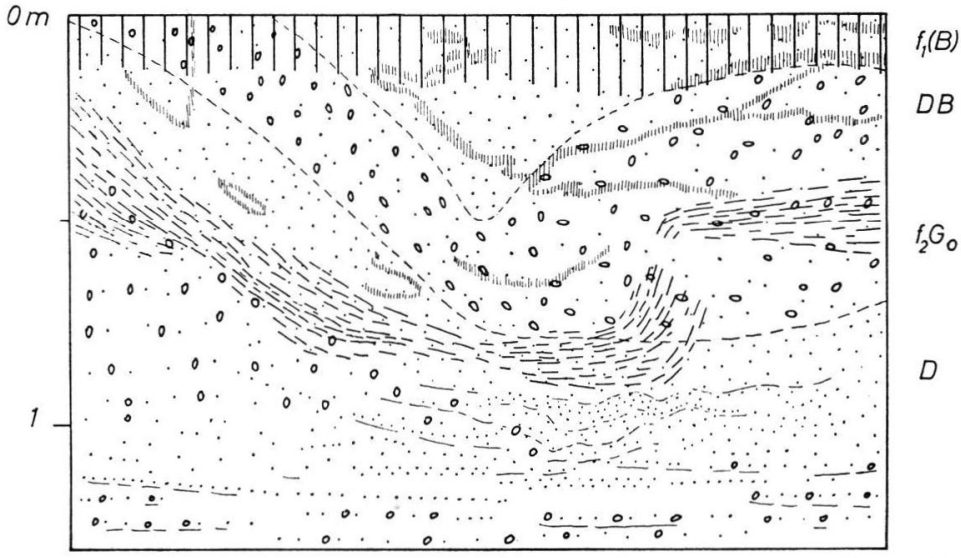

Abb. 8. Profil Krefeld-Coenen. Fossile Braunerde auf verwürgter Krefelder Terrasse.

Die Schichtung der Terrassenschotter ist durch Kryoturbation stark gestört. Auf den gestörten Kiesen hat eine schwache Braunerdebildung stattgefunden (vgl. Profil Kaarst/ Neuß). Die Tonanreicherungsbänder sind ebenfalls jünger als der Frostschubboden und sind entstanden durch Tondurchschlämmung aus der aus dem abgetragenen jüngsten Löß gebildeten Parabraunerde.

Durch die Frostbewegung gestört ist der fossile Grundwasserhorizont $f_{2} G_{0}$; er gehört damit zu einer Bodenbildung, die noch vor der Kryoturbation stattgefunden hat. Später hat das Grundwasser diese Höhe während der Bodenbildung nicht mehr erreicht.

Bestätigt und ergänzt wird die bodenkundliche Deutung des Profils Krefeld-Coenen durch das

Profil Krefeld-Nellessen (21) (s. Abb. 9)

Kiesgrube Nellessen in Krefeld-Benrad, M.-Bl. Krefeld (4605), 38,5 m über NN, eben, aufgenommen im April 1959.

$\begin{array}{lr}\text { Ap } & 0-25 \mathrm{~cm} \\ \mathrm{~A}_{3} & 25-65 \mathrm{~cm} \\ \mathrm{~B} & 65-105 \mathrm{~cm}\end{array}$

humoser feinsandiger Lehm;

feinsandiger Lehm, Bröckel- bis Polyedergefüge, braun (7,5 YR 4/4); feinsandiger Lehm, Polyedergefüge, Tonhäutchen auf den Gefügeflächen, kräftigbraun (7,5 YR 5/6); nach unten schalten sich dünne, ungestörte Sand- und Feinsandbänder ein, sehr fahlbraun (10 YR 7/3-4) und gelb (10 YR 7/6); in den unverlehmten Sandbändern ist stellenweise Tonsubstanz in dünnen, rötlichbraunen (5 YR 4-5/4) Bändern angereichert; Steinsohle an der Basis; 
$\mathrm{f}(\mathrm{B}) / \mathrm{DB} \quad 105-155 \mathrm{~cm}$

D $\quad 155-300 \mathrm{~cm}$ wechselnd mächtiger, schwach verlehmter Sand, in Frosttaschen bis zu $1,2 \mathrm{~m}$ mächtig, bräunlichgelb (10 YR 6/6), von der Frostbewegung ungestörte Tonanreicherungsbänder vorhanden, rötlichbraun (5 YR 4-5/4); stark frostgestörter kiesiger Sand, lichtgrau (10 YR 7/2); in Frosttaschen ist dichter, etwas plastischer grauer Lößlehm in die Terrassenschotter eingestülpt worden; das Material unmittelbar oberhalb des Lößlehms ist rotbraun und fahlgrau gefleckt, nur vereinzelt treten Tonanreicherungsbänder auf;

$300-350 \mathrm{~cm}+$ kiesiger Sand und Sand, lichtgrau (10 YR 7/2).

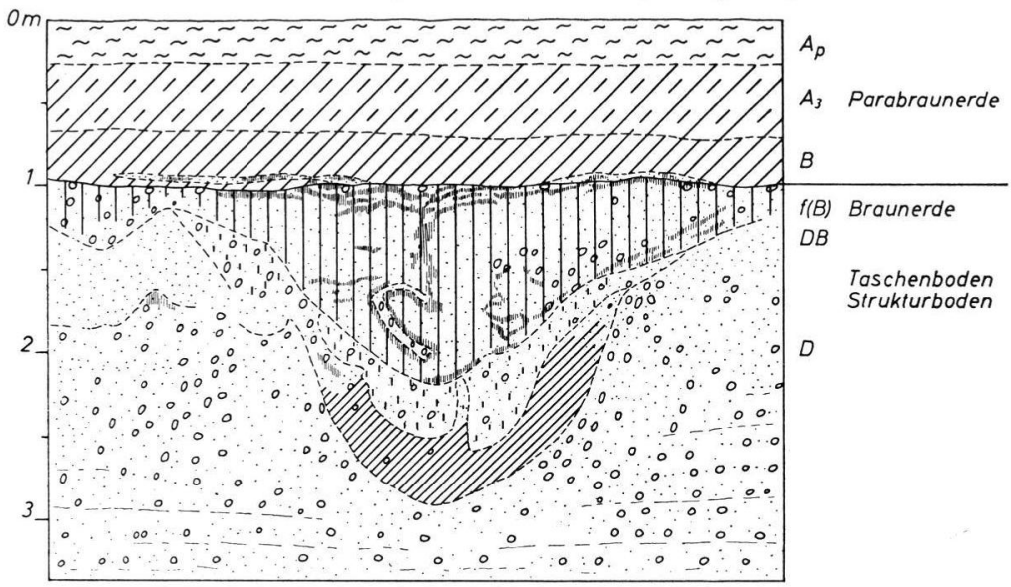

\section{Jüngerer \\ Weichsel-Löß \\ Kaarster \\ Bodenbildung \\ Krefelder Terrasse mit eingewürgtem \\ Lößlehm der \\ Erkelenzer \\ Bodenbildung}

Abb. 9. Profil Krefeld-Nellessen.

Der auf der stark frostgestörten Terrasse lagernde jüngste Löß ist zu einer Parabraunerde verwittert. Die Durchschlämmung der Tonsubstanz reicht bis in die Terrassenschotter hinein. Jünger als der Taschenboden ist ebenfalls die fossile Braunerde auf den Kiesen. Unverwitterte Flugsandbänder an der Basis des überlagernden Lösses zeigen auch hier, daß die Verwitterung des $\mathrm{f}(\mathrm{B}) / \mathrm{DB}$-Horizonts fossil ist und nicht mit der Bodenbildung aus dem überlagernden Löß entstanden ist.

An der Basis von Frosttaschen findet sich oft ein mäßig plastischer Lößlehm in die KT eingestülpt. Das Material ist sehr dicht und führt zu einer schwachen Pseudovergleyung des überlagernden Terrassenmaterials.

Die kräftige Verwitterung des eingestülpten Lößlehms (bis 23\% Ton) hat sicherlich stattgefunden, als das Material noch als geschlossene Decke auf den Terrassenkiesen lagerte. Der verwürgte Lößlehm ist so der Rest eines fossilen Bodens, der sich in schwach eingemuldeten Lagen auf der KT erhalten hat. In ebener Lage und in den Randgebieten der Terrasse fehlen auch diese Reste.

Damit ergibt sich für die KT im Bereich der Krefelder und Aldekerker Platte aus den beschriebenen Profilen folgende geologische Vergangenheit:

1. Ablagerung der Schotter der KT

2. Lößbildung

3. Bildung eines Grundwasserhorizonts und Erkelenzer Bodenbildung

4. Erosion des verwitterten Lößlehms bis auf einen geringen Rest

5. Bildung von Strukturböden und Einstülpung des überlagernden geringmächtigen Lößlehms

6. Bildung einer Braunerde geringer Entwicklungstiefe: Kaarster Bodenbildung

7. Winderosion und Bildung einer Steinsohle

8. Lößbildung mit vorausgehender Flugsandanwehung

9. Parabraunerdebildung aus dem jüngsten Löß und damit Ausbildung von Tonanreicherungsbändern im oberen Teil der Terrassenkiese. 
Der jüngste Löß lagert meistens mit scharfer, ungestörter Grenze auf den Kiesen und Sanden der KT, an deren Oberfläche eine Steinsohle ausgebildet ist. Nur gelegentlich ist die Grenze durch schwache Frostbewegungen uneben oder schwach verwürgt. Kies- und Sandlinsen werden dabei manchmal in den hangenden Löß hineingepreßt.

Die KT zeigt sich in vielen Fällen gänzlich unverwittert. Häufig hat eine schwache Braunerdebildung stattgefunden, wenn sie nur vom jüngsten Löß bedeckt ist. Nur in besonders günstigen Fällen (vgl. Profil Brauweiler) sind noch Merkmale einer eindeutig fossilen Parabraunerde erhalten. Damit unterscheidet sich die Krefelder Terrasse deutlich von der uMT, die stets einen kräftig verwitterten braunlehmartigen gelblichroten Interglazialboden (vgl. uMT) trägt. Wegen des Fehlens des Interglazialbodens sind die Kiese und Sande im Profil Alfter, das sich in der gemeinsamen Fortsetzung von KT und uMT zwischen Bonn und Köln befindet, zur KT zu stellen.

Profil Alfter (14) (s. Abb. 10)

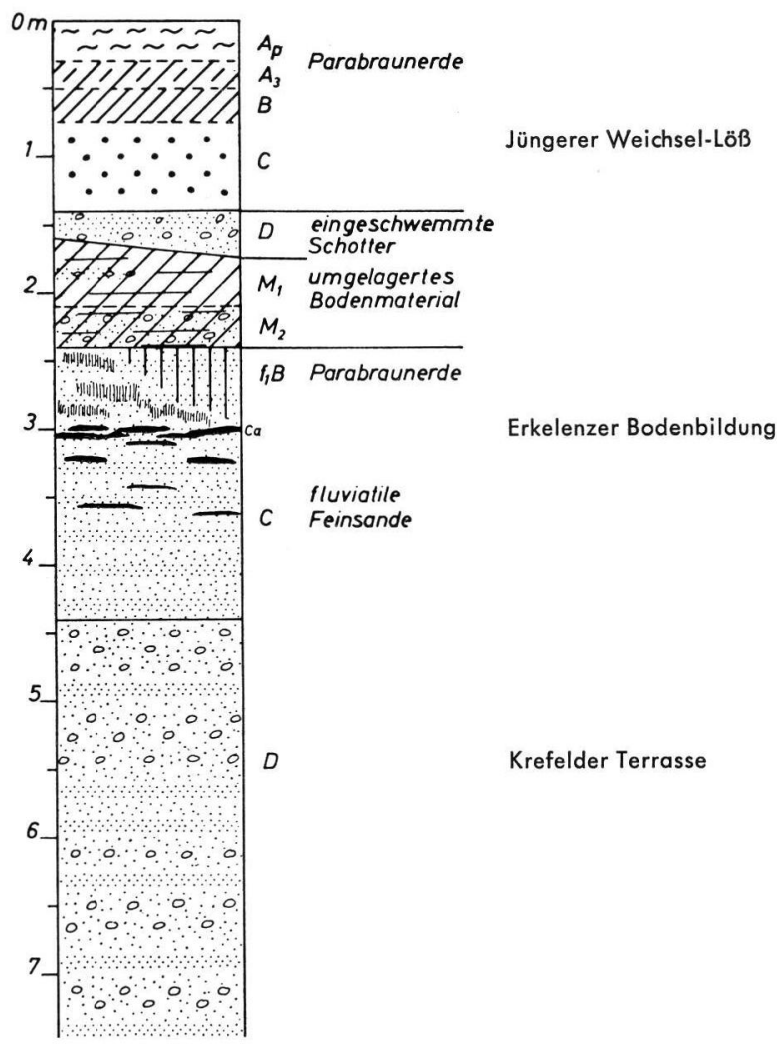

Abb. 10. Profil Alfter.

Kiesgrube am Terrassenrand östlich Alfter bei Bonn, M.-Bl. Bonn (5208), ca. $70 \mathrm{~m}$ über NN, aufgenommen am 16. 7. 1960.

Ap O- $30 \mathrm{~cm}$ humoser feinsandiger Lehm (Lößlehm), dunkelgelblich-braun;

$A_{3} \quad 30-50 \mathrm{~cm}$ feinsandiger Lehm, gelblichbraun, Bröckelgefüge;

B $\quad 50-75 \mathrm{~cm}$ feinsandiger Lehm, kräftigbraun, Polyeder- bis Prismengefüge, Tonhäut-

chen auf den Gefügeelementen;

C $\quad 75-135 \mathrm{~cm} \quad$ Löß, lichtgelblichbraun (10 YR 6/4);

D $135-160 \mathrm{~cm}$ kalkhaltiger kiesiger Sand und steiniger Kies, gelblichbraun (10 YR 5/4), stellenweise nur als Steinsohle vorhanden; 

$\mathrm{M}_{1} \quad 160-210 \mathrm{~cm}$ kalkhaltiger, schwach humoser feinsandiger Lehm, dunkelbraun (7,5 YR 4/4), mit kiesigen Einlagerungen;
$\mathrm{M}_{2} \quad 210-240 \mathrm{~cm}$ schwach lehmiger steiniger Kies, rötlichbraun (5 YR 4/4) und dunkelbraun (7,5 YR 4/4);
$\mathrm{f}_{1} \mathrm{~B} \quad 240-290 \mathrm{~cm} \quad$ Feinsand, sehr fahlbraun (10 YR 7/4), mit Tonanreicherungsbändern, stel- lenweise bis $50 \mathrm{~cm}$ verlehmt, rötlichgelb $(7,5$ YR 6/6), mit lehmigeren Ein- lagerungen und Tonhäutchen auf den Gefügeaggregaten;
C $\quad 290-440 \mathrm{~cm}$ kalkhaltiger. Feinsand, sehr fahlbraun (10 YR 7/4), im oberen Teil mit starker Kalkanreicherung, im unteren Teil einige kiesige Einlagerungen vorhanden;
D $\quad 440-880 \mathrm{~cm}+$ sandiger steiniger Kies.

Die Kiese und Sande (D-Horizont) sind gänzlich unverwittert. Etwas problematisch ist die Stellung der überlagernden fluviatilen Feinsande ( $f_{1} B-$ und C-Horizont). Sie gehen allmählich aus den groben Schottern hervor und sind so wohl am ehesten als eine Hochflutbildung der KT zu deuten. Ähnliche Beobachtungen aus anderen Aufschlüssen der KT liegen nicht vor. Auf den Feinsanden ist noch der untere Teil einer fossilen Parabraunerde ( $\left.f_{1} B-H o r i z o n t\right)$ erhalten, kenntlich an Tonanreicherungsbändern, stellenweise an einer Verlehmungszone mit Tonhäutchen auf den Gefügeelementen und an der starken Kalkanreicherung an der Basis dieses Bodens.

Über der fossilen Parabraunerde aus den fluviatilen Feinsanden folgt eine starke verlehmte Schotterlage, die auf Grund ihrer Färbung als umgelagertes Bodenmaterial des braunlehmartigen gelblichroten Interglazialbodens auf der Oberen Mittelterrasse (oMT) oder der Hauptterrasse (HT) zu deuten ist. Dieses, wie auch das folgende, braune Bodenmaterial sind sicherlich durch Solifluktion von der benachbarten Ville her herangetragen worden. Durch Einschwemmung sind die kryoturbat gestörten, schräg geschichteten Kiese und Sande des D-Horizontes unmittelbar unter dem jüngsten Löß entstanden, der im oberen Teil zu einer Parabraunerde verwittert ist.

Die uMT (=Talwegterrasse) ist in zahlreichen weiteren Kiesgruben zwischen Bonn und Köln aufgeschlossen. Häufig ist der interglaziale Boden auf dem Terrassenmaterial in typischer Ausprägung zu beobachten (vgl. uMT). Immer ist er stark gekappt, so daß nur noch der untere Teil des B-Horizonts vorliegt. In besonders kräftig erodierten Profilen fällt es schwer, ihn von jüngeren Bodenbildungen zu unterscheiden. Große Teile werden sicherlich in den randlichen Gebieten von den Schottern und Sanden der KT eingenommen. Südwestlich von Köln sind so fossile Böden verbreitet, die für die KT typisch sind.

So zeigt das Studium der Aufschlïsse in der uMT zwischen Bonn und Köln, daß diese trotz ihrer morphologischen Einheit zwei verschiedenaltrige Schotterkörper enthält. Im Randgebiet zu den höheren Terrassen sind noch die durch den typischen braunlehmartigen gelblichroten Interglazialboden charakterisierten Schotter der uMT vorhanden (vgl. uMT). Im Randgebiet zur NT fehlt dieser Boden oft ganz (z. B. Efferen bei Köln, im Profil Alfter und östlich von Brühl), so daß hier sicherlich noch die KT enthalten ist. Damit zeigt sich, daß der Bildung dieses Schotterkörpers eine Erosion voranging, die mindestens den ca. $10 \mathrm{~m}$ mächtigen Interglazialboden ausräumte. Dann erreichte die erneute Aufschotterung südlich von Köln genau das Niveau der uMT.

\section{Die Pseudogleye auf der Krefelder Terrasse}

Auf der Krefelder Platte herrschen in flachen, kleinen Geländedepressionen oft von dem beschriebenen, normalen Bild sehr abweichende bodenkundliche Verhältnisse. Schon durch die sehr dunkelgraubraune Farbe des humosen Oberbodens hebt sich das Verbreitungsgebiet dieser Böden deutlich von der dunkelgelblich-braunen Farbe der normalen Parabraunerden ab. Auf Grund ihres Profilaufbaus sind diese Böden als Pseudogleye anzusprechen. 
Profil Krefeld-Boves (22)

Kiesgrube Boves in Krefeld-Benrad, M.-Bl. Krefeld (4605), eben, in einer kleinen Mulde gelegen, 37,5 m über NN, aufgenommen im Mai 1959.

Ap $\quad 0-25 \mathrm{~cm}$ humoser lehmiger Feinsand, sehr dunkelgrau-braun (10 YR 3/2), mit we25- $35 \mathrm{~cm} \quad$ nigen Kieselsteinen durchsetzt (Lößlehm);

g1 25- $35 \mathrm{~cm} \quad$ lehmiger Feinsand mit stark wechselnder Mächtigkeit, lichtgrau (2,5 Y 7/2), unregelmäßig schwach rostbraun gefleckt;

$\mathrm{g}_{2} \quad 35-60 \mathrm{~cm}$ lehmiger Feinsand, lichtgrau (2,5 Y $\left.7 / 2\right)$ und stark rostbraun gefleckt, polyedrisches Gefüge, auf den Gefügeelementen kräftigbrauner Eisenbelag, an der Basis Steinsohle;

$\mathrm{g}_{3} \mathrm{fG}_{0} \quad 60-130 \mathrm{~cm} \quad$ stark gestörter, schichtungsloser, schwach kiesiger Sand, krä̈tigbraun $(7,5$ YR 5/8) und lichtgrau (2,5 Y $7 / 2)$ marmoriert, eingewürgter lichtgrauer $(2,5 \mathrm{Y} 7 / 2)$ sandiger Lehm vorhanden, nach unten allmählicher Ưbergang zu regelmäßiger Bänderung;

$\mathrm{fG}_{0} \quad 130-170 \mathrm{~cm} \quad$ schwach gestörter Sand und kiesiger Sand, lichtgrau $(2,5 \mathrm{Y} 7 / 2) \mathrm{mit}$ bis zu

D $\quad 170-250 \mathrm{~cm}+\quad \begin{aligned} & 20 \mathrm{~cm} \text { mächtigen, kräftigbraunen Bändern }(7,5 \mathrm{Y} \\ & \text { Sand und kiesiger Sand, lichtgrau }(2,5 \mathrm{Y} 7 / 2) \text {. }\end{aligned}$

Die fossilen Grundwasserhorizonte der Krefelder Platte sind meist (vgl. Profil Krefeld-Coenen) vor der Kryoturbation der Terrassenschotter und damit vor Absatz des jüngsten Lösses gebildet worden. Das stellenweise Fehlen sowie die unregelmäßige Ausbildung des $\mathrm{G}_{0}$-Horizonts deuten auch im Profil Krefeld-Boves eine ähnliche zeitliche Abfolge an. Das heutige Grundwasser befindet sich erst in durchschnittlich 3 bis $4 \mathrm{~m}$ Tiefe.

Ein zeitweilig höherer Grundwasserspiegel ist auf der Krefelder Platte während des Postglazials anzunehmen; H. Mertens (mündliche Mitteilung) bezeichnet diese Böden so als Gleye mit stark schwankendem Grundwasser. Böden mit ähnlichem Profil sind aus dem Bereich der NT bisher nicht bekannt. Obwohl sie auf Grund ihrer Horizontfolge als Pseudogleye anzusprechen sind, zeigen sie weder in der Vegetation unter Wald noch beim Ackerbau irgendwelche Anzeichen der Staunässe. Damit sind die Pseudogleye auf der Krefelder Platte als Reliktböden anzusehen, die unter heute nicht mehr gültigen Umweltbedingungen gebildet wurden.

Während kühler und feuchter Klimaperioden (z. B. Jüngere Dryaszeit) hat sich über zeitweise gefrorenem Untergrund in den schwachen Geländedepressionen viel Wasser sammeln und besonders lange halten können. Dazu verhinderte gerade in den Senken die durch Frostschubböden und eingewürgten dichten Lößlehm verdichtete Terrasse ein schnelles Versickern der Feuchtigkeit.

Mit dieser kräftigen und fast ständigen Vernässung des Bodens fand eine starke Entbasung und die Herausbildung eines Pseudogleyprofils statt. Unter späteren günstigeren Klimabedingungen konnte sich in dem bestehenden sauren Milieu keine normale Parabraunerde mehr entwickeln, wie sie für die Lößgebiete der Niederrheinischen Bucht typisch ist.

Unter natürlichen Bedingungen findet in den sauren Pseudogleyen ein Zerfall der Tonminerale ( $\mathrm{pH}$ in $\mathrm{KCl}: 3,5-4)$ statt. Das beim Zerfall der primären Silikate frei werdende Eisen wandert in die tieferen Bodenhorizonte und setzt sich in Konkretionen oder als kräftig brauner Belag auf den Gefügeelementen wieder ab. Durch fortwährende Auslaugung bildet sich schließlich unter dem A-Horizont eine bis zu $40 \mathrm{~cm}$ mächtige Bleichzone heraus, auf der örtlich unter Kiefernwald ein geringmächtiger Sekundärọodsol entstehen kann (in Aufgrabungen des Geologischen Landesamts Krefeld in der Nähe des Forsthauses bei St. Tönis sichtbar).

\section{Die fossilen Böden in den Deckschichten}

Die KT ist zum größten Teil nur von einem 1 bis $1,5 \mathrm{~m}$ mächtigen Lößlehm bedeckt. Diese Decke ist während der letzten Lößbildungsperiode entstanden. In ihrem unteren Teil sind fast immer dünne Sand- und Gerölleinlagerungen enthalten, mit deren Bildung die Lößsedimentation einsetzte. W. WunstorF (1913) bezeichnet deshalb diesen sandigen, 


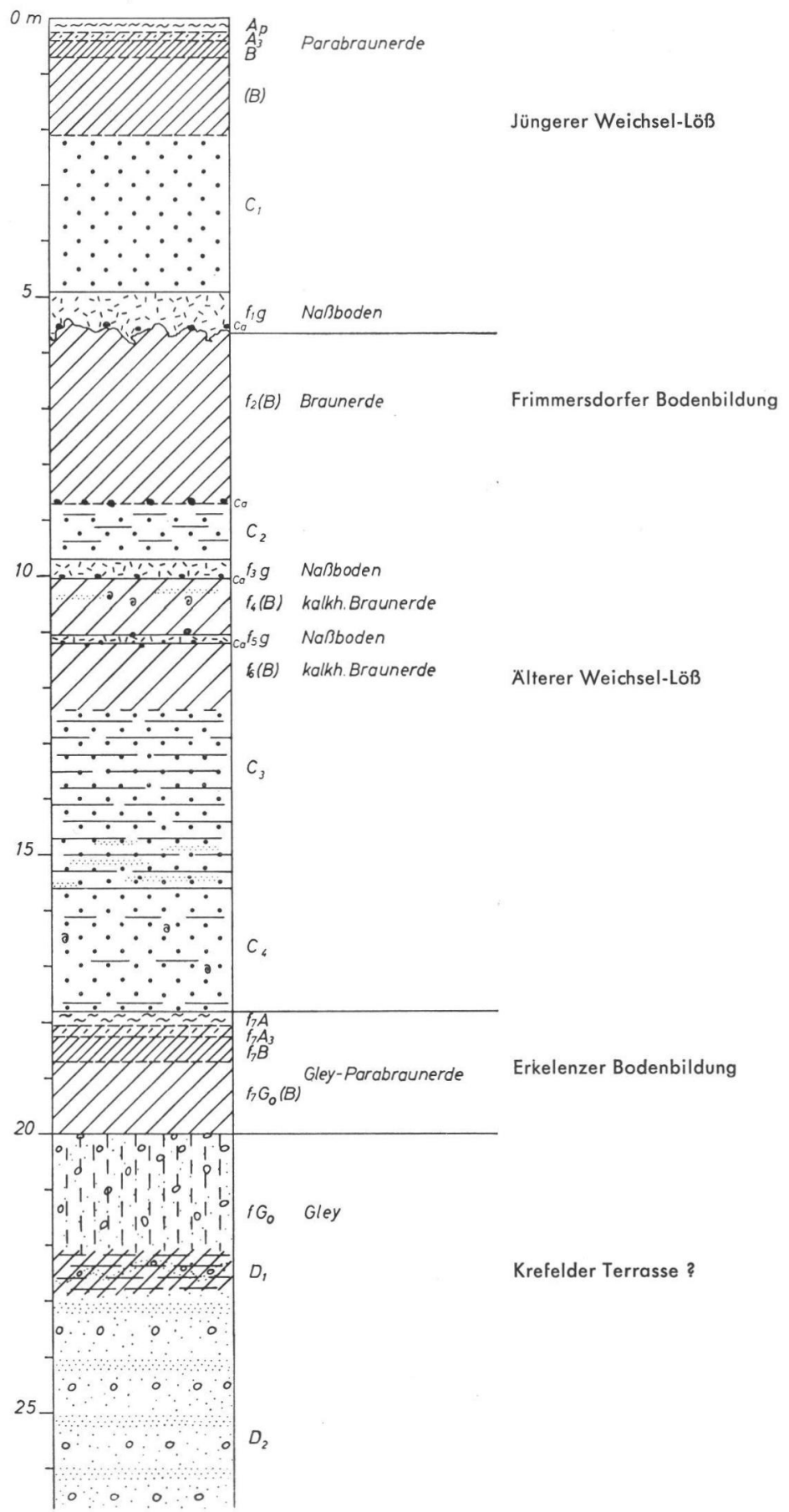

Abb. 11. Profil Frimmersdorf-West. 
z. T. geschichteten Lößlehm, der auch die HT in ihrem Randgebiet überzieht, als fluviatilen Schotterlehm.

In Randgebieten der Terrasse, besonders auf der westlichen Seite, wurde mehr sandiges Material angeweht. Größere Lößmächtigkeit über den Kiesen der KT sind erst am Fuß höherer Terrassenstufen entwickelt. So sind mächtige Lößprofile entlang dem Terrassenrand der uMT auf der Linie Holzheim (Neuß) - Rheydt und bei Brauweiler westlich von Köln in Ziegeleigruben aufgeschlossen.

Profil Frimmersdorf-West (27) (s. Abb. 11)

Braunkohlentagebau Frimmersdorf-West, ra. $300 \mathrm{~m}$ südöstlich der Bundesstraße 1 bei Elfgen, M.-Bl. Grevenbroich (4905), $71 \mathrm{~m}$ über NN., eben, am Fuße der HT, aufgenommen am 16. 3. 1960. Ap O- $25 \mathrm{~cm}$ humoser feinsandiger Lehm, dunkelbraun (10 YR 3/4);

$\mathrm{A}_{3} \quad 25-40 \mathrm{~cm}$ feinsandiger Lehm, Bröckel- bis Polyedergefüge, braun (7,5 YR 5/4); $\mathrm{B} \quad 40-70 \mathrm{~cm}$ feinsandiger Lehm, Bröckel- bis Polyedergefüge, Tonhäutchen auf den Gefügeelementen, braun (7,5 YR 5/4);

(B) $\quad 70-210 \mathrm{~cm}$ feinsandiger Lehm, Bröckelgefüge, rötlichgelb (7,5 YR 6/6);

$\mathrm{C}_{1} \quad 210-490 \mathrm{~cm} \quad \mathrm{Löß}$, nach unten allmählicher Ưbergang zum nächsten Horizont, sehr fahlbraun (10 YR 7/4), in 3,2 m Tiefe einige Lößkindel vorhanden;

$\mathrm{f}_{1} \mathrm{~g} \quad 490-560 \mathrm{~cm}$

$f_{2}$ (B) $\quad 560-870 \mathrm{~cm}$

$\mathrm{C}_{2} \quad 870-970 \mathrm{~cm}$

$\mathrm{f}_{3} \mathrm{~g} \quad 970-1005 \mathrm{~cm}$ kalkhaltiger feinsandiger Lehm, Lößkindel besonders im unteren Teil reichlich vorhanden, sehr fahlbraun (10 YR 7/4), rostbraune Röhren und Flecken vorhanden, Liegendgrenze stark kryoturbat gestört;

feinsandiger Lehm, bräunlichgelb (oben: 10 YR 6/8, unten 10 YR 6/6), Bröckelgefüge, oben ca. $60 \mathrm{~cm}$ schichtungslos, nach unten zunehmend geschichtet, an der Basis Lößkindelhorizont;

Löß, deutlich sehr fahlbraun (10 YR 7/3) und bräunlichgelb (10 YR 6/6) geschichtet, Bröckelgefüge, kleine weiche Mangankonkretionen vorhanden;

kalkhaltiger feinsandiger Lehm mit kleinen Lößkindeln an der Basis, sehr fahlbraun (10 YR 7/4), reich an Mangankonkretionen, Bröckelgefüge;

$\mathrm{f}_{4}(\mathrm{~B}) \quad 1005-1105 \mathrm{~cm}$

kalkhaltiger feinsandiger Lehm, oben bräunlichgelb (10 YR 6/6) und unten gelb (10 YR 7/6), wenige Mangankonkretionen und im oberen Teil sandigere Einlagerungen vorhanden, Fossilhorizont mit Lößschnecken, schichtungslos, Bröckelgefüge, Lößkindel an der Basis;

$\mathrm{f}_{5} \mathrm{~g} \quad 1105-1120 \mathrm{~cm}$

$\mathrm{f}_{6}$ (B) $1120-1240 \mathrm{~cm}$

$\mathrm{C}_{3} \quad 1240-1560 \mathrm{~cm}$ kalkhaltiger feinsandiger Lehm, fehlbraun (10 YR 6/3), mit kleinen gelben Flecken, kleine Lößkindel an der Basis, Bröckelgefüge;

kalkhaltiger feinsandiger Lehm, bräunlichgelb (10 YR 6/6), nach unten gelb (10 YR 7/6) werdend, Bröckelgefüge, allmählicher Ubbergang zum nächsten Horizont;

Löß mit deutlicher Schichtung, bindigere, dunklere Schichten sind zwischengelagert, nach unten stellen sich immer mehr sandigere Einlagerungen ein, Farben gelb (10 YR 7/6), bräunlichgelb (10 YR 6/6) und sehr fahlbraun (10 YR 7/4), scharfe Grenze zum nächsten Horizont;

$\mathrm{C}_{4} \quad 1560-1780 \mathrm{~cm}$ Löß, der Kalkgehalt nimmt nach unten ab, Lößschnecken vorhanden, ungeschichtet, allmählicher Übergang zum nächsten Horizont, oben gelblichbraun (10 YR 5/4), unten lichtgelblichbraun (10 YR 6/4), viele Mangankonkretionen vorhanden;

$\mathrm{f}_{7} \mathrm{~A} \quad 1780-1805 \mathrm{~cm}$

$\mathrm{f}_{7} \mathrm{~A}_{3} \quad 1805-1825 \mathrm{~cm}$

$\mathrm{f}_{7} \mathrm{~B} \quad 1825-1870 \mathrm{~cm}$

$\mathrm{f}_{7} \mathrm{G}_{0}$ (B) $1870-2000 \mathrm{~cm}$ schwach humoser feinsandiger Lehm, dunkelbraun (10 YR 4/3), viele Mangankonkretionen vorhanden;

feinsandiger Lehm, schwach plattiges Gefüge, lichtgelblichbraun (10 YR 6/4), Mangankonkretionen vorhanden;

feinsandiger Lehm, kräftig braun (7,5 YR 5/6), Bröckel- bis kantengerundetes Kleinpolyedergefüge, Tonhäutchen auf den Gefügeelementen;

feinsandiger Lehm, Polyeder- bis Plattengefüge, gelblichbraun (10 YR $5 / 4$ ), rostbraun und fahlgrau gefleckt, nach unten zunehmende Flekkung und Marmorierung, Mangankonkretionen vorhanden, Liegendgrenze scharf oder schwach gewellt;

$\mathrm{fDG}_{0} \quad 2000-2200 \mathrm{~cm}$ kiesiger Sand, im oberen Teil schwarz (Manganabsatz durch Grundwasser), im unteren Teil hauptsächlich krättigbraun (10 YR 5/8) gefärbt (Grundwasserbildung), durch Frostbewegungen stark gestörte Lagerung; 
$D_{1} \quad 2200-2300 \mathrm{~cm}$ plastischer und dichter, schwach feinsandiger Lehm mit Kieseleinlagerungen, umgelagertes Bodenmaterial, in trockenem Zustand Zerfall in kleine Polyeder, gelblichrot (5 YR 4/8), z. T. auch gebleicht;

$\mathrm{D}_{2} \quad 2300-2700 \mathrm{~cm}+$ kiesiger Sand mit vereinzelten Grundwasserhorizonten, die Kryoturbation verliert sich nach unten.

Die Profilentwicklung ist in diesem Aufschluß sehr unterschiedlich. Umlagerungen von Bodenmaterial sind sehr verbreitet, so daß die Löß- und Lößlehmfolge nur noch an wenigen Stellen zu gliedern ist. Das beschriebene Profil ist ein besonders günstiger Ausschnitt aus der Grubenwand.

Im Liegenden der Lösse lagern unverwitterte Kiese und Sande (Oberkante ca. $55 \mathrm{~m}$ über NN.), die bisweilen durch eingelagerte lößlehmartige, schluffige Lehme vertreten werden. In die Profilbeschreibung wurde eine Einlagerung von plastischem, intensiv verwittertem Lößlehm aufgenommen, die stark kryoturbat gestört ist. Bei der unmittelbaren Nachbarschaft der HT ist es durchaus möglich, daß Bodenmaterial vom Hang her zur Zeit der Ablagerung der Schotter eingeschwemmt wurde.

G. v. D. Brelie, K. KILPPER \& R. Teichmüller (1959) rechnen die Schotter noch zur uMT; das Fehlen des braunlehmartigen Interglazialbodens, der auf der uMT sehr verbreitet ist, und die Höhenlage, die der KT näher steht als der der uMT, läßt daran denken, daß es sich auch hier um Schotter der KT handeln könnte. Uber den Schottern folgt mit scharfer Grenze eine geringmächtige Lößlehmfolge, die zu einer Gley-Parabraunerde verwittert ist. Mit der Bildung dieses Bodens, der nur auf kurze Entfernung zu beobachten ist, sind wahrscheinlich die Grundwasserabsätze in den Terrassenschottern entstanden. Aus dem folgenden, stark schichtigen Löß ist eine $3,1 \mathrm{~m}$ mächtige Braunerde, Boden $\mathrm{f}_{2}$ gebildet worden. $\mathrm{Da}$ der Boden $\mathrm{f}_{2} \mathrm{z}$. T. erodiert ist, ist die typologische Ansprache nicht sicher. Lößkindel an der Basis dieses Bodens sowie die Zunahme der Farbintensität nach oben beweisen den autochthonen Charakter dieses Bodens.

Das Material des schichtigen Lösses $(4,90 \mathrm{~m}-17,70 \mathrm{~m})$ ist lokal im oberen Teil nur wenig umgelagert. Daher haben sich unter der Braunerde $f_{2}$ noch vier weitere fossile Böden erhalten können. Die fossilen Böden $f_{4}$ und $f_{5}$ sind mit ihrer typischen rostbraunen Fleckung als Naßböden anzusprechen. Eine schwache Braunerdebildung hat jeweils unterhalb der beiden Naßböden im Bereich der Horizonte $f_{4}(B)$ und $f_{6}(B)$ stattgefunden. In beiden Horizonten nimmt die Farbintensität nach oben zu. Gut erhaltene Gehäuse von Lößschnecken zeigen, daß der Kalkgehalt z. T. noch primär ist. Daher werden die Böden $\mathrm{f}_{4}$ und $\mathrm{f}_{6}$ als kalkhaltige Braunerden angesprochen.

Das Vorkommen von Kalk in einem autochthonen, braunen Bodenmaterial ist überraschend. Die Verlehmung ist nur sehr gering, so daß der Kalkgehalt durchaus noch primär sein kann. Andererseits müssen wir damit rechnen, daß diese Böden bei der starken Hanglage während ihrer Entstehung durch Hangnässe immer wieder von neuem aufgekalkt wurden. Eine dritte Möglichkeit der Aufkalkung ist durch das Sickerwasser gegeben. Bei der rezenten Bodenbildung wird Kalk gelöst, abwärts geführt und sekundär in den begrabenen, fossilen Böden wieder abgeschieden. Über der Braunerde folgt als jüngstes ein schichtungsloser, sehr mächtiger Löß, auf dem eine 2,10 m mächtige Parabraunerde gebildet wurde. An der Basis dieses Lösses tritt noch einmal ein Naßboden $\left(f_{1}\right)$ auf, der mit der Braunerde $\mathrm{f}_{2}$ stark verwürgt ist.

Wahrscheinlich haben sich während der Bildungszeit der Schichtfolge von $4,90 \mathrm{~m}$ bis $17,80 \mathrm{~m}$ Zeiten der Lößanwehung, des Bodenfließens und der Bodenbildung abgelöst. Im Schatten der benachbarten HT kam es so zur Bildung eines sehr mächtigen, schichtigen und stark gegliederten Lösses, der an anderer Stelle fehlt (vgl. Profil Kaarst/Neuß) oder nur schwach vertreten ist (vgl. die Profile Holzheim und Rheindahlen).

Weit weniger mächtig sind der schichtige Löß und der jüngste Löß in der Ziegeleigrube Dahmen bei Giesenkirchen/Rheydt. 
Profil Giesenkirchen (24) (s. Abb. 12)

Ziegeleigrube Dahmen, südlich der Straße Giesenkirchen-Mühlfort bei Rheydt, M.-Bl. Mönchen-Gladbach (4804), $54 \mathrm{~m}$ über NN, sehr schwach nach N geneigt, aufgenommen am 15. 3. 1960.

$\begin{array}{lr}\text { Ap } & 0-30 \mathrm{~cm} \\ \mathrm{~A}_{3} & 30-65 \mathrm{~cm}\end{array}$

$\mathrm{B}_{1} \quad 65-100 \mathrm{~cm}$

$\mathrm{B}_{2} \quad 100-135 \mathrm{~cm}$

$\mathrm{B}_{3} \quad 135-170 \mathrm{~cm}$

$\mathrm{f}_{1}(\mathrm{~B})_{1} \quad 170-270 \mathrm{~cm}$

$\mathrm{f}_{1}(\mathrm{~B})_{2} \quad 270-320 \mathrm{~cm}$

C $\quad 320-390 \mathrm{~cm}$

$\mathrm{f}_{2} \mathrm{~A}_{3} \mathrm{~g} \quad 390-445 \mathrm{~cm}$

$\mathrm{f}_{2} \mathrm{~A}_{3} \mathrm{Bg} \quad 445-470 \mathrm{~cm}$

$\mathrm{f}_{2} \mathrm{Bg} \quad 470-550 \mathrm{~cm}$

$\mathrm{f}_{2}(\mathrm{~B}) \mathrm{G}_{01} \quad 550-580 \mathrm{~cm}$

$\mathrm{f}_{2}(\mathrm{~B}) \mathrm{G}_{02} \quad 580-600 \mathrm{~cm}$

$f_{3} G_{01} \quad 600-620 \mathrm{~cm}$

$\mathrm{f}_{3} \mathrm{G}_{02} \quad 620-660 \mathrm{~cm}$

$\mathrm{f}_{3}$ Gor $\quad 660-730 \mathrm{~cm}+$ humoser feinsandiger Lehm, dunkelgraubraun, (10 YR 4/2);

feinsandiger Lehm, gelblichbraun (10 YR 5/4);

schwach sandiger feinsandiger Lehm, nach unten sandiger werdend, Úbergangshorizont, kräftigbraun, Bröckel- bis Polyeder-Gefüge $(7,5$ YR 5/6);

schwach lehmiger Sand (Tonanreicherungsbänder), kräftigbraun (7,5 YR 5/6), mit dünnen zwischengelagerten Sandbändern, sehr fahlbraun (10 YR 7/4);

Sand mit wenigen Tonanreicherungsbändern, ungestört, in Frostspalten in den nächsten Horizont hineinreichend, Steinsohle an der Basis;

schichtiger feinsandiger Lehm, oben bräunlichgelb (10 YR 6/6), unten lichtgelblichbraun (10 YR 6/4), Mangankonkretionen vorhanden;

feinsandiger Lehm mit Sand- und Kieseinlagerungen, an der Basis Lößkindelhorizont, gelblichbraun (10 YR 5/6);

geschichteter Löß mit einer Steinsohle an der Basis und sandigen Einlagerungen, gelblichbraun (10 YR 5/6); in den oberen $30 \mathrm{~cm}$ sehr viele Lößkindel vorhanden; eine Kalkbank durchzieht den Horizont;

dünnblättriger feinsandiger Lehm (fahlbraun) (10 YR 6/3), nach unten allmählicher Übergang, im unteren Teil auf Klüften und Gefügeflächen beginnende rostbraune Fleckung und gelblichbrauner (10 YR 5/8) Belag;

feinsandiger Lehm, Übergangshorizont;

feinsandiger Lehm, bindig, wenige Tonhäutchen auf den Gefügeelementen sichtbar, Kleinpolyedergefüge, im unteren Teil setzen Polygone ein, schwach rostbraun gefleckt, nach unten zunehmend fahlgrau gefleckt, kräftigbraun (7,5 YR 5/6), allmählicher Übergang zum nächsten Horizont;

feinsandiger Lehm, mit einer Steinsohle an der Basis und wenigen sandigen Bändern im unteren Teil, lichtgelblichbraun (10 YR 6/4), rostbraun gefleckt, Mangankonkretionen vorhanden;

lehmiger, schwach kiesiger Sand, stark kryoturbat gestört und in Frostspalten und Taschen in den nächsten Horizont hineingeknetet, kräftigbraun (7,5 YR 5/6), rostbraun und fahlgrau gefleckt;

stark kryoturbat gestörter feinsandiger Lehm, gelblichbraun (10 YR $5 / 6)$, rostbraun und fahlgrau gefleckt, auch etwas fahlbraun marmoriert (10 YR 6/3), wenig bindig und locker, undeutlich plattig absondernd, Mangankonkretionen vorhanden;

feinsandiger Lehm, plattiges, grobes Polyedergefüge, Farbe wie $f_{3} G_{01}$, etwas bindiger und fettiger;

feinsandiger Lehm, gelblichbraun (10 YR 5/6), bräunlichgelb (10 YR 6/6) und lichtgelblichbraun (10 YR 6/4) marmoriert, geschichtet.

Durch die günstige Lage unmittelbar nördlich der uMT und östlich der HT (s. Abb. 1) haben sich in der Ziegeleigrube Dahmen zwischen Rheydt und Giesenkirchen auf der KT außerordentlich große Lößmächtigkeiten bilden und erhalten können. Infolge des bei ca. $7 \mathrm{~m}$ stehenden Grundwassers sind die Kiese der KT nicht mehr aufgeschlossen. Die mit dem hohen Grundwasserstand verbundene starke Vergleyung der unteren Bodenhorizonte erschwert die bodenkundliche Deutung des Profils. Die Schichtfolge fällt mit dem Gelände schwach nach Osten ab.

Als ältestes ist ein vergleyter Lößlehm aufgeschlossen (Boden $f_{3}$ ), der von einer stark frostgestörten Fließerde ïberlagert wird. Hier ist nicht mit Sicherheit zu entscheiden, ob auf diesem Lößlehm eine eigene Bodenbildung stattgefunden hat. Aus einem Vergleich mit dem Profil von Wegberg (s. HT) ergibt sich aber, daß der Bildung der Fließerde ( $f_{2}(B) G_{0}$-Horizont) wahrscheinlich die Verwitterung des liegenden Lößlehms vorausgegangen ist. Eine mögliche ehemalige Horizontgliederung des fossilen Bodens $f_{3}$ deutet sich vielleicht in der unterschiedlichen Struktur der Horizonte $f_{3} G_{01}$ und $f_{3} G_{02}$ an. Die Die Korngrößenanalyse zeigt nur einen unwesentlichen Unterschied. 

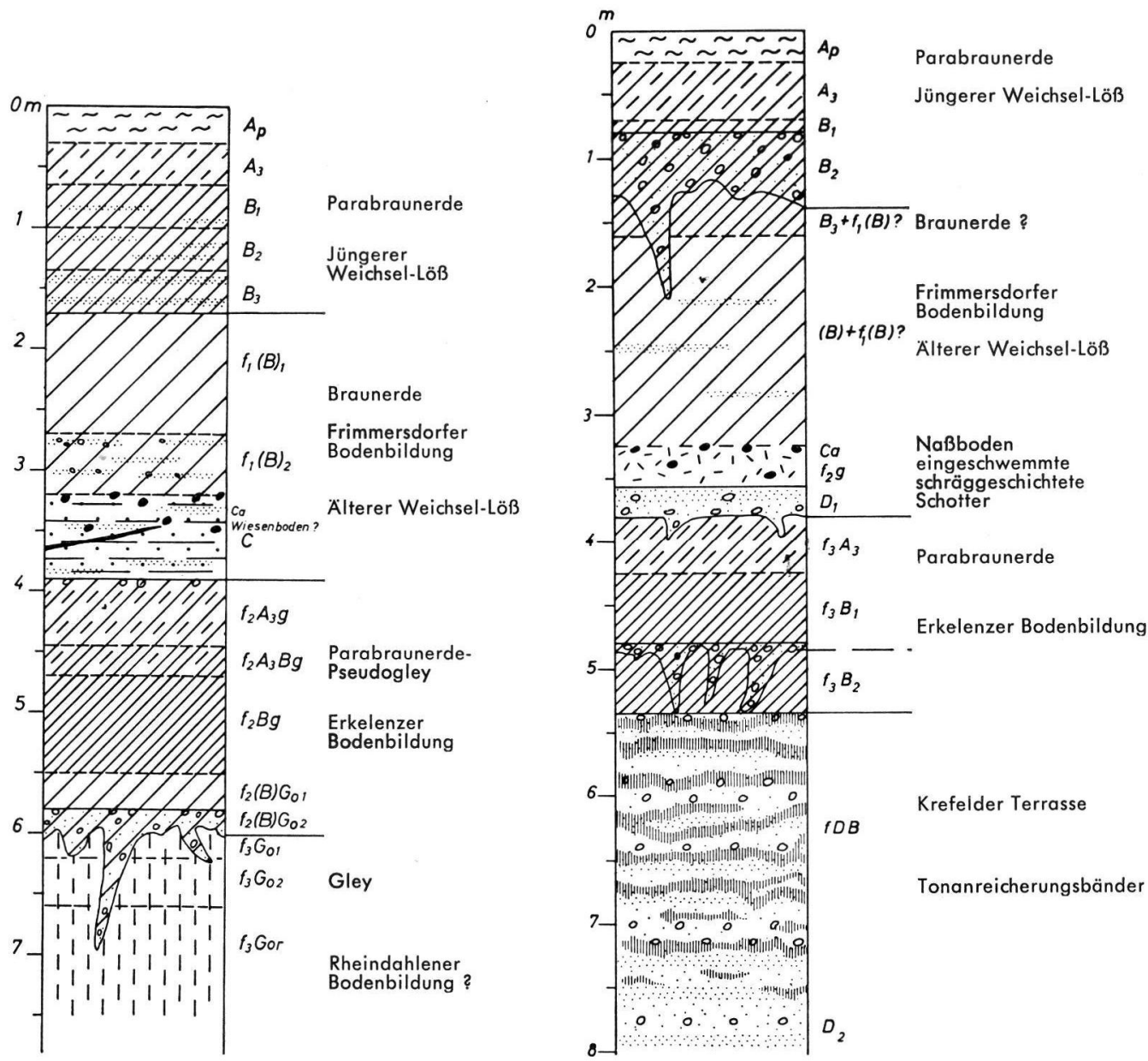

Abb. 12. Profil Giesenkirchen. - Abb. 13. Profil Brauweiler.

Der fossile Boden $f_{2}$ ist ebenfalls noch von Grundwasser beeinflußt. Die Fleckung in den oberen Bodenhorizonten ist sicherlich zum Teil durch Staunässe entstanden, so dał3 der Boden auf Grund der Horizontausbildung als Parabraunerde - Pseudogley angesprochen werden muß.

Über dem Boden $\mathrm{f}_{2}$ ist ein schichtiger Löß abgelagert worden, der bis auf einen geringen Rest verlehmt ist. Bei der Verwitterung dieses Lösses zu einer Braunerde sind mächtige Lößkindel und im unverwitterten Löß eine Kalkbank entstanden; eine derart mächtige Kalkanreicherung ist im Arbeitsgebiet bei der jüngsten Bodenbildung nicht beobachtet worden. Diese starke Kalkanreicherung sowie die Zunahme der Farbintensität nach oben sind charakteristisch für diese Braunerdebildung, die der Braunerde $f_{2}$ des Profils Frimmersdorf-West und der Braunerde $\left(f_{2}\right)$ des Profils Erkelenz (s. HT) entspricht. Mit der Kalkbank ist stellenweise ein sehr geringer Gehalt (ca. 0,3\%) an organischer Substanz verbunden, der ebenfalls die Deutung eines Wiesenbodens für die starke Kalkanreicherung in einer Bank zuläßt.

Der Naßboden im Hangenden der Braunerde fehlt in diesem Aufschluß. Über dem schichtigen $f_{1}(B)$-Horizont folgt gleich der jüngste Löß, der im unteren Teil sehr sandig ausgebildet und zu einer Parabraunerde verwittert ist. Die rezente Bodenbildung reicht 
bis in den $f_{1}(B)$-Horizont hinein. Die leuchtende Färbung dieses Horizonts ist jedoch ein deutlicher Hinweis dafür, daß die Verwitterung im wesentlichen fossil ist.

Noch geringmächtiger und noch mehr zusammengedrängt sind die fossilen Böden in dem

Profil Brauweiler (23) (s. Abb. 13)

Ziegeleigrube der Provinzialanstalt Brauweiler, Nordwand, M.-Bl. Frechen (5006), $58 \mathrm{~m}$ über NN, schwache Hanglage, aufgenommen am 8. 3. 1960.

Ap $\quad 0-25 \mathrm{~cm}$ humoser feinsandiger Lehm, Bröckelgefüge, kräftigdunkelbraun (10 YR

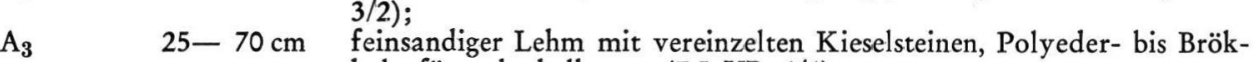
kelgefüge, dunkelbraun (7,5 YR 4/4);

$\mathrm{B}_{1} \quad 70-80 \mathrm{~cm}$ feinsandiger Lehm mit wenigen undeutlichen Tonhäutchen auf den Gefügeflächen, dunkelbraun, UUbergangszone, Grenze zum Liegenden nur schwach gewellt;

$\mathrm{B}_{2} \quad 80-125 \mathrm{~cm}$ schwach lehmiger kiesiger Sand in stark wechselnder Mächtigkeit, an der Südwand nur noch als Steinsohle erhalten, braun (7,5 YR 4/4), stark kryoturbat gestört, greift in Taschen in den Untergrund hinein, drei bis $10 \mathrm{~cm}$ mächtige Tonanreicherungsbänder vorhanden, gelblichrot (5 YR 4/6);

$\mathrm{B}_{3}+\mathrm{f}_{1}(\mathrm{~B}) \quad 125-160 \mathrm{~cm}$ schichtiger feinsandiger Lehm mit sandigen Einlagerungen, an der Südwand schichtungslos und ohne Einlagerungen, kräftigbraun (7,5 YR 5-6/6), Bröckelgefüge, auf Klüften starke Tonanreicherung (gelblichrot, 5 YR 4/6), stark kryoturbat gestört;

(B) $+f_{1}$ (B) $160-360 \mathrm{~cm}$ schichtiger feinsandiger Lehm mit dünnen Sandlinsen, nach unten werden die Sandbänder häufiger und schwach kiesig, an der Südwand schichtungslos und ohne Sandeinlagerungen, wenige Mangankonkretionen vorhanden, die nach unten häufiger werden, lockeres Bröckelgefüge, gelblichbraun (10 YR 5/4), an der Basis stellenweise Lößkindelhorizont;

$\mathrm{f}_{2} \mathrm{~g} \quad 360-380 \mathrm{~cm}$ kalkhaltiger feinsandiger Lehm, gelblichbraun (10 YR 5/6), rostbraun gefleckt, an der Basis ist ein bis $50 \mathrm{~cm}$ mächtiger, schräggeschichteter, schwach kiesiger Grobsand enthalten (fluviatiler Sand), der stellenweise mit dem Liegenden verwürgt ist ( $\mathrm{D}_{1}$-Horizont);

$\mathrm{f}_{3} \mathrm{~A}_{3} \quad 380-425 \mathrm{~cm} \quad$ feinsandiger Lehm, im oberen Teil kalkhaltig, viele Mangankonkretionen vorhanden, Polyeder- bis Bröckelgefüge, gelblichbraun (10 YR 5/6);

$\mathrm{f}_{3} \mathrm{~B}_{1} \quad 425-480 \mathrm{~cm}$ feinsandiger Lehm, kräftigbraun (7,5 YR 5/6), Bröckel- bis kantengerundetes Kleinpolyedergefüge, die unteren $20 \mathrm{~cm}$ sind fahlgrau gefleckt, und die Grundfarbe ist nur noch rötlichgelb (7,5 YR 6/6), deutliche Tonhäutchen auf den Gefügeflächen, an der Basis Steinsohle; $\mathrm{f}_{3} \mathrm{~B}_{2} \quad 480-535 \mathrm{~cm}$ feinsandiger Lehm, bräunlichgelb (10 YR 6/6), stark mit Sand und kiesigem Sand verwürgt, kräftigbraun (7,5 YR 5/6), mit kiesigem Sand gefüllte Frosttaschen und -spalten greifen in den Horizont hinein, Manganflecken vorhanden, das Material ist nur z. T. etwas fahlgrau gefleckt;

$\mathrm{fDB} \quad 535-750 \mathrm{~cm}$ Sand und wenig kiesiger Sand, sehr fahlbraun (10 YR 7/4), mit vielen, nach unten weniger werdenden Tonanreicherungsbändern, kräftigbraun $(7,5$ YR 5,6$)$;

$\mathrm{D}_{2} \quad 750-850 \mathrm{~cm}+$ Sand und kiesiger Sand, sehr fahlbraun (10 YR 7/4).

Die innerhalb der Ziegeleigrube in einer Sandgrube aufgeschlossenen Sande und Kiese der KT sind unverwittert und zeigen keine eigene Bodenbildung. Tonanreicherungsbänder kommen bis $3 \mathrm{~m}$ unter der Terrassenoberkante vor. Wahrscheinlich sind sie entstanden durch Tondurchschlämmung aus der Parabraunerde $f_{2}$. Möglicherweise entstammt die Tonsubstanz z. T. einer fast ganz erodierten Parabraunerde, deren Reste in dem stark frostgestörten $\mathrm{f}_{3} \mathrm{~B}_{2}$-Horizont vorliegen. Das mit dem Horizont stark verwürgte kiesige Material ist dann als eine Fließerde zu deuten, die entstanden ist nach der Erosion des fossilen Bodens, zu dem das Material des $\mathrm{f}_{3} \mathrm{~B}_{2}$-Horizonts einmal gehörte und vor der Bildung des Lösses, auf dem die Parabraunerde $\mathrm{f}_{3}$ gebildet wurde.

Im Profil folgen über der Parabraunerde unverwitterte, schräg geschichtete Kiese und Sande. In dieser horizontalen und regelmäßigen Ausbildung über eine Strecke von 
ca. $400 \mathrm{~m}$ ist die Deutung als eine Bildung eines kleinen Nebenflüßchens, für den es an der heutigen Oberfläche keine Hinweise gibt, auszuschließen. So sind denn wie auf der uMT von Bonn bis Köln kurzzeitige, seitliche Einschwemmungen von der Ville her als Ursache für die Ausbildung der Schotterlage anzunehmen.

Uber der Schotterlage folgt der Naßboden $\mathrm{f}_{2}$ aus Löß, an dessen Oberkante stellenweise ein mächtiger Lößkindelhorizont auftritt. Diese starke Kalkanreicherung ist sicherlich während der Bildung des fossilen Bodens auf dem streifigen Löß $\left(B_{3} f_{1}(B)-\right.$ und $(B) f_{1}$ (B)-Horizont) entstanden. Ein weiterer Hinweis auf die Bildung des Bodens $f_{1}$ ist die Fließerde an der Basis des sehr geringmächtigen jüngsten Lösses. Bodenfließen findet meist während eines feucht-kalten Klimas $\mathrm{n}$ a $\mathrm{ch}$ einer Zeit der Bodenbildung und $\mathrm{vor}$ der Lößbildung statt. Aus einem Vergleich mit den Profilen Frimmersdorf und Giesenkirchen ergibt sich, daß eine fossile, später überprägte Braunerde auf dem schichtigen Material vorhanden ist. Die mächtigen Lößkindel und die bis 3,5 m Tiefe reichende Entkalkung des Profils sind weitere Hinweise auf diese fossile Bodenbildung. Mit der Bildung der Fließerde ( $\mathrm{B}_{2}$-Horizont wird schon die nächste Kaltzeit eingeleitet, in der der jüngste Löß zum Absatz kam. Aus diesem Löß wurde während des Spät- und Postglazials eine Parabraunerde gebildet, die auch den fossilen Boden $\mathrm{f}_{\mathbf{1}}$ überprägt hat.

Nur aus der Kenntnis der mächtigen Lößprofile von Frimmersdorf und Giesenkirchen heraus ist das Profil Holzheim zu deuten.

Profil Holzheim (26) (s. Abb. 14)

Ziegeleigrube westlich von Holzheim bei Neuß, $51 \mathrm{~m}$ über NN., eben bis schwach nach $\mathrm{N}$ geneigt, aufgenommen am 15. 3. 1960.

Ap $\quad 0-25 \mathrm{~cm}$ humoser feinsandiger Lehm, dunkelgelblichbraun (10 YR 4/4);

$\mathrm{A}_{3} \quad 25-50 \mathrm{~cm}$ feinsandiger Lehm, kräftigbraun (7,5 YR 5/6), Kleinpolyedergefüge,

$\mathrm{B}_{1} \quad 50-90 \mathrm{~cm}$ feinsandiger Lehm, braun (7,5 YR 4/4), Polyedergefüge, schwache Ton-

häutchen vorhanden;

$\mathrm{B}_{2} \quad 90-115 \mathrm{~cm}$ feinsandiger Lehm, kräftigbraun (7,5 YR 5/6) und lehmiger Feinsand, sehr fahlbraun (10 YR 7/4) in Wechsellagerung, Steinsohle an der Basis, Polyedergefüge, viele Mangankonkretionen vorhanden;

(B) $\quad 115-170 \mathrm{~cm}$

feinsandiger Lehm, bräunlichgelb (10 YR 6/4-6) in stark wechselnder Mächtigkeit, stellenweise nur noch $10 \mathrm{~cm}$, Bröckelgefüge, schwach und unregelmäßig horizontal gestreift, wenige Mangankonkretionen vorhanden;

fA $170-240 \mathrm{~cm}$ humoser feinsandiger Lehm, dunkelbraun (10 YR 4/3), Bröckelgefüge, allmählicher Übergang nach unten;

$\mathrm{fA}_{3} \mathrm{~g} \quad 240-250 \mathrm{~cm}$

$\mathrm{fgB} \quad 250-290 \mathrm{~cm}$

feinsandiger Lehm, lichtgelblichbraun (10 YR 6/4), mit wenigen rostbraunen Flecken und Mangankonkretionen;

feinsandiger Lehm, braun (7,5 YR 4/4), Bröckel- bis Polyedergefüge; auf den Gefügeelementen deutliche Tonhäutchen vorhanden, schwach rostbraun gefleckt, nach unten allmählicher Übergang;

fBg 290-340 cm feinsandiger Lehm, rötlichgelb (7,5 YR 6/6), plattiges Gefüge, Tonhäutchen vorhanden, nach unten zunehmende rostbraune und fahlgraue Fleckung, Steinsohle an der Basis;

fDBG ${ }_{0} \quad 340-350 \mathrm{~cm} \quad$ Sand, an der Oberfläche sehr kiesig, stark rostbraun und fahlgrau gefleckt;

D $\quad 370-410 \mathrm{~cm}+$ Sand mit schwacher Bänderung im oberen Teil.

Die Terrassenschotter sind vom Grundwasser beeinflußt; eine eigene Bodenbildung ist nicht $\mathrm{zu}$ beobachten. Der fossile Boden $\mathrm{f}$ stellt bodentypologisch eine Pseudogley-Parabraunerde mit scharfer Horizontgliederung dar. Starke Durchfeuchtung unter humiden, gemäßigten Klimaverhältnissen hat wahrscheinlich den gebleichten Verarmungshorizont $\mathrm{fA}_{3} \mathrm{~g}$ über dem verdichteten Anreicherungshorizont $\mathrm{fgB}$ entstehen lassen (E. MüCKENhausen 1954). Dieser fossile Boden entspricht auf Grund der Profilentwicklung dem fossilen Boden $\mathrm{f}_{7}$ des Profils Frimmersdorf-West.

Der mächtige schichtige Lößlehm, der im Profil Frimmersdorf-West über dem genannten fossilen Boden liegt, ist im Profil Holzheim auf den ca. $55 \mathrm{~cm}$ mächtigen (B)- 


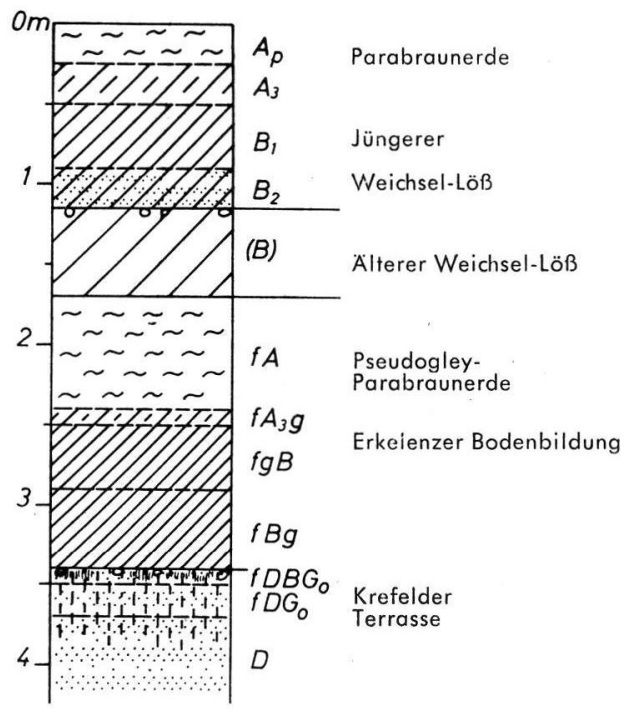

Abb. 14. Profil Holzheim.

Horizont zusammengeschrumpt. Gegen den jüngsten Löß mit seinen Sandbändern im unteren Teil wird er durch eine Steinsohle scharf abgegrenzt. Bei der geringen Mächtigkeit der einzelnen Lösse läßt sich für den unter der Steinsohle lagernden Löß kein eigener Bodentyp mehr angeben. In dem (B)-Horizont ist vielleicht der Rest eines fossilen Bodens enthalten; durch die Parabraunerdebildung auf dem jüngsten Löß ist die fossile Bodenbildung jedoch ganz überprägt worden. Der Ablagerung des jüngsten Lösses, der auch in diesem Profil im unteren Teil sehr sandig ausgebildet ist, geht eine kräftige Erosion voraus. So können die (B)-, fA $\mathrm{f}_{3}$ - und fgB-Horizonte ausfallen. Das Profil der Ziegeleigrube Thelen (25) an der B 1 zwischen Holzheim und Neuß ist ähnlich aufgebaut.

$\mathrm{Z}$ u s a m m e $\mathrm{n}$ a s s u n g. Für eine Gliederung der Deckschichten der KT ist ein Vergleich mit den Deckschichten der HT sehr fruchtbar. Insbesondere die später zu behandelnden Lößprofile von Wegberg (6) und Erkelenz (4) (s. HT) zeigen eine recht vollständige Profilentwicklung.

Der braunlehmartige gelblichrote Interglazialboden $\left(f_{4}\right)$ des Profils Wegberg (s. HT) oder der uMT (s. uMT) tritt im Bereich der KT nicht auf. Mit Ausnahme dieses Bodens sind alle Bodenbildungen der Deckschichten der HT auch in denen der KT nachzuweisen.

Der Erkelenzer Bodenbildung (Profil Erkelenz: $f_{3}$ ) entsprechen mit gleichen charakteristischen Merkmalen im Bereich der KT die folgenden Bodenbildungen: Parabraunerde (Brauweiler: $f_{3}$ ), Gley-Parabraunerde (Frimmersdorf-West: $f_{7}$ ), Pseudogley-Parabraunerde (Holzheim: f) und Parabraunerde - Pseudogley (Giesenkirchen: $\mathrm{f}_{2}$ ).

Die Rheindahlener Bodenbildung (Erkelenz $\mathrm{f}_{4}$ ) läßt sich im Hangenden der Krefelder Mittelterrasse nicht nachweisen. Im Profil Giesenkirchen tritt unter dem Erkelenzer Boden $\left(f_{2}\right)$ eine Fließerde auf, die einen älteren, stark verlehmten Lößlehm $\left(f_{3}\right)$ überlagert. Dieser Lößlehm und der Lößlehm des $\mathrm{f}_{3} \mathrm{~B}_{2}$-Horizonts in Brauweiler könten zur Rheindahlener Bodenbildung gehören. Im Profil Wegberg trennt eine Fließerde in gleicher Position zwei verschiedenaltrige Lösse voneinander. Wahrscheinlich setzen sich diese Horizonte jedoch aus umgelagertem Lößlehm zusammen.

Aus dem schichtigen Löß über der Parabraunerde hat sich eine z. T. erodierte Braunerde gebildet (Brauweiler und Giesenkirchen $\mathrm{f}_{1}$, Frimmersdorf-West $\mathrm{f}_{2}$ ). Infolge der großen Mächtigkeit sind im Profil Frimmersdorf-West unter der Braunerde $f_{2}$ noch zwei Naßböden und zwei kalkhaltige Braunerden erhalten. Aus der Wechsellagerung ergibt 
sich, daß die allgemein verbreitete Schichtung das Ergebnis von wiederholter Lößbildung und Bodenfließen ist. Dadurch erreicht dieser Löß nur an besonders günstigen Lagen eine größere Mächtigkeit.

Meist ist über der KT nur noch der jüngste Löß erhalten. Der Lößlehm, auf dem die fossile Parabraunerde (Brauweiler $f_{3}$ und Giesenkirchen $f_{2}$ ) gebildet wurde und der schichtige Löß mit der fossilen Braunerde (Brauweiler $\dot{f}_{1}$ und Frimmersdorf-West $f_{2}$ ) haben sich nur in den Randgebieten zu höheren Terrassen erhalten oder sind sogar nur hier abgelagert worden. Auf der Krefelder und Kempener Platte konnten sich Reste dieser Böden in schwach muldigen Lagen vor der Erosion bewahren und wurden dann mit den Terrassenkiesen verwürgt. So hat die Braunerdebildung, die auf dem schichtigen Löß zu beobachten ist (Frimmersdorfer Bodenbildung), im Bereich der Krefelder Platte (s. Profil Kaarst) auf dem Terrassenmaterial selbst stattgefunden (Kaarster Bodenbildung).

Der im unteren Teil sehr sandige jüngste Löß lagert meist mit einer Steinsohle über dem schwach verwitterten schichtigen Löß oder den Kiesen und Sanden der KT. Nur im Profil Frimmersdorf fehlen die Steinsohle und die Sandeinlagerungen, so daß hier die Winderosion, die der Ablagerung der Sandlagen vorausging, nicht stattfand und der Naßboden $f_{1}$ im jüngsten Löß noch erhalten ist.

Es ergibt sich damit folgende Gliederung der fossilen Böden auf der KT und ihren Deckschichten:

1. Absatz der Kiese und Sande der KT; eine eigene Bodenbildung ist unter den vollständigen Lößprofilen auf dem Terrassenmaterial nicht nachzuweisen.

5. Lößbildung (Brauweiler und Giesenkirchen), umgelagertes Bodenmaterial ?

6. Bodenbildung: Gley? (Giesenkirchen), Parabraunerde? (Brauweiler).

7. Erosion und Bodenfließen (Brauweiler und Giesenkirchen).

8. Lößbildung (in allen beschriebenen Gruben).

9. Bodenbildung: Parabraunerde (Brauweiler: $f_{3}$ ), Gley-Parabraunerde (FrimmersdorfWest: $f_{7}$ ), Pseudogley-Parabraunerde (Holzheim: $f$ ) und Parabraunerde-Pseudogley (Giesenkirchen: $\mathrm{f}_{2}$ ), Erkelenzer Bodenbildung.

10. Erosion (in allen Gruben).

11. Ablagerung eines schichtigen Lösses durch wiederholte Bildung von kalkhaltigen Braunerden und Naßböden, Bodenfließen und Lößsedimentation (FrimmersdorfWest (!), Brauweiler und Giesenkirchen), Kryoturbation (Brauweiler).

12. Frimmersdorfer Bodenbildung: Braunerde.

13. Erosion (in allen Gruben).

14. Lößbildung und Bildung eines Naßbodens (Frimmersdorf-West: $f_{1}$ ).

15. Winderosion und erneuter Lößabsatz mit einleitender Flugsandbildung (in allen Profilen außer Frimmersdorf-West), Lößbildung ohne Erosion (Frimmersdorf-West).

16. Bildung einer Parabraunerde (in allen untersuchten Gruben).

$\mathrm{Nachwe}$ is der Krefelder Terrasse auf der rechten Rheinseite $\mathrm{z}$ wischen $\mathrm{Hilden}$ und Leverkusen

Bei der geologischen Kartierung des Meßtischblatts Hilden (4807) ergab sich südlich von Hilden folgende Terrassengliederung:

Hauptterrasse
Obere Mittelterrasse
Untere Mittelterrasse
Niederterrasse
Hochflutbett des Rheins

ca. $105 \mathrm{~m}$ über NN. $76 \mathrm{~m}$ über $\mathrm{NN}$. $61 \mathrm{~m}$ über NN. $43 \mathrm{~m}$ über NN. $37 \mathrm{~m}$ über $\mathrm{NN}$.

Die KT schien hier wie auf dem südlich anschließenden Blatt Leverkusen (4907) nicht ausgebildet zu sein.

Ein Profil der Rheinterrassenfolge zwischen Hilden und Langenfeld (s. Abb. 15) zeigt, 
daß sich in dem als NT (43 m über NN.) kartierten Gebiet noch eine weitere Terrassenstufe abgrenzen läßt, die $51 \mathrm{~m}$ über NN liegt und im Gegensatz zur eigentlichen NT eine Flugsandbedeckung aufweist. Die Geländekante zur nächst höheren Terrasse, der uMT, ist sehr ausgeprägt. Bis zum Südteil des Blatts Hilden steigt die als NT mit Flugsandbedeckung kartierte Terrasseneinheit bis auf $54 \mathrm{~m}$ über NN. an.

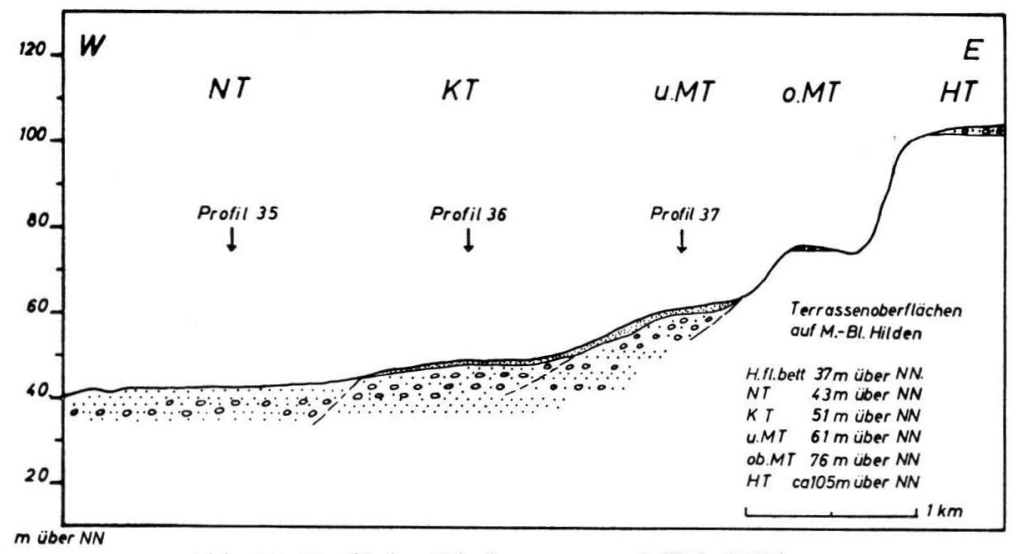

Abb. 15. Profil der Rheinterrassen südlich Hilden.

Im Nordteil von Blatt Leverkusen (4907) ist die gleiche Terrassenstufe, die hier mit einer deutlichen Geländekante von der NT abgesetzt ist, als jüngste MT kartiert worden, während die südliche Fortsetzung der uMT des Blatts Hilden nur noch stellenweise angedeutet ist.

Die auf Blatt Hilden als NT, auf Blatt Leverkusen als jüngste MT kartierte Terrassenstufe liegt zwischen der uMT und der NT. Bei einem Vergleich mit den Terrassen im linksrheinischen Gebiet ist die fragliche Terrassenstufe auf Grund ihrer Höhenlage als KT zu bezeichnen: Die KT liegt südlich von Neuß bei Neukirchen meist $50-53 \mathrm{~m}$ üb. NN.

Bei der geologischen und bodenkundlichen Profilaufnahme der Kiesgruben im linksrheinischen Gebiet zeigten sich klare Unterschiede in der Profilausbildung zwischen der NT, der KT und der uMT. Durch eine bodenkundliche Aufnahme der Aufschlüsse läßt sich prüfen, ob die Parallelisierung der fraglichen Terrassenstufe mit der KT zu Recht besteht.

Die Kiesgrube Langenfeld auf Blatt Leverkusen ist in ihrem Profilaufbau typisch für die Verhältnisse in der NT.

\section{Profil Langenfeld (35)}

Kiesgrube westlich der Straße Langenfeld-Hitdorf, an der Bahnlinie, M.-Bl. Leverkusen (4907), $44 \mathrm{~m}$ über NN., eben, aufgenommen im Juni 1959.

\section{Ap $\quad 0-20 \mathrm{~cm}$ humoser feinsandiger Lehm;}

$\mathrm{A}_{3} \quad 20-65 \mathrm{~cm}$ lehmiger Sand, kräftigbraun (7,5 YR 5/6);

B 65- $110 \mathrm{~cm}$ schwach lehmiger Sand, kräftigbraun $(7,5$ YR 5/6), bis $10 \mathrm{~cm}$ mächtige

DB $\quad 110-260 \mathrm{~cm} \quad \begin{aligned} & \text { Tonanreicherungsbänder enthalten, rötlichbraun (5 YR 4/4); } \\ & \text { Sand und kiesiger Sand, sehr fahlbraun (10 YR 7/3), mit regelmäßigen, }\end{aligned}$

rötlichbraunen (5 YR 4/4) Tonanreicherungsbändern;

D 260-1000 cm + kiesiger Sand und sandiger Kies, sehr fahlbraun (10 YR 7/3).

Die Schotter und Sande der NT sind unverwittert und zeigen die charakteristische bräunlichrote Bänderung der postglazialen Parabraunerde auf dem Hochflutlehm. Die Profilentwicklung entspricht also der der linksrheinischen NT.

Bei der Verlegung der Nord-West-Olleitung im Herbst 1958 war die uMT südlich von Hilden in einem bis 2,5 $\mathrm{m}$ tiefen Graben gut aufgeschlossen. Die geologischen und bodenkundlichen Verhältnisse in diesem Gebiet sind dem Profil Egelsberg bei Krefeld 
(s. uMT) sehr ähnlich, und rechtfertigen damit die stratigraphische Stellung dieser schmalen Terrassenleiste als uMT:

\section{Profil Hilden (37) (s. Abb. 16)}

Aufschluß an der Trasse der Nord-West-Ölleitung, südöstlich von Hilden bei Verlach, M.-Bl. Hilden (4807), 61,4 $\mathrm{m}$ über NN, eben, aufgenommen im November 1958.

Ap $\quad 0-20 \mathrm{~cm}$ humoser Sand:

(B) $\mathrm{A}_{31}$ 20- $50 \mathrm{~cm}$ sehr schwach lehmiger Sand, mit wenigen Kieselsteinen durchsetzt, rötlichgelb (7,5 YR 6/6);

$\mathrm{CA}_{32} \quad 50-75 \mathrm{~cm}$ Sand mit wenigen Kieselsteinen, an der Basis wenige Mangankonkre$\mathrm{CB} \quad 75-125 \mathrm{~cm} \quad \begin{aligned} & \text { tionen, sehr fahlbraun (10 YR 7/4); } \\ & \text { lehmiger Sand mit wenigen Kieselsteinen, kräftigbraun (7,5 YR 5/6), }\end{aligned}$ mit wenigen gebleichten Flecken, (dieser Horizont ist vielleicht z.ugleich der Rest eines fossilen Bodens), Basisgrenze stark gewellt;

$\mathrm{fB}_{1} \quad 125-185 \mathrm{~cm} \quad$ lehmiger kiesiger Sand, gelblichrot (5 YR 4/8), plastisch und dichr, mit gebleichten, senkrechten Bahnen, die leuchtend rostbraune Ränder besitzen, schichtungslos, allmählicher Übergang zum nächsten Horizont;

$\mathrm{fB}_{2} \quad 185-270 \mathrm{~cm}+\quad$ schwach lehmiger kiesiger Sand mit wenigen Sandbändern, gelblichrot (5 YR 4/8), das Material wird nach unten weniger plastisch, nur stellenweise erscheint in $250 \mathrm{~cm}$ Tiefe schon der normalgraue, unverwitterte Terrassenkies.
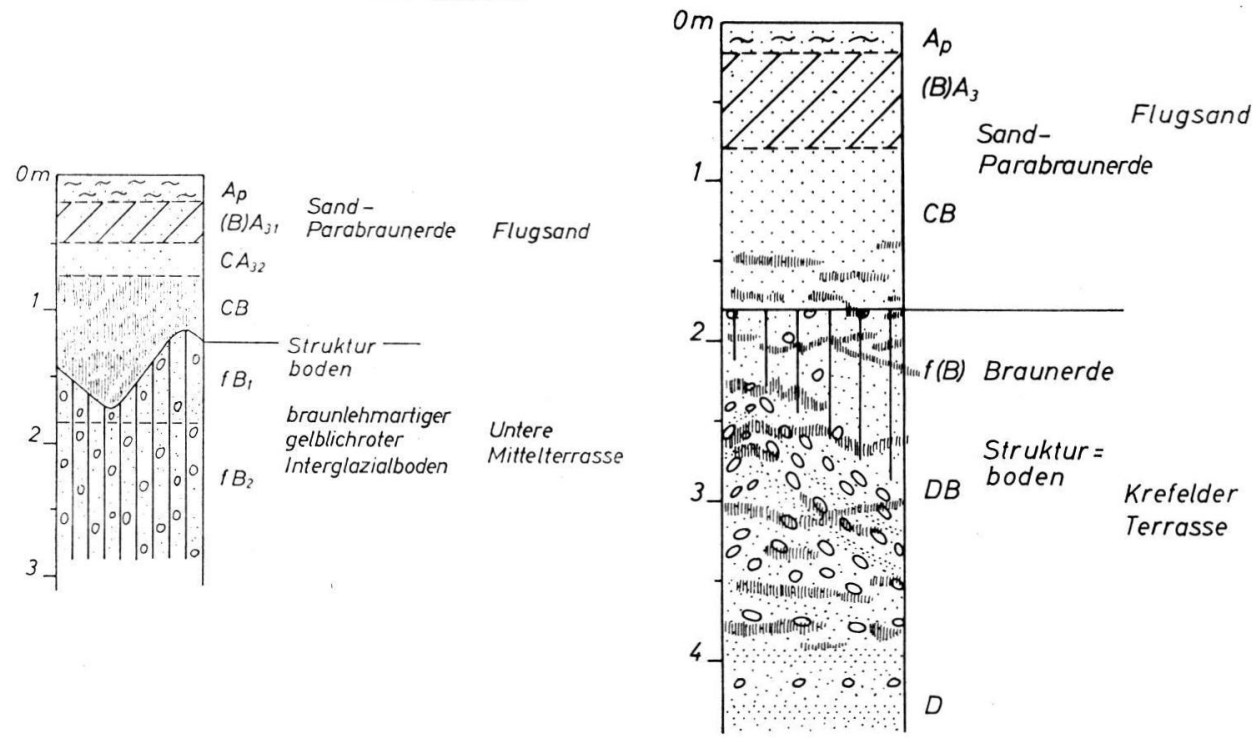

Abb. 16 (links). Profil Hilden. - Abb. 17 (rechts). Profil Richrath.

Die Schotter und Sande der uMT südöstlich Hilden sind durch eine intensive Bodenbildung zu einem braunlehmartigen gelblichroten Interglazialboden verwittert. Dieser interglaziale Boden scheint später nur noch wenig erodiert worden zu sein. Das Bodenmaterial ist noch sehr dicht und führt zu einer schwachen Pseudovergleyung in den unteren Partien des bis 1,5 m mächtigen Flugsands, der im Profil zu einer Sand-Parabraunerde verwittert ist. Bei einer nur $50 \mathrm{~cm}$ mächtigen Flugsandauflage sind Pseudogleye sehr verbreitet (W. PAAS 1959). Die Grenzlinie zwischen dem Flugsand und dem stark verwitterten Terrassenmaterial ist durch Kryoturbation stark wellig ausgebildet. Möglicherweise ist in dem in die Terrassenschotter eingearbeiteten verlehmten Flugsandmaterial noch der Rest eines weiteren fossilen Bodens enthalten. Eine scharfe Grenze zwischen CB- und $\mathrm{CA}_{32}$-Horizont fehlt jedoch.

Die fragliche Terrasse, die auf Grund ihrer Höhenlage zur KT gestellt wurde, ist in zahlreichen Kiesgruben zwischen Hilden und Langenfeld gut aufgeschlossen. 
Profil Richrath (36) (s. Abb. 17)

Kiesgrube östlich der Straße Hilden-R.ichrath, M.-Bl. Hilden (4807), $51 \mathrm{~m}$ über NN, eben, aufgenommen im Juli 1959.

$\begin{array}{lr}\mathrm{Ap} & 0-20 \mathrm{~cm} \\ \text { (B) } \mathrm{A}_{3} & 20-80 \mathrm{~cm} \\ \mathrm{CB} & 80-180 \mathrm{~cm}\end{array}$

humoser Sind;

$\begin{array}{ll}\text { (B) } \mathrm{A}_{3} & 20-80 \mathrm{~cm} \\ \mathrm{CB} & 80-180 \mathrm{~cm}\end{array}$

sehr schwach lehmiger Sand, gelblichbraun (10 YR 5/4);

$\mathrm{f}(\mathrm{B}) \quad 180-220 \mathrm{~cm}$

Sand, sehr fahlbraun (10 YR 7/4), im unteren Teil mit Tonanreicherungsbändern, die ungestört und regelmäßig verlaufen, an der Basis Steinsohle;

DB $\quad 220-280 \mathrm{~cm}$

in Frosttaschen unterschiedlich mächtiger Sand mit einzelnen Kieselsteinen, gelblichbraun (10 YR 5/4), wenige Tonanreicherungsbänder vorhanden (5 YR 4/4), deutlich verlehmt;

DB

kiesiger Sand, unverwittert, stark kryoturbat gestört, mit unruhig

$\mathrm{D}$

$280-500 \mathrm{~cm}+$ verlaufenden Tonanreicherungsbändern;

unverwitterter Sand und kiesiger Sand.

Auf den Schottern und Sanden ist eine fossile Braunerde gebildet, die in den sandigeren Frosttaschen bis $1,20 \mathrm{~m}$ mächtig wird. Im Durchschnitt ist der Boden jedoch ca. $40 \mathrm{~cm}$ mächtig und entspricht damit den fossilen Braunerden auf der KT im linksrheinischen Gebiet (vgl. Profil Kaarst). Der Flugsand ist zu einer Sand-Parabraunerde verwittert. Tonanreicherungsbänder, die bei der Bildung dieses Bodens entstanden sind, reichen bis $4 \mathrm{~m}$ Tiefe.

Trotz fehlender Lößbedeckung gleichen sich die bodenkundlichen Verhältnisse auf der

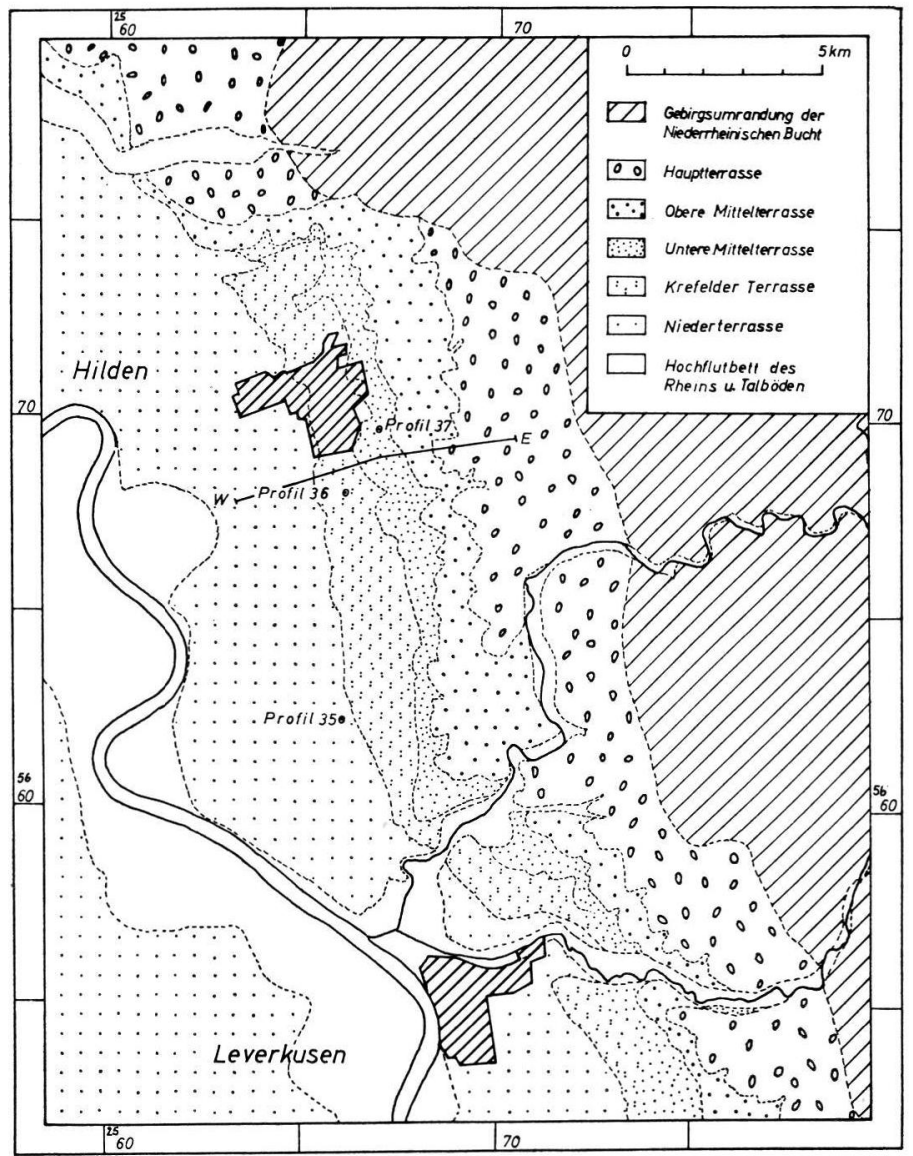

Abb. 18. Terrassengliederung auf der rechten Rheinseite zwischen Düsseldorf und Köln.

13 Eiszeit und Gegenwart 
KT zwischen Hilden und Leverkusen und im Bereich der Krefelder Platte durchaus. Die Verbreitung dieser Terrasse im rechtsrheinischen Gebiet ist in Abb. 18 dargestellt.

Während nördlich der Wupper noch eine genaue Trennung von KT und uMT möglich ist, ist eine Unterscheidung zwischen Wupper und Dhünn nordwestlich von Leverkusen wegen des geringer werdenden vertikalen Abstands zwischen den beiden Stufen kaum noch möglich. Östlich von Leverkusen lassen sich die beiden Stufen nicht mehr trennen, sie konvergieren also im rechtsrheinischen Gebiet auf der gleichen Höhe wie im linksrheinischen Gebiet (vgl. Abb. 1).

\section{Die Untere Mittelterrasse (uMT) und die glazialen Schotter und Sande der Rißvereisung}

Verbreitung und Morphologie: Die uMT besitzt im Niederrheinischen Tiefland beiderseits des Rheins eine große Verbreitung. Zwischen Bonn und Köln ist sie deutlich von der NT und der Oberen Mittelterrasse (oMT) abgesetzt und tritt in weiten, zusammenhängenden Flächen auf. Westlich und nordöstlich von Köln spaltet sie sich in die uMT und die KT. Die uMT besitzt eine sehr wellige und unruhige Oberfläche, und die Kiese und Sande verbergen sich im linksrheinischen Gebiet unter einer z. T. sehr mächtigen Lößdecke. Während die Terrasse linksrheinisch nur bis auf die Höhe von Neuß zu beobachten ist, ist sie rechtsrheinisch mit einigen Unterbrechungen bis Dinslaken zu verfolgen (H. W. Quirzow 1956).

Gleichalt mit der uMT sind die Absätze der Rißvereisung i.e.S. (Drenthe). Im Ruhrgebiet konnten W. Löscher (1922) und H. G. Steinmann (1925) nachweisen, daß das Terrassenmaterial durch das Inlandeis noch gestört ist, daß es jedoch selber bereits nordisches Material enthält. Nach J. D. DE Jong (1956) setzen sich die Stauchmoränen im Niederrheingebiet fast ausschließlich aus aufgestauchten Kiesen und Sanden der uMT zusammen. Vor den Stauchmoränen haben sich Sander gebildet. Diese sind in den zahlreichen Inselbergen aufgeschlossen.

Die fossile n Böden: Die uMT und die glazialen Schotter und Sande der Rißvereisung sind in vielen Kiesgruben besonders im Randgebiet zu jüngeren Terrassen gut aufgeschlossen. Die bodenkundlichen Verhältnisse sind sehr einheitlich. Die fossilen Böden sind alle \pm erodiert, so daß meist nur noch die unteren Bodenhorizonte erhalten sind. Unterschiede treten nur in wenigen, durch Grundwasser beeinflußten Profilen auf. Ein wahrscheinlich nur wenig erodierter Boden ist am Egelsberg bei Krefeld aufgeschlossen.

Profil Egelsberg (11) (s. Abb. 19)

Müllgrube in der alten Kiesgrube am Egelsberg bei Krefeld-Traar, M.-Bl. Krefeld (4605), $42 \mathrm{~m}$ über NN, aufgenommen im Mai 1959.

Ap $\quad 0-30 \mathrm{~cm}$ humoser, schwach lehmiger Sand;

(B) $\mathrm{A}_{3} \quad 30-55 \mathrm{~cm} \quad$ schwach lehmiger Sand, gelblichbraun (10 YR 5/6);

$\mathrm{CB} \quad 55-65 \mathrm{~cm}$ Sand (Flugsand), lichtgelblichbraun (10 YR 6/4), mit unregelmäßigen rötlichbraunen (5 YR 4/4) Tonanreicherungsbändern, in Frostspalten bis $150 \mathrm{~cm}$ Tiefe reichend, oberhalb der Terrassenschotter z. T. rostbraun gefleckt;

$\mathrm{fB}_{1} \quad 65-95 \mathrm{~cm}$ lehmiger kiesiger Sand, gelblichrot (5 YR 5/8), in feuchtem Zustand plastisch und klebend, trocken in kleine Polyeder zerfallend, schichtungslos;

$\mathrm{fB}_{2} \quad 95-210 \mathrm{~cm}$ schwach lehmiger kiesiger Sand, gelblichrot (5 YR 5/8), schichtungslos;

$\mathrm{fB}_{3} \quad 210-500 \mathrm{~cm}+$ Sand und kiesiger Sand, gelblichrot (5 YR 4/6), kräftig braun $(7,5 \mathrm{YR}$ $5 / 8$ ) und bräunlichgelb (10 YR 6/6) gebändert, die Farbintensität nimmt nach unten allmählich ab, Schichtung nur noch im oberen Teil schwach gestört.

Die Kiese sind durch eine intensive Bodenbildung stark verlehmt und kräftig gelblichrot gefärbt. $\mathrm{Da}$ das Bodenprofil nicht vollständig erhalten ist, ist eine sichere bodentypologische Ansprache nicht mehr möglich. E. MückenHausen (1954) bezeichnet diesen 

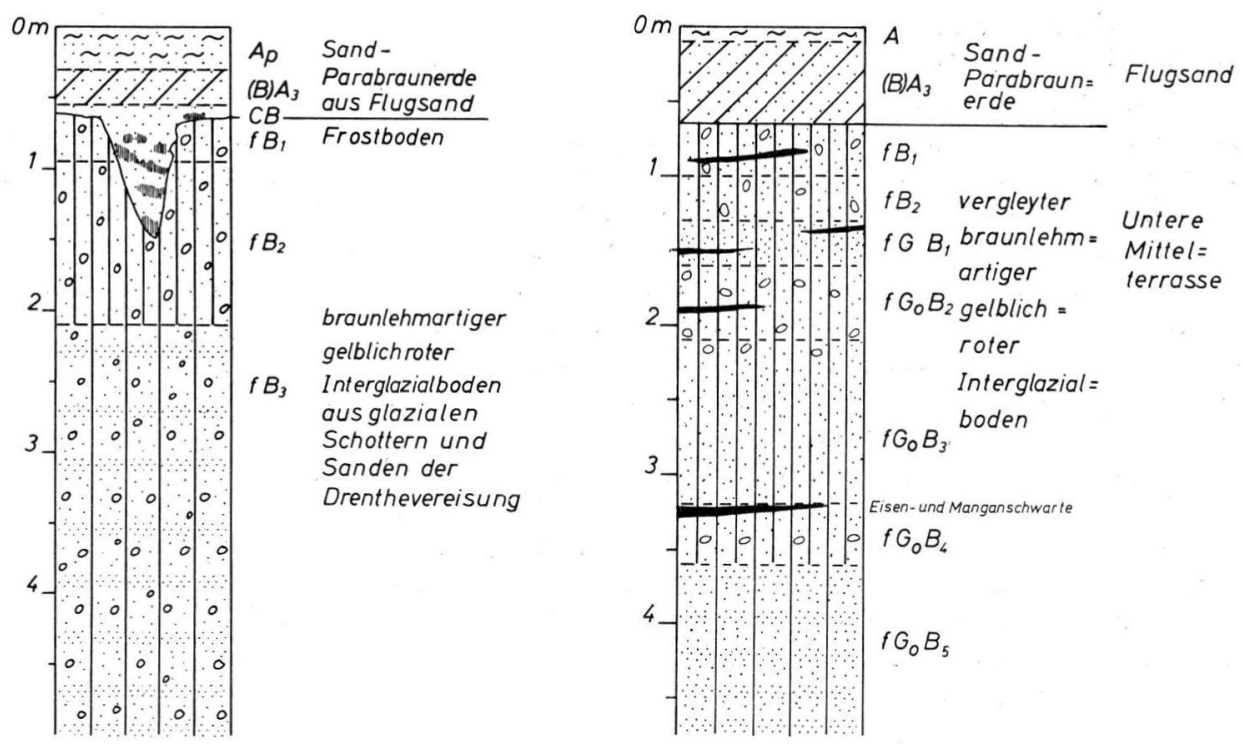

Abb. 19 (links). Profil Egelsberg. - Abb. 20 (rechts). Profil Brück.

Boden mit Vorbehalt als einen sandigen Braunlehm im Sinne W. L. KubiËNA's (1953), der wahrscheinlich dem Red Yellow-Podsolic soil der südöstlichen USA entspricht. Die typologischen Merkmale des Braunlehms, wie Plastizität des Bodenmaterials, große Dichte (Pseudovergleyung des überlagernden Flugsands!) und die intensive Färbung der B-Horizonte sind im Profil nachweisbar (s. HT).

Der Red-Yellow Podsolic soil der USA besitzt über dem dichten B-Horizont einen bis $30 \mathrm{~cm}$ mächtigen Verarmungshorizont ( $A_{2}$-Horizont) und einen bis $5 \mathrm{~cm}$ mächtigen humosen Horizont ( $\mathrm{A}_{1}$-Horizont). Beide Horizonte fehlen im Profil Egelsberg. Stellenweise ist Flugsand mit den liegenden Schottern verwürgt, so daß hier der Eindruck von der Anwesenheit eines $A_{2}$-Horizonts entsteht. Die röntgenographische Untersuchung der Tonsubstanz hat ergeben, daß die Bodenbildung auf den Kiesen und Sanden der Drenthe-Vereisung nicht identisch ist mit dem Red-Yellow Podsolic soil. Dieser Boden der USA besitzt in der Tonfraktion ein Si/Al-Verhältnis von annähernd $2: 1$; die Tonminerale gehören in der Hauptsache der Kaolinit-Halloysit-Gruppe an. Die fossilen Böden des Arbeitsgebiets besitzen jedoch neben Kaolinit einen beträchtlichen Gehalt an Illit und Muskowit (vgl. die Röntgenanalyse). Die mikromorphologischen Untersuchungen zeigen wiederum enge Beziehungen zu den Braunlehmen an. Daher wird bei der bodentypologischen Ansprache dieser Böden der neutrale Begriff „braunlehmartiger gelblichroter Interglazialboden" verwendet. Der über der Terrasse lagernde Flugsand ist zu einer SandParabraunerde verwittert. Rötlichbraune Tonanreicherungsbänder treten nur in Frostspalten deutlicher in Erscheinung. Weniger typisch sind die interglazialen Böden im nördlichen Niederrheingebiet ausgebildet; Verlehmung und Färbung sind nicht so kräftig (z. B. in der Kiesgrube zwischen Keppeln, Udem und Goch (13) im Reichswald im Kreise Kleve). Die Böden sind hier vielleicht stärker erodiert worden; möglicherweise deutet sich hier schon eine regionale Klimaänderung an.

Gut ausgeprägt ist dagegen die intensive Verlehmung und Färbung in der Kiesgrube unterhalb der Ziegeleigrube Weglau bei Koblenz-Metternich (Profilbeschreibung bei $\mathrm{H}$. RemY \& W. PAAS 1959).

Die Bodenbildung auf der uMT sieht der Bodenbildung auf der HT und der oMT 
sehr ähnlich; Plastizität, Verlehmung und Färbung des Bodens auf der jüngeren Terrasse sind jedoch geringer (vgl. Korngrößenanalyse und Dünnschliffuntersuchungen).

Die beschriebenen Profile stellen die normale, auf der uMT vorherrschende Bodenbildung dar. Abweichungen von dieser normalen Ausbildung stellen sich ein, sobald die Böden unter stärkerem Grundwassereinfluß gebildet wurden, oder wenn sie nachträglich in den Schwankungsbereich des Grundwassers gelangten.

Grundwassereinfluß müssen wir bei der Herausbildung vieler Bodenprofile auf der rechten Rheinseite zwischen Troisdorf und Köln annehmen. Merkmale dieser vom Grundwasser geprägten Interglazialböden sind: stellenweise Bleichung des Bodenmaterials durch Reduktion und Fortführung der Ton- und Eisensubstanz, Absatz von Eisen- und Manganverbindungen in verhärteten, schwarzen und rostbraunen Krusten und Schwarten und Bildung von Grundwasserhorizonten (Go-Horizonte), die sich durch ihre stumpfgelbe Farbtönung von den echten Verwitterungshorizonten unterscheiden.

Die Krustenbildung ist jedoch kein ausschließliches Merkmal für Grundwasserbildung. Nach E. MücKenhausen $(1950,1954)$ können sie ausgefällte Verwitterungslösungen darstellen. Immer sind sie aber an Stellen größerer Feuchtigkeit (z. B. Hanglage) gebunden. In ebener Lage konnten sie bei fehlenden Grundwasserhorizonten trotz starker Verdichtung selbst auf dem Material der HT nicht beobachtet werden.

Ein anschauliches Bild der sekundär vergleyten braunlehmartigen gelblichroten Interglazialböden vermittelt das

Profil Brü ck (16) s. Abb. 20)

Kiesgrube bei Brück/Köln-Mülheim, M.-Bl. Mülheim/Köln (5008), $61 \mathrm{~m}$ über NN, Hang zur NT, aufgenommen im Juni 1959.

A $\quad 0-10 \mathrm{~cm}$ humoser, schwach lehmiger Sand mit wenigen Kieselsteinen durchsetzt

(B) $\mathrm{A}_{3} \quad 10-65 \mathrm{~cm}$

$\mathrm{fB}_{1} \quad 65-100 \mathrm{~cm}$

$\mathrm{fB}_{2} \quad 100-130 \mathrm{~cm}$

$\mathrm{fGoB}_{1} \quad 130-160 \mathrm{~cm}$

$\mathrm{fGoB}_{2} \quad 160-210 \mathrm{~cm}$

$\mathrm{fGoB}_{3} \quad 210-320 \mathrm{~cm}$

$\mathrm{fGoB}_{4} \quad 320-360 \mathrm{~cm}$
(Flugsand);

schwach lehmiger Sand mit allmählichem Übergang zur Terrasse;

schwach lehmiger kiesiger Sand, gelblichrot (5 YR 4/8), mit wenigen schwarzen Krusten; Kryoturbation vorhanden;

kiesiger Sand, gelblichrot (5 YR 5/8);

schluffiger Sand, bräunlichgelb (10 YR 6/8) mit schwarzen Krusten; kiesiger Sand, gelblichrot (5 YR 5/8), mit schwarzen Krusten, gestörte Lagerung;

schwach lehmiger Sand, gelblichrot (5 YR 5/8), z. T. auch dunkler und heller gebändert und stumpfgelb getönt;

kiesiger Sand, dunkelrötlichbraun (2,5 YR 3/4) und wenig gelblichrot gefärbt (5 YR 5/8), oben mit einem ca. $10 \mathrm{~cm}$ mächtigen schwarzen Band;

$\mathrm{fG}_{\mathrm{OB}} \quad 360-460 \mathrm{~cm}+$ lehmiger Feinsand, gelblichbraun (10 YR 5/6).

Die Verkniipfung von Krustenbildung und Grundwasser wird besonders in der Kiesgrube Lind bei Wahn offensichtlich, wo der Abbau bis zum Grundwasserspiegel geht. Unmittelbar oberhalb des Grundwasserspiegels befinden sich schwarze Eisen- und Mangankrusten; linsenförmig in diese Schwarten ist stumpfgelblichrotes Bodenmaterial eingeschlossen.

$\mathrm{Zus}$ ammenfassung. Die typische Bodenbildung der uMT ist ein braunlehmartiger gelblichroter Interglazialboden, der morphologisch dem sandigen Braunlehm im Sinne W. L. KüIËNA's oder dem Red-Yellow Podsolic soil der südöstlichen USA nahe steht. Durch Grundwasser wird dieser Boden bisweilen überprägt. Eisen- und Manganschwarten und Grundwasserhorizonte sind Ausdruck dieser sekundären Vergleyung. Die ähnliche Bodenbildung auf der HT und der oMT ist im Vergleich zu der auf der uMT, der Frechener Bodenbildung (s. unten), noch wesentlich kräftiger.

Die fossilen Böden in den Deckschichten

Das Profil Frechen liegt auf der uMT; nur noch schwach ist die KT abgesetzt.

Profil Frechen (17) (Abb. 21)

Ziegeleigrube nordöstlich von Frechen, M.-Bl. Frechen (5006), $68 \mathrm{~m}$ über NN, sehr schwach nach O geneigt, aufgenommen am 17. 7. 1960. Profilaufbau der Deckschichten in der Ziegeleigrube: 


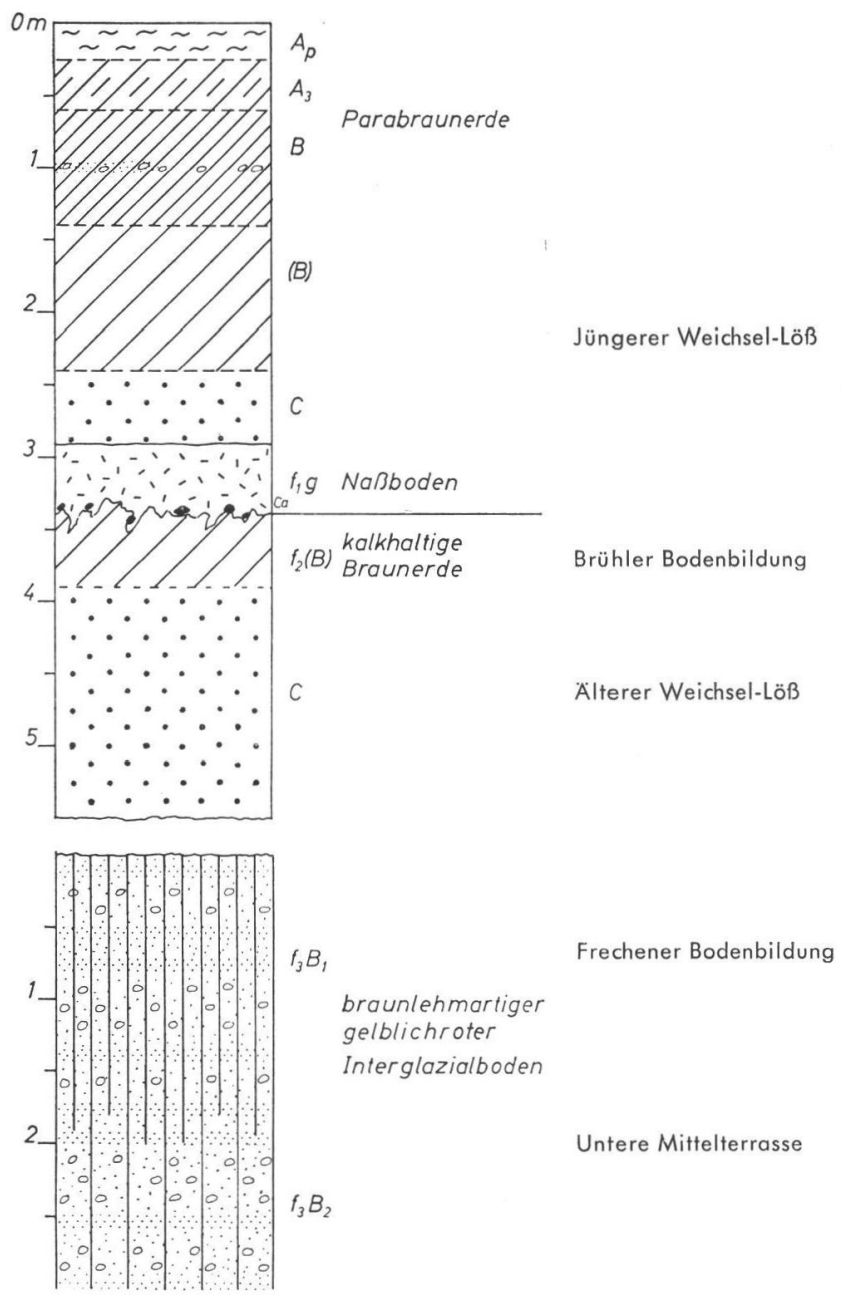

Abb. 21. Profil Frechen.

Ap $\quad 0-25 \mathrm{~cm}$

$\mathrm{A}_{3} \quad 25-60 \mathrm{~cm}$

B $\quad 60-140 \mathrm{~cm}$

(B) $\quad 140-240 \mathrm{~cm}$

C $\quad 240-290 \mathrm{~cm}$

$\mathrm{f}_{1} \mathrm{~g} \quad 290-340 \mathrm{~cm}$

$\mathrm{f}_{2}$ (B) $\quad 340-390 \mathrm{~cm}$

C $\quad 390-550 \mathrm{~cm}+$

Prof illa f b a u der

$\mathrm{f}_{3} \mathrm{~B}_{1} \quad 0-200 \mathrm{~cm}$

$\mathrm{f}_{3} \mathrm{~B}_{2} \quad 200-300 \mathrm{~cm}+$ humoser feinsandiger Lehm;

feinsandiger Lehm, Bröckelgefüge, braun;

feinsandiger Lehm, Polyedergefüge, Tonhäutchen auf den Gefügeelementen, kräftigbraun, bei $100 \mathrm{~cm}$ sandige und schwach kiesige Einlagerungen vorhanden, die nach $N$. sehr mächtig werden;

feinsandiger Lehm, braun, Bröckelgefüge;

Löß, lichtgelblichbraun (10 YR 6/4);

kalkhaltiger feinsandiger Lehm, lichtgelblichbraun (10 YR 6/4), schwach rostbraun und fahlgrau gefleckt, an der Basis Lößkindel vorhanden, mit dem Liegenden stark verwürgt;

kalkhaltiger feinsandiger Lehm, gelblichbraun (10 YR 5-6/4), die oberen $10 \mathrm{~cm}$ sind bräunlichgelb (10 YR 6/8) gefärbt, Bröckelgefüge; Löß, lichtgelblichbraun (10 YR 6/4), schwach gestreift.

Terrasse in der Kiesgrube:

lehmiger kiesiger Sand, geblichrot (5 YR 5/6), mit vielen lehmigeren Einlagerungen (5 YR 4/6), nach unten allmählicher Übergang;

schwach lehmiger kiesiger Sand, rötlichgelb (7,5 YR 6/6), weniger stark gebändert. 
Auf dem Schotterkörper ist noch deutlich der untere Teil des B-Horizonts eines braunlehmartigen gelblichroten Interglazialbodens zu erkennen. In der Kiesgrube werden die Schotter überlagert von dem jüngsten Löß, auf dem im unteren Teil ein Naßboden $\left(f_{1} g-\right.$ Horizont) und oben die rezente Parabraunerde ausgebildet sind. Vollständiger ist das Lößprofil in der Ziegeleigrube, wo es nach unten durch eine stark verwürgte, kalkhaltige Braunerde ( $\mathrm{f}_{2}(\mathrm{~B})$-Horizont) aus einem streifigen Löß ergänzt wird.

Die Ziegelei zwischen Kendenich und Kalscheuren (18) liegt schon südlich der Vereinigung der KT und uMT. Auch hier sind die Schotter kräftig verwittert; zum Unterschied vom Profil Frechen ist jedoch der Boden durch Grundwasser sekundär stark verändert, so daß bodentypologisch ein vergleyter braunlehmartiger gelblichroter Interglazialboden mit den typischen Merkmalen wie Dichte, Plastizität und Färbung vorliegt.

Profil Kalscheuren (18) (s. Abb. 22)

Alte Kies- und Lehmgrube der Ziegelei zwischen Kendenich und Kalscheuren, M.-Bl. Brühl (5107), $60 \mathrm{~m}$ über NN, sehr schwach nach O geneigt, aufgenommen am 19. 7. 1960: Ap

$0-25 \mathrm{~cm}$ humoser feinsandiger Lehm (Lößlehm);

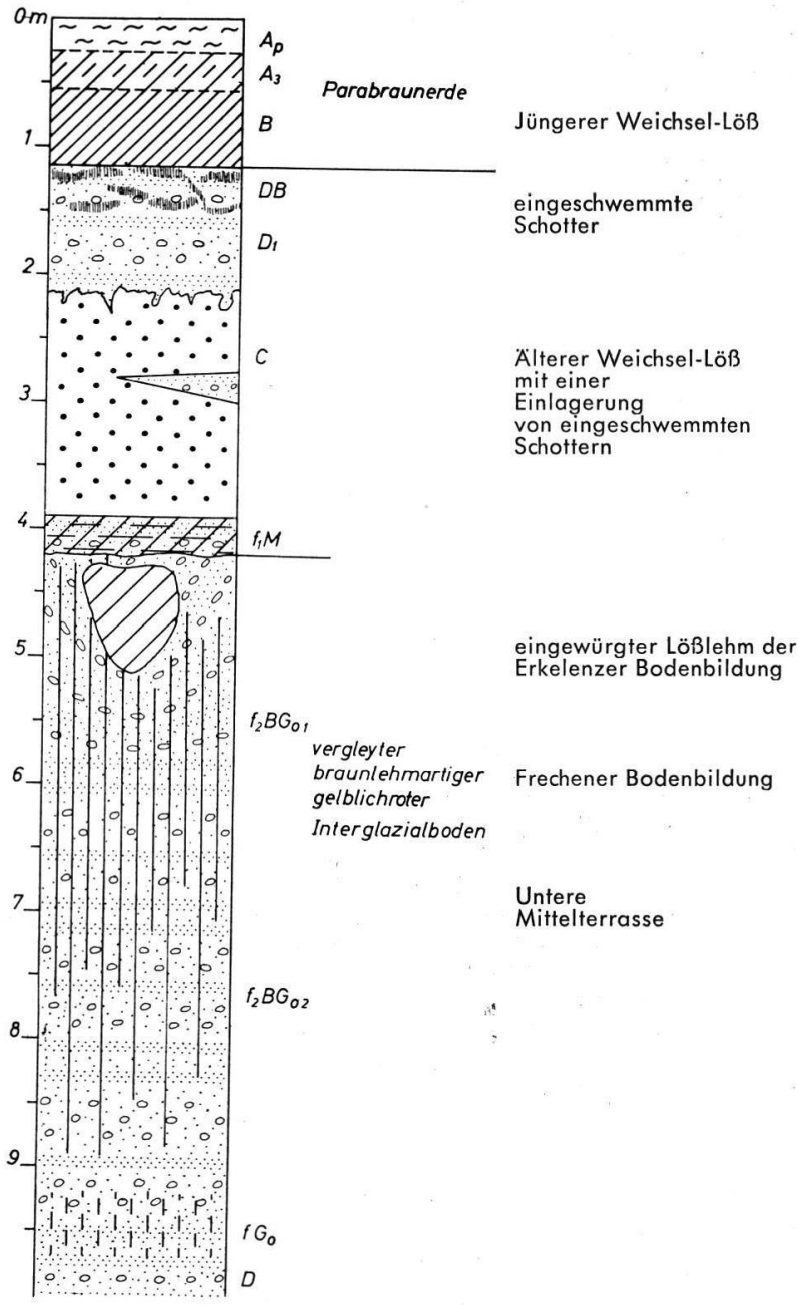

Abb. 22. Profil Kalscheuren. 


$\begin{array}{lr}\mathrm{A}_{3} & 25-55 \mathrm{~cm} \\ \mathrm{~B} & 55-115 \mathrm{~cm} \\ \mathrm{D}_{1} & 115-215 \mathrm{~cm} \\ \mathrm{C} & 215-390 \mathrm{~cm} \\ & \\ \mathrm{f}_{1} \mathrm{M} & 390-420 \mathrm{~cm} \\ \mathrm{f}_{2} \mathrm{BGO}_{1} & 420-750 \mathrm{~cm}\end{array}$

feinsandiger Lehm, gelblichbraun (10 YR 5/4) Bröckelgefüge;

feinsandiger Lehm, nach unten sandig werdend, Grenze zum Liegenden nicht scharf, braun;

schräg geschichteter kiesiger Sand, sehr fahlbraun (10 YR 7/4), im oberen Teil mit Tonanreicherungsbändern (DB-Horizont), Grenze nach unten stellenweise kryoturbat gestört;

Löß, nur stellenweise entkalkt, sehr fahlbraun (20 YR 6/3), im unteren Teil etwas dunkler gefärbt (10 YR 5/4), Schottereinlagerungen vorhanden;

lehmiger kiesiger Sand, geschichtet, gelblichbraun (10 YR 5/6), Grenze nach unten scharf;

lehmiger kiesiger'Sand, kräftig braun (7,5 YR 5/8), mit lehmigeren dunkelrötlichbraunen Bändern und dünnen schwarzen Eisen- und Manganschwarten; besonders im oberen Teil sind die Kiese wieder stellenweise normalgrau gefärbt. In die Terrassenschotter eingewürgt ist ein wenig bindiger, rostbraun und stark fahlgrau gefleckter fein-

$\mathrm{f}_{2} \mathrm{BGO}_{2} \quad 750-870 \mathrm{~cm} \quad \begin{aligned} & \text { sandiger Lehm; } \\ & \text { kiesiger Sand, kräftig braun (7,5 YR 5/6) mit dünnen rötlichbraunen }\end{aligned}$ (5 YR 5/8) Bändern;

$\mathrm{D}_{2} \quad 870-950 \mathrm{~cm}+$ kiesiger Sand, normalgrau, mit einem fossilen Grundwasserhorizont im unteren Teil (fGo-Horizont).

In die Schotter ist in Frosttaschen ein wenig bindiger, pseudovergleyter Lößlehm eingewürgt. Möglicherweise ist dieser Lößlehm bei der gleichen Bodenbildung verwittert worden wie das stark kiesige, braune, umgelagerte Bodenmaterial ( $f_{1}$ M-Horizont) unmittelbar im Hangenden der Terrassenschotter. Dieser Boden auf Löß ist zu Beginn der nächsten kalten Phase bis auf einen Rest erodiert und dann in Frosttaschen in die Terrassenschotter eingestïlpt worden. Fließendes Wasser scheint an der Erosion und an der Umlagerung des Bodenmaterials mitgewirkt zu haben.

Unverwitterte Kiese und Sande treten in und auf dem folgenden, etwas streifigen Löß auf, der nur stellenweise entkalkt und schwach verlehmt ist. Ober den Schottern lagert schließlich ein geringmächtiger und sehr sandiger jüngster Löß, der zu einer Parabraunerde verwittert ist. In diesem Profil zeigt sich also, daß nach dem Absatz und der Verwitterung mindestens eines Lösses kurzfristige Einschwemmungen, kenntlich an den Schotterlagen, während der Ablagerung eines streifigen Lösses stattgefunden haben.

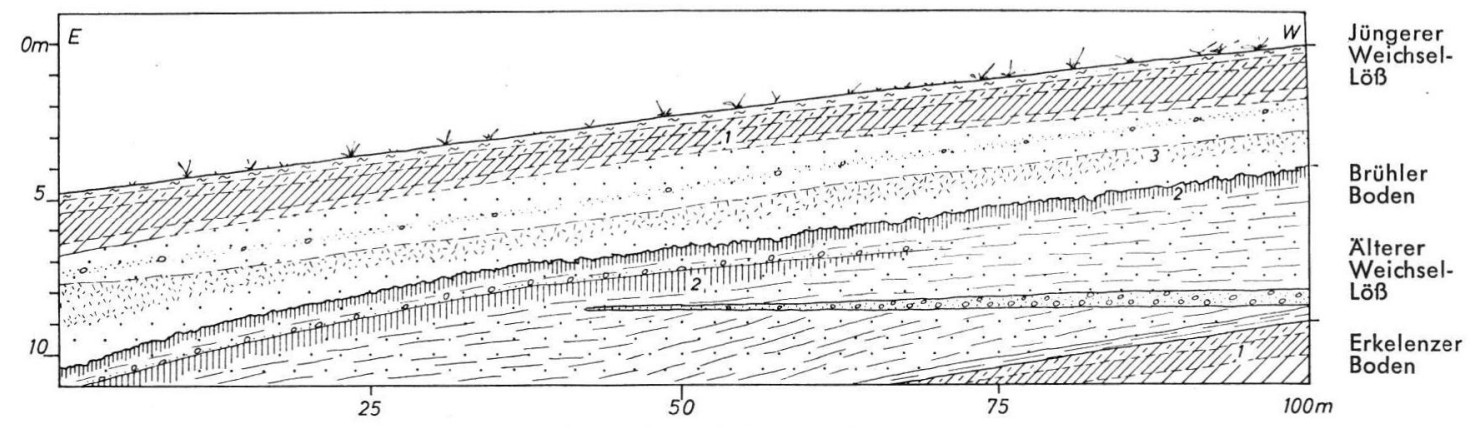

Abb. 23. Profil an der Südwand der nördlichen Ziegeleigrube Brühl.

1 Parabraunerde, 2 kalkhaltige Braunerde, 3 Naßboden.

Schräggeschichtete Kiese und Sande im Hangenden einer fossilen Parabraunerde aus Löß finden sich ebenfalls in den Ziegeleigruben bei Brühl (15) (s. auch H. REMY 1960b). Die Aufschlüsse liegen mit 80 und $90 \mathrm{~m}$ über NN. schon im Hang zur oMT (s. Abb. 23). Die fossile Parabraunerde wird auf Grund ihrer bodenkundlichen Merkmale mit der Parabraunerde $\mathrm{f}_{3}$ des Profils Erkelenz (vgl. HT) parallelisiert. Darüber folgen, in einem etwas streifigen Löß eingelagert, fluviatile Kiese und Sande. Durch eine Steinsohle und eine kalkhaltige Braunerde wird dieser Löß in 2 Teile gegliedert. Die Grenze zum jïng- 
sten Löß wird durch eine mit dem hangenden Löß stark verwürgte, kalkhaltige Braunerde gebildet. Der jüngste Löß besitzt, wie im Profil Frechen (17), im unteren Teil einen mächtigen Naßboden und im mittleren Teil eine Flugsandeinlagerung. Durch die spätund postglaziale Bodenbildung ist er $\mathrm{zu}$ einer fast $2 \mathrm{~m}$ mächtigen Parabraunerde verwittert.

$\mathrm{Z}$ us a mmenf assung. Für das Studium der Deckschichten bietet die uMT keine günstigen Voraussetzungen. In den meisten Aufschlüssen sind die Terrassenschotter nur von dem jüngsten Löß bedeckt. Erst im Hang zu der oMT stellen sich vollständigere Profile ein. Die fossile Parabraunerde im Profil Brühl wird mit dem Boden $\mathrm{f}_{3}$ des Profils Erkelenz parallelisiert. Gleichalt mit diesem Boden sind möglicherweise die stark erodierte Parabraunerde auf den fluviatilen Feinsanden im Profil Alfter $\left(f_{1} B-H o r i z o n t\right)(s . ~ K T)$ und ebenfalls die Bodenbildung auf dem stark pseudovergleyten, in die Terrasse eingewürgten Lößlehm im Profil Kalscheuren (Erkelenzer Bodenbildung).

Mit der Klimaverschlechterung zu Beginn der nächsten Kältephase wurde der gebildete Boden bis auf geringe Reste erodiert. Das Bodenmaterial der Profile Alfter ( $\mathrm{M}_{1}$-Horizont) und Kalscheuren $\left(f_{1} M\right)$ ist wahrscheinlich das Produkt dieses Umlagerungsprozesses.

Dann erfolgte der Absatz eines streifigen Lösses (Brühl, Kalscheuren, Frechen), der oberflächlich zu einer kalkhaltigen Braunerde verwittert ist (Brühler Boden). Eine weitere kalkhaltige Braunerde gliedert im Profil Brühl den schwach streifigen Löß noch einmal in zwei Teile. In diesem Löß sind zwischen Bonn und Köln in verschiedener Position schräg geschichtete, unverwitterte Kiese und Sande eingelagert: In Brühl finden sie sich unmittelbar über der Parabraunerde und im unteren Teil des streifigen Lösses, im Profil Kalscheuren treten sie zwischen dem streifigen und dem jüngsten Löß auf; unterhalb des jüngsten Lösses werden sie ebenfalls im Profil Alfter beobachtet. Zwischen der Bildung der fossilen Parabraunerde und der Bildung des jüngsten Lösses sind mit einem streifigen Löß über der uMT von Bonn bis Köln schräg geschichtete Kiese und Sande abgesetzt worden.

Die Deutung dieser Schotterlagen als Hochflutbildungen des Rheins ist wenig glaubhaft. Wahrscheinlicher ist die Annahme, daß die Kiese und Sande seitliche Einschwemmungen von der benachbarten Ville her darstellen. Zur Klärung dieser Frage wurden Schwermineralanalysen aus den Schotterlagen in Brühl und Kalscheuren durchgeführt, die freundlicherweise Dr. H. GEwEHR ausführte. Alle vier untersuchten Streupräparate zeigten eine Schwermineralführung, wie sie für die HT typisch ist. Pyroxene konnten nur ganz vereinzelt nachgewiesen werden; Turmalin, Granat, Epidot und Zirkon stellen den Hauptanteil.

Eine Überflutung der älteren Lößgebiete durch den Rhein im Bereich der uMT nördlich von Bonn nahm E. Zimmermann (1918) an. In weiter Verbreitung fand er hier eine bis $2 \mathrm{~m}$ mächtige Schottereinlagerung zwischen zwei verschiedenaltrigen Lößstufen, die er beide mit dem „jüngeren“ Löß des nördlichen Niederrheingebiets parallelisierte.

H. Breddin (1925) faßt dagegen die von E. Zimmermann beobachtete ältere Lößstufe als eine Lehmeinlagerung in der uMT auf. Wie der „jüngere“ Löß nur außerhalb der NT verbreitet ist, so soll der „ältere" Löß die uMT meiden.

Der jüngste Löß ist durch einen Naßboden (Frechen, Brühl) und durch Flugsandeinlagerungen im mittleren Teil gegliedert. Während des Spätglazials und des Holozäns verwitterte er zu einer Parabraunerde.

\section{Die Obere Mittelterrasse (oMT)}

Verbreitung und Morphologie: Die oMT tritt rechtsrheinisch als eine schmale Terrassenleiste unterhalb der HT von Bonn bis Duisburg am Gebirgsrand entlang auf. Linksrheinisch erreicht sie nach H. W. Quirzow (1956) südöstlich von Grevenbroich und nach W. MonreaL (1959) bei Straelen auf dem Viersener Halbhorst eine größere flächenhafte Verbreitung. 
Der Leuzitphonolithtuff in den Mittelterrassenkiesen bei Gohr n. Neuß. Die Schotteroberkante im Aufschluß Gohr nördlich von Neuß liegt mit $61 \mathrm{~m}$ über NN im Niveau der uMT unmittelbar am Abfall zur NT (s. Abb. 1). Nach Westen steigt das Gelände allmählich zu einer kleinen Insel aus oMT an. R. VINkEN (1959) stellte das Schottermaterial auf Grund der starken Augitführung (z. T. 60-70\% vulkanische Mineralien) zur uMT. Ein ähnlich hoher Gehalt an vulkanischen Mineralien herrscht nach R. VINKEN in dem Terrassenmaterial des Aufschlusses Anstel, der daher gleichfalls zur uMT gestellt wurde, obwohl er wenige Kilometer weiter nördlich im Hang von der oMT zur NT liegt. Der sehr hohe Gehalt an Brauner Hornblende (bis 29\%) und der niedrige Quarzgehalt sollen durch Umlagerung der weiter südlich anstehenden oM'T entstanden sein.

Bei der bodenkundlichen Profilaufnahme fand sich in der Kiesgrube Broich bei Gohr, $4,5 \mathrm{~m}$ unter der Terrassenoberkante, in der Schichtung ein bis $5 \mathrm{~cm}$ mächtiger Tuffhorizont, der durch Terrassenmaterial sehr verunreinigt ist. Eine qualitative Schwermineraluntersuchung durch Prof. J. Frechen ergab folgenden Schwerminrealbestand:

Aegirinaugit bis Aegirin, z. T. idiomorph, starke Hahnenkammbildung

bräunlicher Augit mit Manganeinschluß (selten)

Sanidin

Hornblende, braun (frisch)

Biotit, z. T. idiomorph (frisch und reichlich)

Magnetit

Apatit, fast idiomorphe Säulchen mit Poren, z. T. schwach abgerollt

Titanit, idiomorph und kantenscharf (reichlich).

Daneben treten noch folgende Rheinminerale auf:

Epidot, Zirkon, Granat, Grïne Hornblende, brauner Turmalin (Schörl).

Der Tuff ist auf Grund seiner Mineralzusammensetzung als le u z it p h o nolith is cher Tuff zu bezeichnen.

Tuffeinlagerungen in Kiesen und Sanden der Mittelterrassen sind bisher im Mittelrheingebiet in der Literatur aus der Mittleren Mittelterrasse (Apollinaristerrasse) bei Remagen (E. KAISER 1903) und ein leuzitphonolithischer Tuff auf der oMT von Leubsdorf südlich Linz (O. WILcKens 1931) beschrieben worden. Aus der uMT ist bisher noch keine Bimseinlagerung bekannt gemacht worden.

Neuere Untersuchungen (J. Frechen 1959) haben diese spärlichen Angaben in der Literatur bestätigt. So besitzt eine helle Tuffeinlagerung in den Kiesen und Sanden der oM'T am kleinen Petersberg bei Niederbreisig nach freundlicher mündlicher Mitteilung von Prof. J. Frechen folgende Mineralzusammensetzung:

Aegirinaugit bis Aegirin 80-90\%

Sanidin (wenig)

Biotit

Hornblende, gelb bis dunkelbraun, bräunlich-schwarz

Magnetit (wenig)

Apatit (reichlich)

Titanit

Granat

Auch hier liegt ein leuzitphonolithischer Tuff vor. Schon der qualitative Vergleich mit der Mineralzusammensetzung der Tuffeinlagerung von Gohr zeigt eine weitgehende Übereinstimmung, so daß es berechtigt erscheint, das Material auf die gleiche Eruption zurückzuführen.

So gehört wahrscheinlich das Material der Kiesgrube Gohr zur oMT, obwohl die Grube im Niveau der uMT liegt. Eine Umlagerung des Tuffbandes aus der oMT in die uMT hinein ist auszuschließen, da das vulkanische Material auf eine $50 \mathrm{~cm}$ mächtige Zone beschränkt ist. Gleichzeitig gehört der Aufschluß Anstel noch zur oMT. Die uMT stellt daher in diesem engen Gebiet keine eigene Aufschüttungsterrasse dar, sondern ist eine Erosionsform in der oMT. 
Die fossilen Böden auf der Oberen Mittelterrasse

Die fossilen Böden auf der oMT sind ähnlich ausgebildet wie die auf der jHT. Die Aufschlüsse sind sehr selten und bei der geringen Ausdehnung der Terrasse am Gebirgsrand meist stark erodiert. Auf Grund ihrer morphologischen Übereinstimmung werden die Böden der oMT zusammen mit denen der jHT bearbeitet.

\section{Die Deckschichten der Oberen Mittelterrasse}

Da die oMT nur als schmale Leiste am Gebirgsrand entlang auftritt, sind die Deckschichten höchst lückenhaft entwickelt. H. REMY (1960) fand in dem Lößprofil über den Kiesen und Sanden der oMT am Rodderberg (10) zwei fossile Böden, die er mit Vorbehalt der Göttweiger und der Paudorfer Bodenbildung gleichstellt. Weitere, durch fossile Böden gegliederte Lößprofile im Hangenden der oMT sind bisher nicht bekannt geworden.

\section{Die Jüngere Hauptterrasse (jHT)}

Verbreitung und Morphologie: Die Hauptterrassen setzen sich aus drei verschiedenen Stufen zusammen, der Älteren Hauptterrasse (äHT'), der Jüngeren Hauptterrasse (jHT) und der Unterstufe der Hauptterrasse (s. Abb. 1.). Die bodenkundliche Untersuchung beschränkt sich auf die in zahlreichen Gruben sehr gut aufgeschlossene mittlere Stufe. Diese tritt als Plateauterrasse (H. W. Quirzow 1956) rechtsrheinisch entlang dem Rheinischen Schiefergebirge, auf der Ville und dem Viersener Halbhorst auf; im westlichen Sendungsgebiet nehmen die Schotter große Flächen im Venloer Graben, im Erftbecken und auf der Rurscholle ein. Die übrigen Stufen besitzen nur lokale Bedeutung und sind schlecht aufgeschlossen.

\section{Die fossilen Böden auf der Jüngeren Hauptter rasse}

Für die Untersuchung der fossilen Böden auf der HT eignen sich besonders die Aufschlüsse im östlichen Teil der Niederrheinischen Bucht, d.h. im pleistozänen Hebungsgebiet. Hier sind die Schotter bei fehlender Lößbedeckung durch kräftige interglaziale Bodenbildungen stark verwittert. Dagegen ist im westlich gelegenen Senkungsgebiet diese Bodenbildung weit weniger auf den Hauptterrassenschottern verbreitet. Wahrscheinlich verhinderte in diesem Gebiet vielfach eine später wieder erodierte Lößlehmdecke, die heute nur noch lokal vorhanden ist, die Bildung eines interglazialen Bodens auf den Schottern und Sanden selbst. Nur an Geländekanten, wie im Tal der Rur, der Wurm, der Erft und anderer kleiner Flüsse und im südlichen Teil des Erft-Beckens sind die Schotter immer kräftig verwittert. Der typische Boden der HT fehlt im Bereich des Venloer Grabens westlich von Mönchen-Gladbach ganz.

Ein mächtiger, charakteristischer und wahrscheinlich nur wenig erodierter fossiler Boden auf den Schottern und Sanden der jHT ist bei Pützlohn (1) in der Rur-Scholle aufgeschlossen: Die Jülicher Bodenbildung.

\section{Profil Pützlohn (1)}

Pützlohn, zwischen Weisweiler und Jülich, Tagebau Indegebiet, M.-Bl. Eschweiler (5103), schwach nach S geneigt, $137 \mathrm{~m}$ über NN, aufgenommen im November 1959.

$0-40 \mathrm{~cm}$ schwach kiesiger feinsandiger Lehm, verwürgter Rest des abgeräumten

\section{Bodens (Lößlehm);}

$\mathrm{A}_{3} \quad 40-55 \mathrm{~cm} \quad$ kiesiger Sand und sandiger Kies, an der Oberkante Steinsohle, nach

$\mathrm{fB}_{1} \quad 55-240 \mathrm{~cm}$
unten allmählicher Ưbergang zum nächsten Horizont, normalgrau;

$\mathrm{fB}_{1} \quad 55-240 \mathrm{~cm}$ lehmiger sandiger Kies, gelblichrot (5 YR 4/8), plastisch und dicht, in trockenem Zustand in kleine, scharfkantige Polyeder zerfallend, schichtungslos, nach unten heller und weniger plastisch werdend;

$\mathrm{fB}_{2} \quad 240-380 \mathrm{~cm}$ lehmiger steiniger Kies, gelblichrot (5 YR 4/8), dicht;

$\mathrm{fB}_{3} \quad 380-530 \mathrm{~cm}$ lehmiger steiniger Kies, rot bis gelblichrot $(2,5 \mathrm{YR} 4 / 6-5 \mathrm{YR} 4 / 8)$, mit wenigen gebleichten Stellen, nur stellenweise vorhanden;

$\mathrm{fB}_{4} \quad 530-1500 \mathrm{~cm}+$ schwach lehmiger steiniger Kies, kräftigbraun, (7,5 YR 5/6), mit wenigen gelblichroten (5 YR 4/8) Bändern im oberen Teil, die Schichtung ist bis ca. $700 \mathrm{~cm}$ Tiefe gestört. 
Mit den charakteristischen Merkmalen Plastizität, Intensität der Verlehmung, Färbung und Dichte gehört der beschriebene Boden einer Bodenklasse an, die W. L. KubiËNA (1953) „bolusartige Silikatböden (Plastosols)“ genannt hat. Eine genaue bodentypologische Ansprache ist wie bei der uMT wegen des Fehlens der oberen Bodenhorizonte nicht möglich. Auf Grund der Färbung ist der fossile Boden auf der HT als Braunlehm zu bezeichnen; und zwar ist auf dem sehr kiesigen Material ein „sandiger Braunlehm“ zu erwarten, der über einem dichten B-Horizont noch die Horizonte $A_{2}$ und $A_{1}$ (W. L. KubiëNA 1953) besitzt. Trotz starker Übereinstimmung mit dem Braunlehm KUBIËNA's wird (s. uMT) in dieser Arbeit die Bezeichnung braunlehmartiger Interglazialboden verwandt.

Der beschriebene Boden liegt unmittelbar oberhalb des Tals der Inde, so daß das Regenwasser z.T. oberflächlich ohne nennenswerte Erosion abfließen kann. In ebener Lage neigt der fossile Boden der Hauptterrasse sehr zur Pseudovergleyung. Der sehr verdichtete Boden verhindert ein schnelles Versickern des Regenwassers, so daß die oberen Bodenhorizonte wie auch die Deckschichten durch Staunässe ein ausgeprägt marmoriertes Profil erhalten. In der Formsandgrube Lobberich (2) im Kreis Kempen-Krefeld auf dem Viersener Halbhorst ist der fossile Boden der HT durch Staunässe im oberen Teil stark lichtgrau gefleckt. Mit dieser Fleckung ist eine Abnahme der Farbintensität zu beobachten. Während die unteren Bodenhorizonte noch den Farbwert 5 YR 4/8 haben, beträgt dieser oben nur noch 5 YR 5/8. Sicherlich hat in den heute pseudovergleyten Profilen eine einheitliche Ausbildung der Bodenhorizonte bestanden wie im Profil Pützlohn (1), so daß die Pseudovergleyung ein sekundäres Merkmal dieser Böden ist. Im Bereich der HT sind Böden verbreitet, die durch Eisen- und Manganschwarten stark verdichtet und verfestigt sind. Mit der Bildung dieser Schwarten ist eine teilweise Bleichung der Schotter und Sande verbunden. Die Ursachen für die Schwartenbildung sind sehr verschieden.

a) Hangnässe: Die Kiesgrube am Rodderberg bei Mehlem befindet sich in der oMT, die ähnlich wie die HT verwittert ist. Das Bodenprofil ist typisch für einen durch Hangnässe geprägten braunlehmartigen gelblichroten Interglazialboden.

Profil Rodderberg (10) (s. Abb. 24)

Kiesgrube am Rodderberg bei Mehlem, stark nach NE zum Rheintal geneigt, $110 \mathrm{~m}$ über NN, aufgenommen im Juni 1959.

Der Boden ist z. T. abgetragen;

$\mathrm{fB}_{1} \quad 0-40 \mathrm{~cm}$ schwach lehmiger, schwach kiesiger Sand, leuchtend gelblichrot (5 YR $4 / 8$ ), etwas plastisch;

$\mathrm{fB}_{2} \quad 40-240 \mathrm{~cm} \quad$ schwach lehmiger kiesiger Sand und schwach lehmiger Sand in Wechsellagerung, in der Hauptsache gelblichrot gefärbt (5 YR 5/8), viele, bis $3 \mathrm{~cm}$ mächtige, schwarze Eisen- und Manganschwarten vorhanden; in Verbindung mit den schwarzen Bändern ist der Boden auch leuchtend gelblichrot (5 YR 4/8) und dunkelrot (2,5 YR 3/6) gefärbt;

$\mathrm{fB}_{3} \quad 240-500 \mathrm{~cm} \quad$ kiesiger Sand, sehr stark gelblichrot (5 YR 5/6) gebändert, nach unten zunehmend fahlbraun (10 YR 7/4) gefärbt;

$\mathrm{fB}_{4} \quad 500-700 \mathrm{~cm}+$ kiesiger Sand, sehr fahlbraun (10 YR 7/4) mit gelblichroter Bänderung (5 YR 5/8).

Durch die Hangfeuchtigkeit wurden Eisen- und Manganverbindungen lokal gelöst, verlagert und in Schwarten wieder abgesetzt. Diese Schwarten besitzen einen durchschnittlichen Gehalt von $38,3 \% \mathrm{Fe}_{2} \mathrm{O}_{3}$ und $1,5 \% \mathrm{MnO}\left(=1,3 \% \mathrm{Mn}^{++}\right)$. Die Schwartenbildung durch Hangnässe ist im Gegensatz zu der durch Grundwasser auf die oberen Bodenhorizonte beschränkt.

b) Grundwasser: In vielen Kiesgruben, z. B. der Formsandgrube Ratingen (3), sind die Schotter in ebener Lage durch mächtige Eisen- und Manganabsätze stark verfestigt. Neben diesen verfestigten Schwarten (s. uMT) finden sich meist noch normal verwitterte Partien. Hier ist der fossile Boden durch steigendes Grundwasser sekundär verändert worden. Eisen- und Manganverbindungen wurden im Grundwasserschwankungsbereich gelöst und 


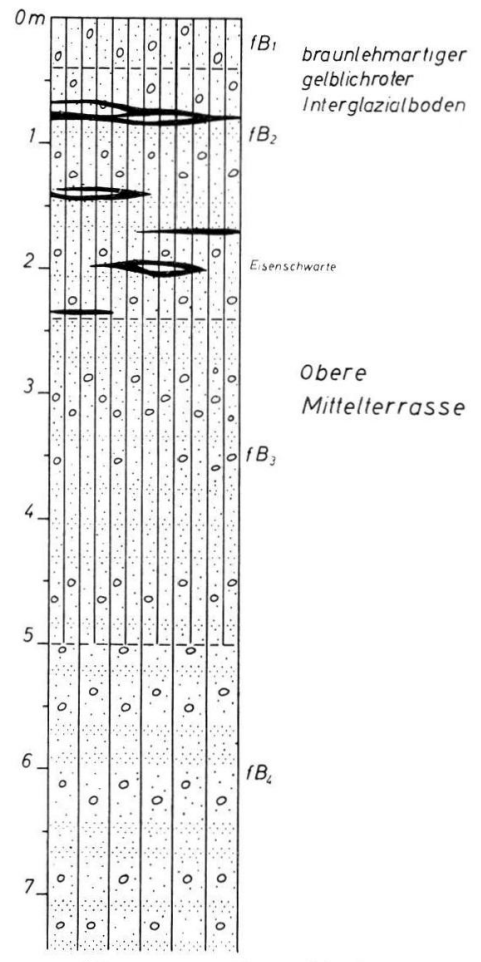

Abb. 24. Profil Rodderberg.

zu Schwarten angereichert. Im Gegensatz zur Pseudovergleyung ist die Schwartenbildung nicht auf die oberen Bodenhorizonte beschränkt, sondern sie kann das ganze Profil erfassen.

$\mathrm{Z}$ us a m me n f s s u n. Die Schotter der jHT und der oMT sind durch eine intensive Bodenbildung zu einem „braunlehmartigen gelblichroten Interglazialboden“ verwittert worden. An sehr trockenen Standorten ist das Bodenprofil einheitlich ausgebildet ohne irgendwelche Anzeichen der Staunässe. In ebener Lage und in Hanglage neigt der Boden jedoch zur Pseudovergleyung: Marmorierung und Schwartenbildung sind Merkmale der Vernässung. Daneben lassen sich die Eisen- und Manganschwarten z. T. auch auf sekundären Grundwassereinfluß zurïckführen.

\section{Die fossilen Böden in den Deckschichten}

In der Grube der Ziegelei Gillrath bei Erkelenz ist im Gegensatz zu den meisten anderen Aufschlüssen kein Grundwassereinfluß und nur ein ganz geringer Staunässeeinfluß vorhanden. So eignet sich dieser Aufschluß bei einer ziemlich großen Mächtigkeit der ver. schiedenaltrigen Lösse gut für eine bodenkundliche Untersuchung der fossilen Böden in den Deckschichten der HT.

\section{Profil Erkelenz (4) (s. Abb. 25)}

Ziegeleigrube Gillrath, nördlich der Straße Erkelenz-Wockerath, M.-Bl. Titz (4904), Ostwand der Grube, $95 \mathrm{~m}$ über NN, aufgenommen am 10. 3. 1960.

Ap O- $25 \mathrm{~cm}$ humoser feinsandiger Lehm, dunkelgelblichbraun (10 YR 4/4) (Löß-

$\mathrm{A}_{3} \quad 25-60 \mathrm{~cm}$ feinsandiger Lehm, lichtgelblichbraun (10 YR 6/4);

$\mathrm{B}_{1} \quad 60-120 \mathrm{~cm}$ feinsandiger Lehm, polyedrisches Gefüge, Tonhäutchen auf den Gefügeflächen, gelblichbraun (7,5 YR 5/6); 


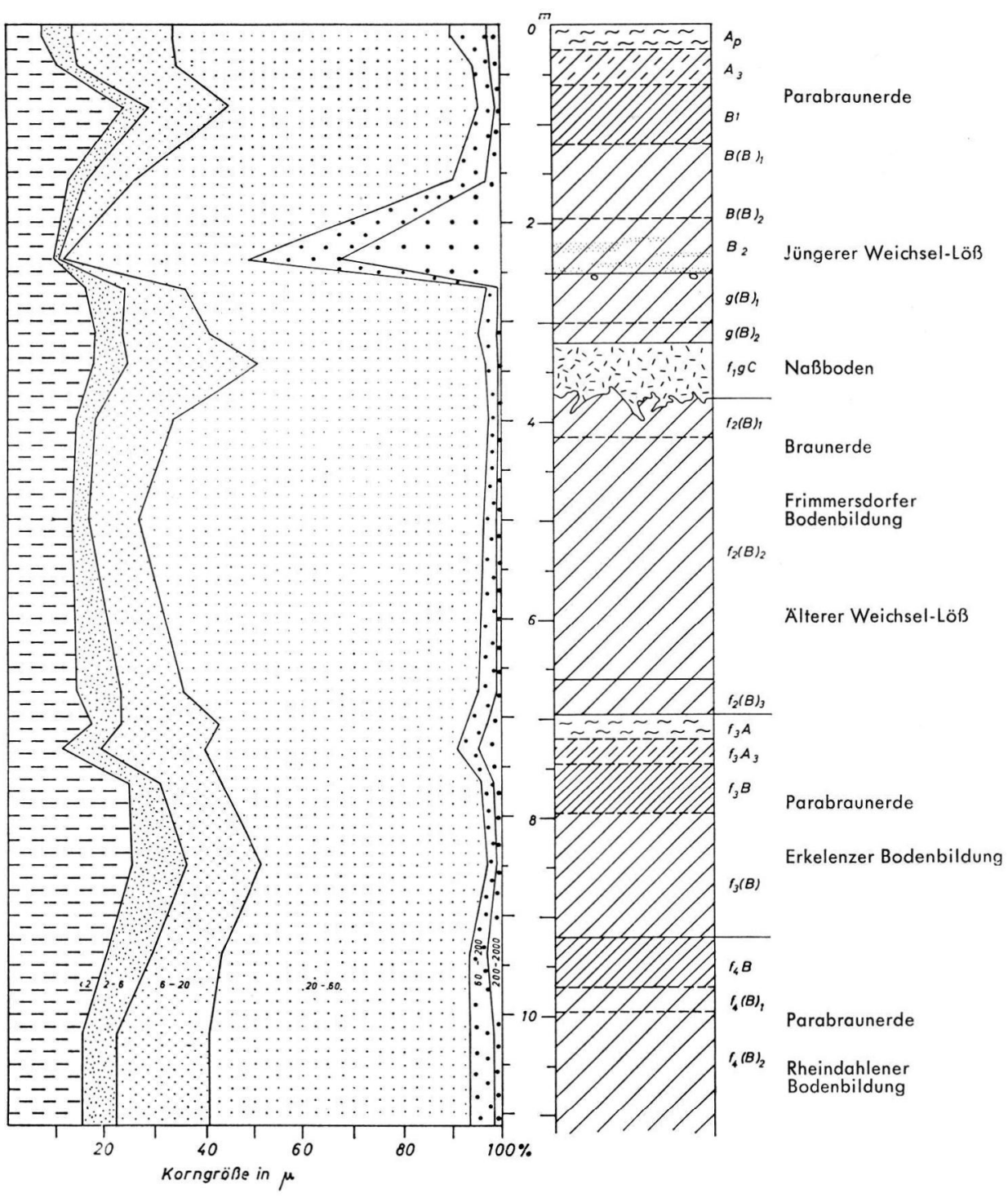

Abb. 25. Profil Erkelenz. Das Korngrößendiagramm zeigt bei den Parabraunerden in der Zunahme der feinsten Korngrößen die Tondurchschlämmung aus den A-Horizonten in die B-Horizonte hinein und in der Zunahme der gröbęren Korngrößen die Einlagerung von Flugsand im jüngsten Löß.
$\mathrm{B}(\mathrm{B})_{1} \quad 120-140 \mathrm{~cm}$
feinsandiger Lehm, rötlichgelb (7,5 YR 6/6), Übergangsschicht, nur noch vereinzelt Tonhäutchen auf den Gefügeflächen, Polyeder- bis Bröckelgefüge, kleine, weißlichgraue Flecken vorhanden, wenig bindig;
$\mathrm{B}(\mathrm{B})_{2} \quad 140-195 \mathrm{~cm}$
feinsandiger Lehm, rötlichgelb (7,5 YR 6/6), und lehmiger Feinsand, gelb (10 YR 7/6), in Wechsellagerung, Bröckelgefüge, Tonhäutchen nur noch selten zu beobachten;
$\mathrm{B}_{2} \quad 195-250 \mathrm{~cm}$
wie B(B), jedoch feiner gebändert, im unteren Teil treten Sandbänder (bis $5 \mathrm{~cm}$ mächtig) auf, in denen z. T. Tonsubstanz angereichert ist (kräftigbraun, 7,5 YR 5/6), an der Basis mit einer Steinsohle eine scharfe Grenze zum Liegenden bildend; 


\begin{tabular}{|c|c|c|}
\hline $\mathrm{g}(\mathrm{B})_{\mathbf{1}}$ & $250-300 \mathrm{~cm}$ & $\begin{array}{l}\text { feinsandiger Lehm, Brökelgefüge, lichtgelblichbraun (10 YR 6-7/4), } \\
\text { stellenweise schwach bräunlichgelb (10 YR 6/8) und schmutziggrau } \\
\text { gefleckt; }\end{array}$ \\
\hline $\mathrm{g}(\mathrm{B})_{2}$ & $300-320 \mathrm{~cm}$ & $\begin{array}{l}\text { feinsandiger Lehm, wie } g(B)_{1} \text {, etwas dunkler gefärbt, lichtgelblich- } \\
\text { braun (10 YR 6/4); }\end{array}$ \\
\hline $\mathrm{f}_{1} \mathrm{gC}$ & $320-375 \mathrm{~cm}$ & $\begin{array}{l}\text { kalkhaltiger feinsandiger Lehm, etwas heller als } \mathrm{g}(\mathrm{B})_{4} \text { gefärbt, licht- } \\
\text { gelblichbraun (10 YR 6/4), sehr schwach rostbraun und fahlgrau ge- } \\
\text { fleckt, der Horizont ist sehr stark kryoturbat gestört und greift in } \\
\text { Spalten und Taschen in den nächsten Horizont hinein; }\end{array}$ \\
\hline $\mathrm{f}_{2}(\mathrm{~B})_{1}$ & $375-425 \mathrm{~cm}$ & $\begin{array}{l}\text { feinsandiger Lehm, im oberen Teil stark kryoturbat gestört, Bröckel- } \\
\text { gefüge, geschichtet (jedoch im oberen Teil weniger ausgeprägt), oben } \\
\text { bräunlichgelb (10 YR 6/8), nach unten bald Ubergang zu gelb (10 YR } \\
\text { 7/8), allmählicher Ưbergang zu gelb (10 YR 7/8), allmählicher Über- } \\
\text { gang zum nächsten Horizont; }\end{array}$ \\
\hline $\mathrm{f}_{2}(\mathrm{~B})_{2}$ & $425-660 \mathrm{~cm}$ & $\begin{array}{l}\text { deutlich geschichteter feinsandiger Lehm, hellere und dunklere Bän- } \\
\text { der vorhanden; die Grundfarbe ist bräunlichgelb (10 YR 6/6); Man- } \\
\text { gankonkretionen verbreitet; }\end{array}$ \\
\hline $\mathrm{f}_{2}(\mathrm{~B})_{3}$ & $660-695 \mathrm{~cm}$ & $\begin{array}{l}\text { feinsandiger Lehm, wahrscheinlich umgelagertes Bodenmaterial), mit } \\
\text { scharfer Grenze zum Hangenden, schichtungslos, bräunlichgelb (10 YR } \\
5-5 / 6) \text {, Bröckelgefüge, auf Schichtfugen etwas blättrig absondernd; } \\
\text { dieser Horizont wird nach Süden mächtiger und ist dann im oberen } \\
\text { Teil fleckig ausgebildet (Naßboden); }\end{array}$ \\
\hline $\mathrm{f}_{3} \mathrm{~A}_{1}$ & $695-720 \mathrm{~cm}$ & $\begin{array}{l}\text { schwach humoser feinsandiger Lehm, dunkelgelblichbraun (10 YR 4/4), } \\
\text { Bröckelgefüge, Mangankonkretionen vorhanden; }\end{array}$ \\
\hline $\mathrm{f}_{3}$ & 720 & $\begin{array}{l}\text { feinsandiger Lehm, lichtgelblichbraun (10 YR 6-7/4) Mangankonkre- } \\
\text { tionen und wenige weißlichbraune Flecken vorhanden, Bröckelgefüge; }\end{array}$ \\
\hline$f_{3}$ & 745 & $\begin{array}{l}\text { feinsandiger Lehm, kräftigbraun ( } 7,5 \text { YR } 5 / 6) \text {, Brödkelgefüge bis kan- } \\
\text { tengerundetes Kleinpolyedergefüge, nur noch stellenweise Tonhäut- } \\
\text { chen auf den Gefügeflächen zu beobachten, wenige Mangankonkretio- } \\
\text { nen vorhanden; }\end{array}$ \\
\hline $\mathrm{f}_{3}(\mathrm{~B})$ & $795-920$ & $\begin{array}{l}\text { feinsandiger Lehm, gelblichbraun (10 YR } 5 / 6) \text {, Bröckel- bis Polyeder- } \\
\text { gefüge, kleine weißlichgraue Flecken vorhanden, vielleicht ist im } \\
\text { unteren Teil noch ein Rest } A_{3} \text { des Bodens } \mathrm{f}_{4} \text { enthalten; }\end{array}$ \\
\hline $\mathrm{f}_{4} \mathrm{~B}$ & $920-970$ & $\begin{array}{l}\text { feinsandiger Lehm, schwach plattiges Polyeder-Gefüge, kräftigbraun } \\
\text { ( } 7,5 \text { YR } 5 / 4-6 \text {, etwas nach } 10 \text { YR neigend), Mangankonkretionen } \\
\text { vorhanden, Mangananflüge auf den Kluftflächen; }\end{array}$ \\
\hline $\mathrm{f}_{4}(\mathrm{~B})$ & $970-99$ & $\begin{array}{l}\text { feinsandiger Lehm, gelblichbraun ( } 10 \text { YR } 5 / 4 \text {, etwas nach } 7,5 \text { YR } \\
\text { neigend), blättriges Bröckelgefüge, auf Klüften stellenweise noch Ton- } \\
\text { häutchen und Mangananflüge vorhanden; }\end{array}$ \\
\hline $\mathrm{f}_{4}(\mathrm{~B}$ & $995-1100 \mathrm{~cm}$ & $\begin{array}{l}\text { feinsandiger Lehm, schichtig absondernd, bräunlichgelb (10 YR 6/6), } \\
\text { schwach heller und dunkler gestreift, stellenweise ist eine rostbraune } \\
\text { Fleckung schwach angedeutet. }\end{array}$ \\
\hline
\end{tabular}

Die Lagerungsverhältnisse sind an der Ostwand regelmäßig (s. Abb. 25); die Oberfläche der unteren Böden fällt flach nach Norden ein. Dagegen ist das Profil an der Nordwand bewegter. Als ältestes ist ein schwach erodierter Boden $\left(f_{4}\right)$ aufgeschlossen. Trotz des Fehlens eines $A_{1}$ - und eines $A_{3}$-Horizonts ist dieser Boden auf Grund der Ausbildung der Tonhäutchen im $f_{4}$-Horizont als eine Parabraunerde anzusprechen. Der nächst jüngere Boden $\left(f_{3}\right)$ ist ebenfalls als eine Parabraunerde zu bezeichnen. Er unterscheidet sich von dem Boden $\mathrm{f}_{\mathbf{4}}$ deutlich durch die Struktur und die Farbe. Ferner zeigt die Korngrößenanalyse mit einem etwas höheren Tongehalt eine nur wenig kräftigere Verlehmung im Boden $f_{3}$ an. Weißlichgraue Flecken im $f_{3}(B)$-Horizont deuten einen nur schwach wirksamen Staunässeeinfluß des $\mathrm{f}_{4} \mathrm{~B}$-Horizonts an.

Dem Absatz des folgenden schichtigen Lösses, auf dem sich der Boden $\mathrm{f}_{2}$ gebildet hat, geht eine kräftige Erosion voraus, die eine breite, an der Nordwand sichtbare Rinne geschaffen hat. Das Material ist mehr als $6 \mathrm{~m}$ tief entkalkt. In der benachbarten Ziegeleigrube Gottschalk, früher Heppener, befindet sich an der Grenze zum kalkhaltigen, schichtigen Löß eine ca. $5 \mathrm{~cm}$ dicke Kalkbank. Die Bodenbildung $\mathrm{f}_{2}$ aus dem schichtigen Material ist typologisch nicht sicher anzusprechen, da der Boden z. T. erodiert ist. Auf Grund seiner heutigen Profilentwicklung ist er als eine z. T. erodierte Braunerde zu bezeichnen. 
Nach der Bildung des Bodens $\mathrm{f}_{2}$ und dessen teilweiser Erosion folgt wieder eine Zeit der Lößsedimentation. Im unteren Teil dieses Lösses tritt ein durch die ganze Grube verfolgbarer Naßboden $f_{1}$ auf, der meist mit stark kryoturbat gestörter Grenze unmittelbar auf der mehr oder weniger erodierten Braunerde $f_{2}$ lagert.

Im Dünnschliff besitzt das Bodenmaterial noch typische Merkmale eines unverwitterten Lösses: die splittrigen Mineralkörner (20-60 $\mu \mathrm{Größe)} \mathrm{sind} \mathrm{in} \mathrm{einer} \mathrm{geflockten,} \mathrm{grusigen}$ Masse von kleineren und größeren Kalzitaggregaten eingebettet. Als Hinweis auf eine beginnende schwache Bodenbildung sind bräunliche wolkige Zonen anzusehen. Kleine zerrissene konkretionsartige Bildungen von gelblich-brauner Farbe sind Anzeichen einer Pseudovergleyung. Das Ausmaß dieser Staunässe ist nicht abzuschätzen, da der Boden infolge des hohen Kalkgehalts größere Eisenverlagerungen verhindert und so nur schlecht zeichnet.

Eine scharfe Begrenzung des Naßbodens nach oben fehlt. Diese allmähliche Abnahme der Fleckung läßt vermuten, daß die Pseudovergleyung gleichzeitig mit der Lößakkumulation wirksam war, der Naßboden ist z. T. synsedimentär mit dem Löß entstanden. Der gefleckte Löß kennzeichnet so möglicherweise einen Abschnitt feuchterer Klimabedingungen während der Lößsedimentation. Auf den wenig einheitlichen Verlauf der letzten Kaltzeit weisen neben dem Naßboden Sandbänder hin ( $\mathrm{B}_{2}$-Horizont), die mit einer Steinsohle beginnen und den jüngsten Löß noch einmal untergliedern. Im Spätglazial und Holozän verwitterte der jüngste Löß zu einer Parabraunerde. Die mechanische Durchschlämmung der Tonsubstanz reichte sogar bis $2,5 \mathrm{~m}$ Tiefe, wie kräftig-braune Tonanreicherungsbänder in den sandigeren Teilen des $\mathrm{B}_{2}$-Horizonts zeigen (vgl. Profil Wegberg).

Ganz entkalkt sind die Profile in den beiden Ziegeleigruben zwischen Wegberg und Uvekoven im Kreise Erkelenz. Die unmittelbar benachbarten Gruben liegen am Nordwestrand des großen Lößgebiets von Erkelenz. In einem flachen Hang hat sich hier inselartig eine bis ca. $10 \mathrm{~m}$ mächtige Lößlehmfolge erhalten:

\section{Profil Wegberg (6) (s. Abb. 26)}

Ziegelei Simons (Wegberger Ringofenziegelei), westlich der Straße Uvekoven-Wegberg, Kreis Erkelenz, Westseite der Abbauwand, M.-Bl. Wegberg (4803), $76 \mathrm{~m}$ über NN., schwach nach NE geneigt.

$\begin{array}{lr}\text { Ap } & 0-30 \mathrm{~cm} \\ \mathrm{~A}_{3} & 30-60 \mathrm{~cm} \\ \mathrm{~B}_{1} & 60-105 \mathrm{~cm} \\ \mathrm{~B}_{2} & 105-165 \mathrm{~cm}\end{array}$

humoser, schwach sandiger feinsandiger Lehm, dunkelbraun (10 YR $3 / 3)$;

schwach sandiger feinsandiger Lehm, Polyedergefüge, manchmal auch etwas krümelig besonders auf Grabgängen, kräftigbraun (7,5 YR 5/6); Sand, bräunlichgelb (10 YR 6/6), mit dünnen lehmigen Sandbändern, gelblichrot (5 YR 5/6), Tonanreicherungsbänder;

lehmiger Sand (Tonanreicherungshorizont), gelblichrot (5 YR 5/6) und kräftigbraun (7,5 YR 5/6), mit wenigen dünnen zwischengelagerten, ungestörten Sandbändern (bräunlichgelb (10 YR 6/6) und vereinzelten dünnen Einlagerungen von feinsandigem Lehm, die Grenze nach unten ist schwach kryoturbat gestört, an der Basis Steinsohle, z. T. auch eine geringmächtige Fließerde vorhanden;

$\mathrm{B}_{3} \mathrm{f}_{1}(\mathrm{~B}) \quad 165-210 \mathrm{~cm}$ feinsandiger Lehm, stellenweise ist Sandmaterial in Frostspalten in Frostspalten in diesem Horizont enthalten, Bröckelgefüge mit etwas horizontaler Absonderung, Tonhäutchen auf Klüften und Wurzelröhren, gelblichbraun (10 YR 5/8), Mangankonkretionen vorhanden;

$\mathrm{f}_{1}(\mathrm{~B})_{1} \quad 210-300 \mathrm{~cm}$

$f_{1} g(B) \quad 300-320 \mathrm{~cm}$

$\mathrm{f}_{1}(\mathrm{~B})_{2} \quad 320-405 \mathrm{~cm}$ feinsandiger Lehm mit wenigen kryoturbat gestörten Sandbändern, gelblichbraun (10 YR 5/8), Bröckelgefüge mit etwas blättriger Absonderung, Mangankonkretionen vorhanden;

Sand mit wenigem feinsandigem Lehm vermischt, rötlichgelb (7,5 YR 6/8), rostbraun gefleckt, Mangankonkretionen vorhanden;

geschichteter feinsandiger Lehm, bräunlichgelb (10 YR 5-6/6), an der Basis Steinsohle mit schwach gewellter Grenze zum nächsten Horizont, dünne mit Sand und kiesigem Sand gefüllte Frostspalten dringen ca. $30 \mathrm{~cm}$ in den nächsten Horizont hinein, blättriges Gefüge; 

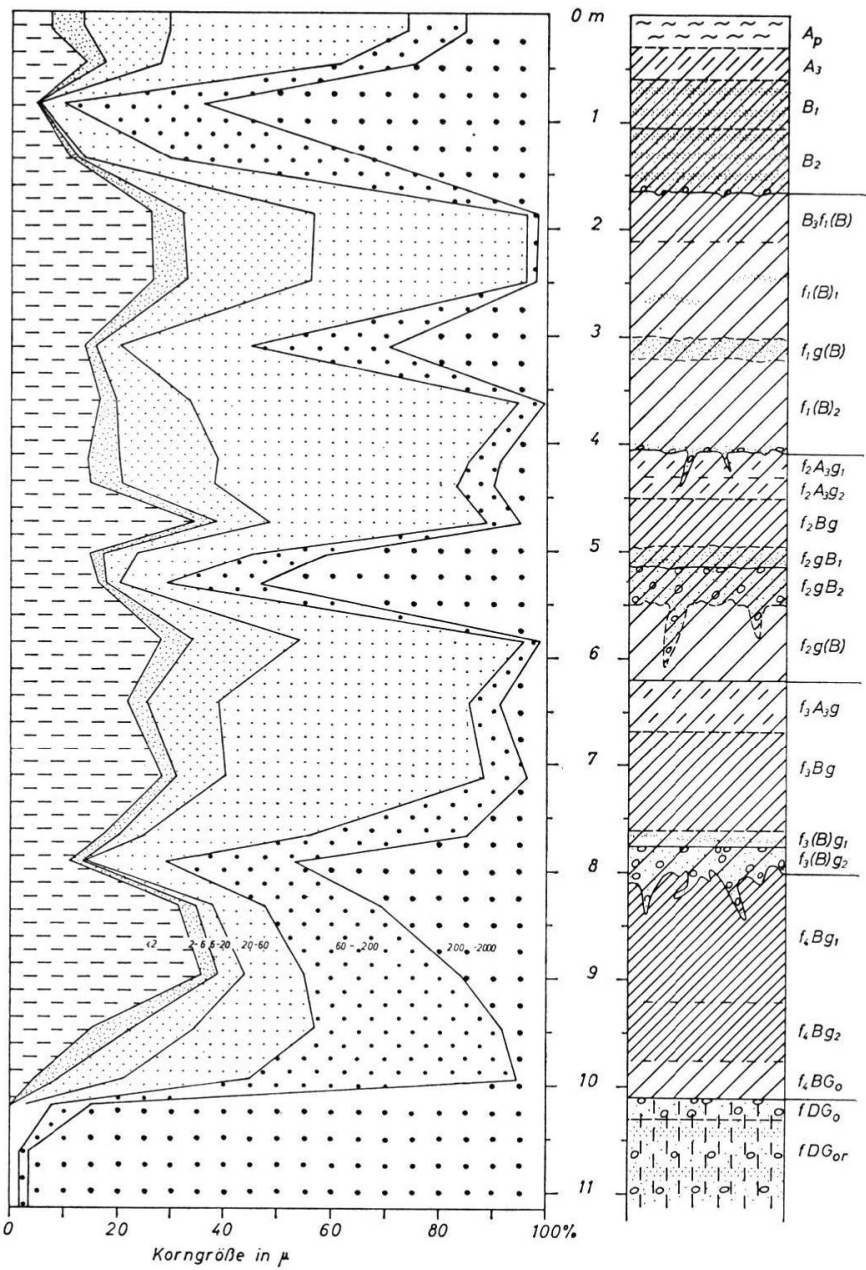

Parabraunerde

Jüngerer Weichsel-Löß

Braunerde

Frimmersdorfer Bodenbildung

Alterer Weichsel-Löß

Erkelenzer Bodenbildung

Parabraunerde-Pseudogley

Rheindahlener Bodenbildung

braunlehmartiger

gelblichroter

Boden

Wegberger Bodenbildung

Hauptterrasse

Abb. 26. Profil Wegberg. Die bodenkundlichen und geologischen Grenzen treten im Korngrößendiagramm deutlich in Erscheinung: Verarmung der $\mathrm{A}_{\mathrm{g}} \mathrm{g}$-Horizonte an Tonsubstanz gegenüber den Bg-Horizonten (bei den Parabraunerde-Pseudogleyen), Abschluß der Bodenbildung durch Solifluktion und damit Ablagerung von gröberem Material, Flugsandbildung als Vorläufer der Lößakkumulation.

$\mathrm{f}_{2} \mathrm{~A}_{3} \mathrm{~g}_{1} \quad 405-430 \mathrm{~cm}$ feinsandiger Lehm mit bis $\mathrm{zu} 2 \mathrm{~cm}$ Durchmesser dicken Mangankonkretionen, Polygone gehen von diesem Horizont aus und reichen bis $40 \mathrm{~cm}$ in den Üntergrund hinein, fahlgelb $(2,5 \mathrm{Y} 7 / 4)$, Bröckelgefüge;

$\mathrm{f}_{2} \mathrm{~A}_{3} \mathrm{~g}_{2} \quad 430-450 \mathrm{~cm}$

$\mathrm{f}_{2} \mathrm{Bg} \quad 450-495 \mathrm{~cm}$

$\mathrm{f}_{2} \mathrm{gB}_{1} \quad 495-515 \mathrm{~cm}$ feinsandiger Lehm mit vielen dicken Mangankonkretionen, besonders starke Anreicherung oberhalb des $\mathrm{f}_{2} \mathrm{Bg}$-Horizonts, Polygone vorhanden, fahlgelb (10 YR 7/4), Bröckelgefüge;

feinsandiger Lehm, kräftigbraun (7,5 YR 5/6), stark rostbraun (7,5 YR $6 / 8)$ und fahlgelb (2,5 Y 8/4) gefleckt, besonders in der Umgebung der Polygone starke rostbraune Fleckung, Bröckelgefüge bis kantengerundetes Kleinpolyedergefüge, Tonhäutchen auf Gefügeelementen nur schwach ausgebildet;

schwach kryoturbat gestörter lehmiger Sand (Flugsand), rötlichgelb (7,5 YR 6/6), schwach gewellte Grenze zum Hangenden und Liegenden, an der Basis Steinsohle, gelblichrote (5 YR 5/6) Tonanreicherungsbänder vorhanden. schwach rostbraun und fahlgrau gefleckt, besonders in der Nähe von Polygonen, Mangankonkretionen vorhanden; 


\begin{tabular}{|c|c|c|}
\hline $\mathrm{f}_{2} \mathrm{gB}_{2}$ & $515-550 \mathrm{~cm}$ & $\begin{array}{l}\text { stark verwürgter lehmiger kiesiger Sand und lehmiger Sand (Fließ- } \\
\text { erde), greift in Taschen und Frostspalten in den Untergrund hinein, } \\
\text { kräftigbraun ( } 7,5 \text { YR 5/8 und } 7,5 \text { YR 6/6), Polygone vorhanden, } \\
\text { schwach rostbraun und fahlgrau gefleckt, groß3e Mangankonkretionen } \\
\text { vorhanden (Fließerde). }\end{array}$ \\
\hline$f_{2} g(B)$ & $550-620 \mathrm{~cm}$ & $\begin{array}{l}\text { feinsandiger Lehm, gelblichbraun (10 YR 5/8), allmählicher Ubergang } \\
\text { nach unten, wenige Polygone vorhanden, Polyedergefüge, Mangan- } \\
\text { flecken vorhanden; }\end{array}$ \\
\hline $\mathrm{f}_{3} \mathrm{~A}_{3} \mathrm{~g}$ & $620-665 \mathrm{~cm}$ & $\begin{array}{l}\text { feinsandiger Lehm, mit vielen, nach unten häufiger werdenden Man- } \\
\text { gankonkretionen, unmittelbar oberhalb des } \mathrm{f}_{3} \text { Bg-Horizonts besonders } \\
\text { reichlich vorhanden, bräunlichgelb (10 YR 6/6), etwas blättrig abson- } \\
\text { derndes Bröckelgefüge; }\end{array}$ \\
\hline $\mathrm{f}_{3} \mathrm{Bg}$ & $665-760 \mathrm{~cm}$ & $\begin{array}{l}\text { feinsandiger Lehm mit vielen Polygonen, Tonhäutchen auf den Ge- } \\
\text { fügeelementen noch sichtbar, Kleinpolyedergefüge mit ausgeprägt plat- } \\
\text { tiger Absonderung, Grundfarbe: bräunlichgelb (10 YR 6/6), auf den } \\
\text { Gefügeflachen krä̈tigbraun (7,5 YR 5/6), fahlgelb }(2,5 \mathrm{Y} \text { 8/4) und } \\
\text { rötlichgelb }(7,5 \mathrm{YR} 6 / 8) \text { gefärbt, allmählicher Übergang zum nächsten } \\
\text { Horizont; }\end{array}$ \\
\hline$f_{3}(B) g_{1}$ & $760-775 \mathrm{~cm}$ & $\begin{array}{l}\text { feinsandiger Lehm und lehmiger Sand in Wechsellagerung, fast unge- } \\
\text { störte Lagerung, Polygone und Mangankonkretionen vorhanden } \\
\text { bräunlichgelb (10 YR 6/6-8), stark rostbraun gefleckt, Bröckelgefüge; }\end{array}$ \\
\hline$f_{3}(B) g_{2}$ & $775-810 \mathrm{~cm}$ & $\begin{array}{l}\text { schwach lehmiger Sand und kiesiger Sand, } 20-150 \mathrm{~cm} \text { mächtig, röt- } \\
\text { lichgelb (10 YR 6/8), Polygone reichen von oben bis in diesen Hori- } \\
\text { zont hinein, fahlgrau und rostbraun gefleckt, kleine Mangankonkre- } \\
\text { tionen vorhanden, sehr stark kryoturbat gestört, greift in Taschen und } \\
\text { Spalten tief in den nächsten Horizont hinein (Fließerde); }\end{array}$ \\
\hline \multirow[t]{2}{*}{$\mathrm{f}_{4} \mathrm{Bg}_{1}$} & $810-860 \mathrm{~cm}$ & $\begin{array}{l}\text { tischer sandiger Lehm, leuchtend gelblichrot (5 YR 4/8), mit } \\
\text { genden und liegenden Horizont stark verwürgt, Mangankon- } \\
\text { n und fahlgraue Flecken vorhanden; }\end{array}$ \\
\hline & $860-920$ & $\begin{array}{l}\text { feinsandiger Lehm, gelblichrot }(5 \\
(2,5 \text { Y } 7 / 2) \text { Flecken, sehr plastisct } \\
\text { rhanden; }\end{array}$ \\
\hline $\mathrm{f}_{4} \mathrm{Bg}_{2}$ & -975 & $\begin{array}{l}\text { sandiger Lehm, kräftigbraun (7,5 YR 5/8), weniger stark gebleicht, sehr } \\
\text { plastisch; }\end{array}$ \\
\hline $\mathrm{f}_{4} \mathrm{BGO}_{\mathrm{O}}$ & $975-1010$ & $\begin{array}{l}\text { teinsandiger Lehm und Sand in Wechsellagerung, sehr fahlbraun (10 } \\
\text { YR } 7 / 4-6) \text { und kräftigbraun }(7,5 \text { YR } 5 / 8 \text { ) in Bändern gefärbt; }\end{array}$ \\
\hline DGo & $1010-103 c$ & $\begin{array}{l}\text { kiesiger Sand, bräunlichgelb (10 YR 6/8), mit einem bis } 10 \mathrm{~cm} \text { mäch- } \\
\text { tigen schwarzen Manganhorizont; }\end{array}$ \\
\hline DGor & $1030-1070$ & $\begin{array}{l}\text { kiesiger Sand, sehr fahlbraun (10 YR 8/4) wenige rostbraune Flecken } \\
\text { vorhanden. }\end{array}$ \\
\hline
\end{tabular}

Besondere Bedeutung erlangt der Aufschluß der Ziegelei Simons durch das Vorkommen des kräftig verwitterten untersten Bodens $\left(f_{4}\right)$, der in allen untersuchten Lößprofilen des Arbeitsgebiets nicht mehr erhalten ist. Die Schichtenfolge fällt mit dem Gelände flach nach NE zu einem Tälchen ab. So ist nur in der SE-Ecke der Grube noch das Liegende der L.̈̈ßfolge, die vergleyten Schotter und Sande der HT, aufgeschlossen. Das fossile Grundwasser hat sich bis in den hangenden Lößlehm ( $f_{4} \mathrm{BG}_{0}$-Horizont) hinein ausgewirkt. Mit dem allgemeinen flachen Einfallen der Schichten nach NE erfaßt die Vergleyung weitere jüngere Horizonte; die jüngste noch vom Grundwasser geprägte Bodenbildung ist in der NE-Ecke der Boden $\mathrm{f}_{2}$.

Das Material des Bodens $\mathrm{f}_{4}$ ist stark sandig ausgebildet; Sandbänder leiten wie bei allen folgenden Lößbildungsperioden dieses Profils die Lößsedimentation ein. Rezent ist der Boden $\mathrm{f}_{4}$ in Deutschland nicht bekannt. Die außerordentlich hohe Plastizität, die große Dichte, die intensive gelblichrote Färbung (5 YR 4/8) und die starke Verlehmung sind allgemeine Merkmale einer Bodenklasse, die W. L. KuBIËNA (1953) „bolusartige Silikatböden (Plastosols)“ genannt hat. Eine typologische Bodenansprache ist wie bei den ähnlichen Bodenbildungen auf den Kiesen und Sanden der HT, der oHT und der uMT nur sehr schwer möglich. Im Schliffbild zeigt dieser Boden einige typische Merkmale des Braunlehms oder des ähnlich ausgebildeten amerikanischen Red-Yellow Podsolic soil. Da jedoch nicht feststeht, ob dieser Boden unter den gleichen Klimabedingungen gebildet 
wurde und da eine abweichende Tonmineralgarnitur vorhanden ist, wird die neutrale Bezeichnung „braunlehmartiger gelblichroter Interglazialboden“ verwandt.

Der Bildung dieses Bodens schließt sich eine Zeit starken Bodenfließens an $\left(f_{3}(B) g_{2^{-}}\right.$ Horizont). Dabei sind sicherlich auch die oberen Bodenhorizonte des Bodens $f_{4}$, der mit der Fließerde stark verwürgt ist, erodiert worden. Diese Zeugen kaltzeitlicher, feuchter Klimaverhältnisse leiten von der interglazialen Bodenbildung zu trockenen, kaltzeitlichen, der nächstjüngeren Lößbildung über. Dieser Löß ist während des nächsten Interstadials zu einem Parabraunerde-Pseudogley, dem Boden $f_{3}$, verwittert worden. Der starke Staunässeeinfluß wird sicherlich durch den dichten Boden $\mathrm{f}_{4}$ verursacht.

Bodenfließen ( $f_{2} g(B)$ - und $f_{2} g B_{2}$-Horizont), Kryoturbation, anschließende Lößbildung mit Sandbändern im unteren Teil ( $\mathrm{f}_{2} \mathrm{gB} \mathrm{B}_{1}$-Horizont) und Verwitterung zu einem Parabraunerde-Pseudogley sind auch aus dem Profilaufbau des fossilen Bodens $\mathrm{f}_{2}$ abzulesen. Die Bodenbildung ist auf Grund ihrer größeren Farbintensität, eines höheren Tongehalts (s. Abb. 26) und ihrer kräftigeren Pseudovergleyung stärker als die des Bodens $\mathrm{f}_{3}$. Der starke Staunässeeinfluß drückt sich ebenfalls aus in besonders dicken Eisen- und Mangankonkretionen mit einem durchschnittlichen Gehalt von $12 \% \mathrm{Fe}_{2} \mathrm{O}_{3}$ und $1,16 \% \mathrm{MnO}$.

Der im Profil folgende schichtige Lößlehm $\left(\mathrm{f}_{1}(\mathrm{~B})_{2}\right)$ ist vom Grundwasser nicht mehr beeinflußt worden. Daher ist sicherlich der 2-3 m über dem heutigen Grundwasser vorkommende fossile Grundwasserhorizont im DGo-Horizont zur Zeit der Bildung des Bodens $f_{2}$ entstanden. So ist es verständlich, daß trotz. starker Vergleyung die einzelnen Horizonte des Bodens $f_{3}$ durch Gefüge- und Dichteprüfung in der NE-Ecke noch zu erkennen sind. Als ein weiteres wichtiges Merkmal zur Gliederung von grundwasser-überprägten Lößprofilen erweist sich so neben der Gefügeuntersuchung das Vorkommen von Fließerden, die besonders dort nützlich sind, wo die Horizontgliederung auf Grund von bodenkundlichen Merkmalen unmöglich ist (vgl. Profil Giesenkirchen). Erosion und nachträgliche Überprägung durch die Parabraunerdebildung auf dem mit Sandbändern beginnenden jüngsten Löß machen eine eindeutige Ansprache des fossilen Bodens $\mathrm{f}_{\mathbf{1}}$, der sich auf dem im Profil folgenden schichtigen Lößlehm gebildet hat, unmöglich. Deutliche Hinweise auf eine eigene Bodenbildung aus dem schichtigen Material sind die sehr mächtige Entkalkung, die Zunahme der Farbintensität nach oben und die in spät- und postglazialen Böden ungewohnte Färbung im oberen Teil des Bodens $f_{1}$. Auf Grund der beschriebenen Merkmale ist der Bòden $f_{1}$ als erodierte Braunerde zu bezeichnen und mit dem Boden $\mathrm{f}_{2}$ des Profils Erkelenz zu parallelisieren.

Der jüngste Löß, der in seinem unteren Teil bei der unmittelbaren Nähe des Flugsandgebiets nördlich von Wegberg schon als Flugsand entwickelt ist, ist zu einer Parabraunerde verwittert. Mit dem Sandigerwerden des Bodenmaterials löst sich der einheitliche B-Horizont (Tonanreicherungshorizont) zu vielen Tonanreicherungsbändern auf.

Die Deutung eines zunehmenden Grundwassereinflusses im Boden $\mathrm{f}_{2}$ mit dem Einfallen der Schichten in östlicher Richtung findet ihre Bestätigung im Profilaufbau der ca. $600 \mathrm{~m}$ entfernt liegenden zweiten Wegberger Ziegeleigrube.

Profil Wegberg-Keller (7) (s. Abb. 27)

Ziegeleigrube Keller NE der Straße Uvekoven-Wegberg (am Grenzlandring), M.-B1. Wegberg (4803), $68 \mathrm{~m}$ über NN., schwach geneigt, aufgenommen am 13. 3. 1960.

Ap $\quad 0-20 \mathrm{~cm}$ humoser feinsandiger Lehm, dunkelbraun (10 YR 3/3) (Lößlehm);

$\mathrm{A}_{3} \quad 20-60 \mathrm{~cm}$ feinsandiger Lehm, Polyeder- bis Bröckelgefüge, braun (7,5 YR 5/4);

$\mathrm{B}_{1} \quad 60-125 \mathrm{~cm}$ feinsandiger Lehm, kräftigbraun (7,5 YR 5/6), Polygone vorhanden, Polyedergefüge;

$\mathrm{B}_{2} \quad 125-145 \mathrm{~cm} \quad$ lehmiger Sand, kräftigbraun (7,5 YR 5/6), mit Tonanreicherungsbändern, rötlichbraun (5 YR 4/4); scharfe, leicht gewellte Grenzlinie nach unten, einzelne Frostspalten greifen bis in den nächsten Horizont hinein; 
$\mathrm{f}_{1} \mathrm{~g}_{1} \quad$ 145-235 cm feinsandiger Lehm, rötlichgelb (7,5 YR 6/6) und sehr fahlbraun (10 YR 7/4) gefleckt und gestreift, in nördlicher Richtung nimmt die Mächtigkeit zu und die starke Fleckung verschwindet, bräunlichgelb (10 YR 6/6-8), Bröckelgefüge;

$\mathrm{f}_{1} \mathrm{~g}_{2} \quad 235-260 \mathrm{~cm}$ feinsandiger Lehm, wie $\mathrm{f}_{1} \mathrm{~g}_{1}$, jedoch stärker gefleckt, Grenze zum nächsten Horizont scharf und leicht gewellt;

$\mathrm{f}_{2} \mathrm{~A} \quad 260-263 \mathrm{~cm} \quad$ fettiges, humoses Bodenmaterial, sehr dunkelbraun (10 YR 2/2), Brökkelgefüge, $33450 \pm 700$ Jahre (Gro-2188);

$\mathrm{f}_{2} \mathrm{Gr}_{2} \quad 263-350 \mathrm{~cm}$ feinsandiger Lehm, lichtgrau (2,5 YR 7/2), mit wenigen rostbraunen Röhren, Bröckelgefüge;

$\mathrm{f}_{2} \mathrm{Gr}_{3} \quad 350-400 \mathrm{~cm} \quad$ feinsandiger Lehm, Bröckelgefüge, ziemlich dicht, lichtgrau (5 Y

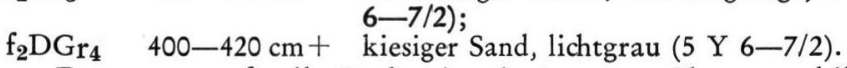

Der unterste fossile Boden ist als Anmoor-Gley ausgebildet und noch vollständig erhalten. Eine quantitative Analyse des humosen Materials des $\mathrm{f}_{2} \mathrm{AG}-$ Horizonts ergab 1,70/0 organische Substanz; Mangan oder Eisen waren in der Probe nicht enthalten. Der Boden liegt ca. $8 \mathrm{~m}$ tiefer als der gleichaltrige Boden $\mathrm{f}_{2}$ der Ziegeleigrube Simons (6), die jüngste, noch vom Grundwasser geprägte Bodenbildung dieses Profils.

Der im Profil folgende schichtige Lößlehm ist im südlichen Teil der Grube stark pseudovergleyt; nach Norden nimmt er jedoch sehr an Mächtigkeit zu und ist dort zu einer Braunerde mit ähnlichem Profilaufbau wie der fossile Boden $f_{1}$ des Profils Wegberg verwittert. Auf dem im unteren Teil sandigen jüngsten Löß ist im Spät- und Postglazial eine Parabraunerde gebildet worden. Das Profil der Ziegeleigrube Pauen (Erkelenz-Gerderath) (5) ist ähnlich entwickelt.

Für eine Gliederung der Niederrheinischen Lösse sind genau horizontierte paläolithische Funde in der Ziegeleigrube Dreesen bei Rheindahlen (Meßtischblatt MönchenGladbach) (K. J. Narr 1951) sehr wertvoll. Einen ähnlichen Aufbau wie die Grube Dreesen zeigt die Ziegeleigrube Dahmen, die bei einer größeren Mächtigkeit der gesamten Schichtenfolge besser zu gliedern ist.

Profil Rheindahlen-Dahmen (8) (s. Abb. 28)

Nordwand der Ziegeleigrube Dahmen östlich der Straße Rheindahlen-Wickrath, M.-Bl. Mönchen-Gladbach (4804), $77 \mathrm{~m}$ über NN, eben, aufgenommen am 7. 3. 1960.

Ap $\quad 25 \mathrm{~cm}$ humoser feinsandiger Lehm, dunkelbraun (10 YR 4/3), Bröckelgefüge; $\mathrm{A}_{3} \quad 25-50 \mathrm{~cm}$ $\mathrm{B}_{1} \quad 50-85 \mathrm{~cm}$ feinsandiger Lehm, gelblichbraun (10 YR 5/6), Bröckelgefüge; feinsandiger Lehm, kräftigbraun (7,5 YR 5/6), Bröckel- bis Polyedergefüge, einzelne Polygone vorhanden, im unteren Teil treten wenige Sandbänder mit einer Steinsohle an der Basis auf;

$\mathrm{B}_{2} \mathrm{f}_{1}(\mathrm{~B}) \quad 85-115 \mathrm{~cm} \quad$ feinsandiger Lehm, gelblichbraun (10 YR 5/6), Bröckel- bis PolyederGefüge mit etwas plattiger Absonderung, Tonhäutchen auf den Gefügeelementen;

(B) $\mathrm{f}_{1}$ (B) $\quad 115-265 \mathrm{~cm}$ geschichteter feinsandiger Lehm mit sandigen Einlagerungen, bräunlichgelb (10 YR 6/6), wenige Mangankonkretionen vorhanden, diskordant auf dem Untergrund lagernd;

$\mathrm{f}_{2} \mathrm{~A}_{1} \quad 265-300 \mathrm{~cm} \quad$ schwach humoser feinsandiger Lehm, Bröckelgefüge, gelblichbraun (10

$\mathrm{f}_{2} \mathrm{~A}_{3} \quad 300-345 \mathrm{~cm}$ YR 5/4), wenige Mangankonkretionen vorhanden;

$\mathrm{f}_{2} \mathrm{~B} \quad 345-410 \mathrm{~cm}$ feinsandiger Lehm, plattiges Gefüge, lichtgelblichbraun (10 YR 6/4) und sehr fahlbraun gestreift, Mangankonkretionen vorhanden;

feinsandiger Lehm, etwas plattiges Bröckel- bis kantengerundetes Kleinpolyedergefüge, nur wenige deutliche Tonhäutchen auf den $\mathrm{Ge}$ fügeflächen sichtbar, Mangankonkretionen vorhanden, allmählicher

$\mathrm{f}_{2}$ (B) $\quad 410-540 \mathrm{~cm}$ Úbergang zum Hangenden und Liegenden, kräftigbraun (7,5 YR 5/6); feinsandiger Lehm, bräunlichgelb (10 YR 6/6), etwas fahlgrau gestreift, Mangankonkretionen reichlich vorhanden, Mangananflüge auf Klüften, Bröckelgefüge;

$\mathrm{f}_{3} \mathrm{~B} \quad 540-585 \mathrm{~cm}$

feinsandiger Lehm, rötlichgelb (7,5 YR 6/6), Polyedergefüge, wenig deutliche Tonhäutchen auf den Gefügeelementen, Mangankonkretionen und Mangananflüge auf Klüften und Röhren reichlich vorhanden;

$\mathrm{f}_{3}(\mathrm{~B}) \mathrm{g}_{1} \quad 585-785 \mathrm{~cm}$ feinsandiger Lehm, fahlgrau und rostbraun gefleckt, Mangankonkretionen vorhanden, etwas blättrig absondernd; 

$\mathrm{f}_{3}(\mathrm{~B}) \mathrm{g}_{2} \quad 785-825 \mathrm{~cm}$ lehmiger Sand, gelblichbraun (10 YR 5/8), mit einer Steinsohle an der Oberfläche, wenige Mangankonkretionen vorhanden, stellenweise ist ein dichter, plastischer, schwach sandiger Lehm eingeknetet, stark fahlbraun und rostbraun gefleckt;
D $\quad 825-835 \mathrm{~cm}+$ kiesiger Sand und Sand, weißlichgrau.
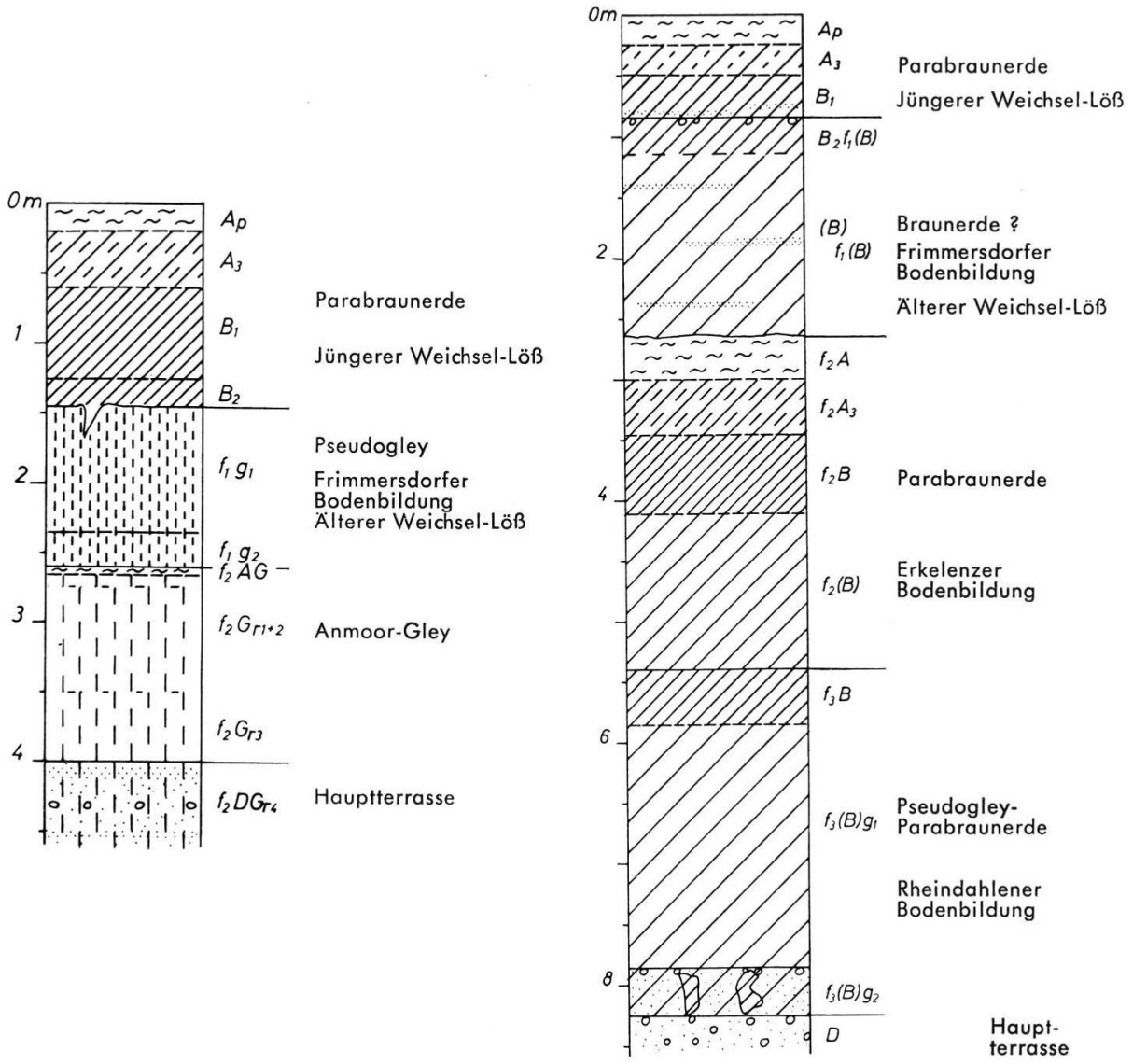

Abb. 27 (links). Profil Wegberg-Keller. - Abb. 28 (rechts). Profil Rheindahlen-Dahmen.

Über den unverwitterten Kiesen der HT folgt mit dem stark frostgestörten $\mathrm{f}_{3}(\mathrm{~B}) \mathrm{g}_{2}$ Horizont eine Fließerde, die wie im Profil Wegberg die Lößbildung einleitet. Das in die Fließerde eingearbeitete plastische Material ist möglicherweise der Rest eines intensiv verwitterten Bodens, der dem braunlehmartigen gelblichroten Interglazialboden des Profils Wegberg entspricht. Auch die weitere Profilentwicklung ist dem Wegberger Profil sehr ähnlich. Die Pseudovergleyung ist jedoch nicht so stark, ferner ist kein Grundwassereinfluß vorhanden.

Die auf dem folgenden Löß gebildete Pseudogley-Parabraunerde mit den Horizonten $f_{3}(B) g_{1}$ und $f_{3} B$ ist $z$. T. erodiert. Durch Gefüge und Farbe deutlich von diesem Boden $z u$ unterscheiden ist die stellenweise noch ganz erhaltene, auf dem nächstjüngeren Löß gebildete Parabraunerde (Boden $\mathrm{f}_{2}$ ).

K. J. Narr (1951) gibt als Fundstelle für die Moustier-Artefakte eine plattig ausgebildete Umlagerungszone zwischen zwei Verlehmungszonen in 3 und 4,5 m Tiefe der Ziegelei Dreesen an. Diesen beiden Verlehmungszonen entsprechen die Böden $f_{2}$ und $f_{3}$ des Profils Dahmen (8) in allen ihren charakteristischen bodenkundlichen Merkmalen. So 
entspricht wahrscheinlich der $\mathrm{f}_{2}(\mathrm{~B})$-Horizont der Palaeolithe führenden Umlagerungszone der ca. $600 \mathrm{~m}$ entfernt liegenden Fundgrube.

Im Profil folgt nun bis zu dem mit Sandbändern über einer Steinsohle beginnenden jüngsten Löß ein schichtiger Lößlehm $\left(\mathrm{B}_{2} \mathrm{f}_{1}(\mathrm{~B})\right.$ - und $(\mathrm{B}) \mathrm{f}_{1}(\mathrm{~B})$-Horizont), der an der Ostwand im unteren Teil noch kalkhaltig ist. Wie in dem Profil Wegberg hat auch hier wahrscheinlich eine Bodenbildung mit anschließender starker Erosion auf dem schichtigen Material vor Absatz des jüngsten Lösses stattgefunden. Mit Vorbehalt wird daher der Boden $f_{1}$ als eine Braunerde bezeichnet.

Sogar bis auf einen Rest von $40 \mathrm{~cm}$ wurde der Boden $\mathrm{f}_{1}$ auf dem schichtigen Material in der Ziegeleigrube Dreesen erodiert; eine Gliederung der geringmächtigen Lößlehmfolge oberhalb der beiden Verlehmungszonen ist, $\mathrm{da}$ die spät- und postglaziale Bodenbildung den fossilen Boden $f_{1}$ ganz überprägt hat, nur noch durch die Steinsohle und die Sandbänder im unteren Teil des jüngsten Lösses möglich.

Auf dem jüngsten Löß hat sich wie in allen bisher beschriebenen Profilen eine Parabraunerde gebildet.

$\mathrm{Z}$ us a m me $\mathrm{n}$ a s s u n g. Die beschriebenen Profile der Deckschichten der HT liegen alle in einem engbegrenzten Gebiet. Die in diesem Gebiet auftretenden gleichaltrigen Böden sind daher unter den gleichen klimatischen Bedingungen gebildet worden. Unterschiede in der bodentypologischen Ausbildung ergeben sich durch Grundwasser, Staunässe und verschiedenes Relief.

Sehr klar ist die Profilentwicklung im Aufschluß Gillrath bei Erkelenz. Dieser Aufschluß ist daher ein günstiger Ausgangspunkt, um die fossilen Böden miteinander zu parallelisieren. Die beiden Parabraunerden $\left(\mathrm{f}_{4}\right.$ und $\mathrm{f}_{3}$ ) unterscheiden sich deutlich durch Farbe und Struktur. In gleicher charakteristischer Ausbildung treten beide Böden im Profil Rheindahlen (8) ( $f_{3}$ und $f_{2}$ ) auf. In dem unteren Boden wirkt sich dazu ein geringer Staunässeeinfluß aus, so daß dieser als Pseudogley-Parabraunerde ausgebildet ist. Noch stärker ist der Staunässeeinfluß im Profil Wegberg (6), wo die entsprechenden Böden beide als Parabraunerde-Pseudogleye auftreten $\left(f_{3}\right.$ und $f_{2}$ ). Im Gefüge und in der Verlehmungsstärke sind sie trotz der starken Pseudovergleyung mit den entsprechenden Böden des Profils Erkelenz (4) zu vergleichen.

Der obere Parabraunerde-Pseudogley $\left(f_{2}\right)$ des Profils Wegberg (6) erfährt mit dem Abfallen des Geländes nach Osten eine zunehmende Vergleyung. In der Ostecke der Grube wird er schon durch einen typischen Gley vertreten. Schließlich tritt er in dem ca. $600 \mathrm{~m}$ entfernt aufgeschlossenen Profil Wegberg-Keller (7) $8 \mathrm{~m}$ tiefer sogar als Anmoor-Gley auf. Die Deckschichten dieser fossilen Böden sind in den Gruben Wegberg (6) und WegbergKeller (7) annähernd gleich ausgebildet.

Im Liegenden der beschriebenen Böden ist nur im Profil Wegberg (6) noch eine weitere kräftige Bodenbildung aufgeschlossen, der braunlehmartige gelblichrote Interglazialboden $\left(f_{4}\right)$. Als Rest ist er vielleicht noch in dem stark verwürgten $f_{3}(B) g_{2}$-Horizont des Profils Rheindahlen (8) enthalten.

Úber den Parabraunerden, den Parabraunerde-Pseudogleyen, dem Naßgley und dem Anmoor-Gley folgt in allen Profilen ein schichtiger Lößlehm, der z. T. Höhenunterschiede ausgleicht, die durch Erosion nach der letzten Bodenbildung entstanden sind. Aus diesem Material ist eine heute $z$. T, erodierte Braunerde gebildet worden (Boden $f_{1}$ der Profile Wegberg, Wegberg-Keller und Rheindahlen, Boden $f_{2}$ des Profils Erkelenz).

Der jüngste Löß beginnt meist mit Sandbändern über einer Steinsohle. Teils wurde die Braunerde auf dem schichtigen Löß durch Solifluktion, teils durch Winderosion mehr oder weniger abgetragen. So ist es verständlich, daß der Naßboden $f_{1}$ des Profils Erkelenz im Liegenden der Steinsohle und der Sandbänder meist erodiert ist.

Der jüngste Löß ist in allen beschriebenen Gruben zu einer Parabraunerde verwittert. 
Aus dem Vergleich der Lößprofile ergibt sich damit folgendes bodenkundliches und geologisches Geschehen für die Deckschichten der HT:

1. Absatz der Hauptterrassenschotter; eine eigene Bodenbildung ist unter dem braunlehmartigen gelblichroten Interglazialboden von Wegberg nicht zu beobachten, aher theoretisch anzunehmen (vermutlich langer Hiatus: Cromer- und Holstein-Interglazial);

2. Lößbildung (Wegberg);

3. Bildung eines braunlehmartigen gelblichroten Interglazialbodens (Wegberg: $f_{4}$ ), Wegberger Bodenbildung;

4. Bodenfließen und Kryoturbation (Wegberg und Rheindahlen);

5. Lößbildung (Erkelenz, Wegberg und Rheindahlen);

6. Bildung einer Parabraunerde (Erkelenz: $\mathrm{f}_{4}$ ), einer Pseudogley-Parabraunerde (Rheindahlen: $\left.f_{3}\right)$, Rheindahlener Bodenbildung;

7. Erosion und Bodenfließen (Wegberg, Erkelenz);

8. Lößbildung (in allen beschriebenen Gruben);

9. Bildung einer Parabraunerde (Erkelenz: $f_{3}$, Rheindahlen: $f_{2}$ ), eines ParabraunerdePseudogleys (Wegberg: $\mathrm{f}_{2}$ ). Sehr hoher Grundwasserstand und damit Bildung eines Gleys (Wegberg: $\mathrm{f}_{2}$ ), Erkelenzer Bodenbildung;

10. Erosion (in allen Gruben) und Bodenfließen (Erkelenz und Wegberg);

11. Bildung eines schichtigen Lösses (in allen Gruben), Naßbodenbildung (Erkelenz);

12. Bildung einer heute z. T. erodierten Braunerde (in allen Gruben);

13. Bodenfließen und Erosion (in allen Gruben);

14. Lößbildung und Bildung eines Naßbodens im unteren Teil dieses Lösses (Erkelenz):

15. Winderosion und erneute Lößbildung mit einleitender Flugsandbildung (in allen Gruben);

16. Bildung einer Parabraunerde (in allen untersuchten Aufschlüssen).

\section{Untersuchungen im Laboratorium}

\section{Korngrößenanalysen}

Von der HT bis zur NT ist eine Abnahme der Verwitterungsintensität und damit der Verlehmung zu beobachten. Um die Stärke der Verlehmung durch eine genaue mechanische Bodenanalyse zu erfassen, wurden mit Hilfe der Pipettmethode nach KöHs die Korngrößenzusammensetzung charakteristischer Horizonte der fossilen und rezenten Böden auf den verschiedenen Terrassen untersucht. Als Dispergierungsmittel diente $250 \mathrm{ccm}$ $0,04 \mathrm{n}$ Natriumpyrophosphat. Um eine möglichst vollständige Dispergierung zu erreichen, wurde die Aufschlämmung 15 min mit Ultraschall (Schallfix) behandelt.

a) Tonanreicherungsbänder in der Niederterrasse

Charakteristisch für viele Niederterrassenaufschlüsse sind Tonanreicherungsbänder, die bei der Bildung der Parabraunerden aus Hochflutlehm oder der Sand-Parabraunerden aus Flugsand entstanden sind. Der durchschnittliche Tongehalt liegt bei 8\%, Schwankungen zwischen 4 und $12 \%$ sind jedoch möglich.

b) Fossile Böden und Tonanreicherungsbänder in der

Krefelder Terrasse

Die Verwitterung der fossilen Braunerde auf der KT ist nur schwach. Diese schwache Bodenbildung drückt sich ebenfalls in einem nur geringen Tongehalt aus, der zwischen 4 und $5 \%$ schwankt.

Höhere Tongehalte herrschen in den bräunlichroten Tonanreicherungsbändern, die z. T. Reste einer fossilen erodierten Parabraunerde sind, z. T. aber auch bei der Entstehung der rezenten Parabraunerde aus dem jüngsten Löß entstanden sind. Der Tongehalt 
in den Tonanreicherungsbändern liegt meist zwischen 6 und 9,5\%, im Durchschnitt ist $8,5 \%$ Ton enthalten.

c) Fossile Böden auf der Unteren Mittelterrasse und a us den glazialen Schottern und Sanden der Drenthe-Vereisung

Sehr unterschiedliche Tongehalte herrschen in den fossilen Böden auf den Kiesen und Sanden der uMT. Die Intensität der Verwitterung dieses braunlehmartigen gelblichroten Interglazialbodens ist jedoch nicht so groß wie die auf dem Hauptterrassenmaterial, so daß die Verlehmung auch nicht so stark ist. Die Tongehalte schwanken zwischen 8 und 12\%; Gehalte bis zu $18 \%$ sind jedoch ebenfalls möglich. Der Durchschnittswert liegt bei ca. $11 \%$.

d) Fossile Böden auf der Oberen Mittelterrasse

Obwohl bodentypologisch auf den Kiesen und Sanden der oMT der gleiche Boden verbreitet ist wie auf der HT, so sind die Tongehalte im Durchschnitt dennoch niedriger. Wahrscheinlich sind bei der flächenmäßig geringen Verbreitung der oMT diese Böden stärker erodiert worden. Die Gehalte liegen meist zwischen 10 und 19\%; sehr häufig tritt der. Wert $14 \%$ auf.

e) Fossile Böden auf der Jïngeren $\mathrm{Hauptter}$ asse

Der braunlehmartige gelblichrote Interglazialboden auf den Kiesen und Sanden der $\mathrm{jHT}$ ist in allen Fällen mehr oder weniger stark erodiert, so daß dieser Boden heute in verschiedener Profilmächtigkeit und sehr unterschiedlicher Verlehmungsstärke vorliegt. So sind die großen Unterschiede in der Korngrößenzusammensetzung der fossilen Böden wahrscheinlich auf die ungleiche Erosion zurückzuführen.

Das Ausgangsgestein für die Bodenbildung ist für alle Gruben annähernd gleich. Unterschiede ergeben sich durch eine stärker sandige oder schotterreiche Zusammensetzung des Materials. Die unverwitterten Kiese und Sande besitzen keinen Tongehalt. In dem stark verwitterten plastischen Bodenmaterial ist dagegen meist ein Tongehalt von 10-20\% enthalten, in weniger erodierten Bodenprofilen (Profil Pützlohn) ist sogar 30\% und mehr enthalten. In den oberen Bodenhorizonten ist 19\% ein häufig auftretender Wert.

\section{Untersuchung der Tonsubstanz mit Hilfe der Röntgenanalyse}

Die Untersuchung der fossilen Böden im Niederrheingebiet zeigt, daß die Terrassen auf Grund ihrer bodenkundlichen Merkmale zu drei Gruppen zusammengefaßt werden können: a. NT und KT, b. uMT und c. oMT und jHT. Die unterschiedliche Verlehmung, Färbung und Plastizität der Böden sind das Ergebnis der Bedingungen, unter denen die Böden gebildet wurden.

Daher ist zu erwarten, daß sich die Böden der drei Terrassengruppen neben den beschriebenen mikroskopischen Merkmalen auch in der Tonmineralgarnitur unterscheiden. Die Bildung bestimmter Tonminerale ist weitgehend abhängig von den herrschenden Klima- und Bodenverhältnissen sowie von der Dauer der Verwitterung. Montmorillonit z. B. bevorzugt mehr basische Böden, während Kaolinit, ein typisches Verwitterungsprodukt tropischer und subtropischer Böden, mehr neutrale bis schwach saure Reaktion bevorzugt. Kaolinit ist so bei den unter feuchtwarmen Klimabedingungen intensiv verwitterten, schwach sauren braunlehmartigen gelblichroten Interglazialböden stark angereichert zu erwarten, während Montmorillonit in den wenig entbasten, neutralen, unter feuchtgemäßigtem Klima verwitterten Boden des Postglazials zu suchen ist.

Die erwarteten Unterschiede kommen bei den an 23 Proben durchgeführten qualitativen Röntgenanalysen nicht in der erwarteten Schärfe heraus. Unterschiede ergeben sich in der Ausbildung des Röntgenspektrums und in dem Fehlen, bzw. Auftreten von weiteren Tonmineralien. 
a. Niederterrasse und Krefelder Terrasse

Aus der KT und der NT wurden die Tonanreicherungsbänder, die bei der fossilen oder rezenten Parabraunerdebildung aus Löß oder Hochflutlehm oder bei der Bildung der Sand-Parabraunerde aus Flugsand entstanden sind, röntgenographisch untersucht. Die geringe Zahl der untersuchten Proben erlaubt es nicht, innerhalb dieser Gruppe Unterschiede herauszuarbeiten.

Die Durchkristallisation der Tonminerale ist in den Tonanreicherungsbändern im Vergleich zu den älteren Terrassen am besten. Die Basenverarmung, die Wirkung der peptisierenden Kieselsäure und der Abbau der Tonsubstanz sind nicht so groß wie in den fossilen Böden auf den älteren Terrassen.

So tritt neben Illit und Kaolinit, die vorherrschend sind, meist ein geringer Gehalt an Montmorillonit auf, ferner ein deutlicher Gehalt an Hydrobiotit und Vermikulit, der stellenweise $20 \%$ und mehr ausmacht.

Eisenoxydhydrate sind in zu geringem Anteil in der Tonmineralfraktion enthalten, als daß sie in nicht angereicherter Form nachgewiesen werden könnten.

b. Untere Mittelterrasse und glaziale Schotter und Sande der Drenthe-Vereisung

Schlechter durchkristallisiert ist die Tonsubstanz in dem weniger stark verwitterten braunlehmartigen gelblichroten Interglazialboden der uMT.

Kaolinit und Illit sind wiederum zu gleichen Anteilen vorherrschend. Vermikulit läßt sich in fast allen untersuchten Proben nachweisen. Hydrobiotit konnte nicht nachgewiesen werden, Montmorillonit war nur schwach angedeutet in einer Probe vorhanden. Vermikulit, ein verhältnismäßig grobkörniger Montmorillonit, tritt als Zwischenprodukt auf bei der Umformung von Illit zu Kaolinit oder Montmorillonit (LAATsCH, 1957, S. 65).

Der Abbau des Illits zu Kaolinit geschieht offensichtlich in den fossilen Böden der Unteren Mittelterrasse weniger schnell und vollständig als in den Böden der älteren Stufen. Das Fehlen von Montmorillonit deutet aber feuchtwarme Klimaverhältnisse an, die schon eine weitgehende Entbasung und damit einen ziemlich schnellen Zerfall des Illits und Vermikulits im Gefolge hatten.

c. Obere Mittelterrasse und die Jüngere Hauptterrasse

Die Tonmineralgarnitur des braunlehmartigen gelblichroten Interglazialbodens auf der HT und der oMT ist gleich und rechtfertigt damit die gleiche bodentypologische Ansprache.

Bezeichnend für die Röntgendiagramme sind die breiten Basis-Interferenzen; die Tonminerale dieses fossilen Bodens sind also sehr schlecht durchkristallisiert. Diese mangelhafte Durchkristallisation beruht wahrscheinlich auf der in schwach saurem Milieu (pH 4-5) vorkommenden stark veptisierenden, wasserhaltigen, kolloidalen Kieselsäure und auf dem starken Zerfall der Tonminerale.

Der starke Abbau der Tonminerale drückt sich ebenfalls in der Zusammensetzung der Tonmineralfraktion aus. Meist konnten nur Kaolinit und Illit mit mehr oder weniger gleichem Anteil in den untersuchten Bodenproben der HT und der oMT nachgewiesen werden. Lediglich in zwei oberflächennah entnommenen Proben trat dazu ganz schwach angedeutet Montmorillonit, Vermikulit und Hydrobiotit auf. Diese geringen Vorkommen sind sicherlich auf Tondurchschlämmung aus dem rezenten Boden aus wenig mächtigem Würm-Löß zurückzuführen.

Das fast ausschließliche Auftreten von Kaolinit und Illit zeigt wie die Färbung, Verlehmung und Plastizität eine sehr intensive und lange Verwitterung unter einem feuchtwarmen Klima an.

$\mathrm{Z}$ us a mmenfassung: Die geschilderten Unterschiede erlauben eine Trennung der Bodenbildungen auf a. NT und KT. b. uMT und c. oMT und HT. Die Ergebnisse 
der Röntgenanalyse sind jedoch sehr vorsichtig zu deuten. Die charakteristischen Merkmale der Böden auf den jüngeren Terrassen können gleichfalls in den älteren Stufen auftreten, wenn spätere Bodenbildungen, wie Verwitterung und Tondurchschlämmung, fossile Böden überprägen. Ferner sind bisweilen Montmorillonit, Vermikulit und Hydrobiotit in den jungen Parabraunerdebändern so wenig enthalten, daß sie mit Hilfe der Röntgenanalyse nicht mehr nachgewiesen werden können.

\section{Untersuchung der Eisenoxyde und Eisenoxydhydrate mit Hilfe der Röntgenanalyse}

Zwischen den Tonanreicherungsbändern in den Kiesen und Sanden der NT und der KT und den fossilen Böden auf den älteren Terrassen bestehen deutliche Unterschiede in der Färbung. Diese unterschiedlichen Farben werden wahrscheinlich durch verschiedene Eisenoxyd- und Eisenoxydhydratformen hervorgerufen.

Die Röntgenanalyse zeigt nun, daß Eisen in einem zu geringen Gehalt im Boden enthalten ist, als daß es in nicht angereicherter Form nachgewiesen werden könnte. Aber auch nach einer Anreicherung mit einem Magnetscheider gelingt es nur bei wenigen Proben, Goethit in Spuren nachzuweisen. Damit bestätigt sich die Beobachtung im Dünnschliff, daß das Eisen im Braunlehmteilplasma in sehr stark peptisierter Form enthalten ist. Etwas häufiger konnte Goethit in Grundwasserbildungen nachgewiesen werden.

Eisen- und Manganschwarten vom Rodderberg (10) mit einem Gehalt von 38,3\% $\mathrm{Fe}_{2} \mathrm{O}_{3}$ (s. HT) schienen für eine röntgenographische Untersuchung besonders günstig zu sein. Trotz des hohen Gehalts an Eisen zeigt das Röntgendiagramm nur schwach Goethit mit einer sehr breiten Basisinterferenz an. Das Eisenoxyd und Eisenoxydhydrat ist also trotz der starken Anreicherung nur sehr schlecht durchkristallisiert. Die Haematitlinien erschienen im Röntgendiagramm erst nach dreistündigem Glühen der Substanz über $900^{\circ} \mathrm{C}$, nachdem das gesamte Eisen in Haematit überführt worden war.

\section{Mikromorphologische Untersuchung der Böden auf den Rheinterrassen')}

Die im folgenden beschriebenen, mikromorphologischen Merkmale der fossilen Böden auf den Rheinterrassen sollen Unterschiede zwischen den verschiedenaltrigen Bodenbildungen herausstellen und eine genauere bodentypologische Ansprache ermöglichen.

a. Niederterrasse und Krefelder Terrasse

Die Untersuchung beschränkt sich auf die Tonanreicherungsbänder, die entstanden sind durch Tonmineraleinschlämmung aus der über den Terrassenkiesen lagernden Parabraunerde aus Hochflutlehm oder Löß. Während die Bänder in der NT nachweisbar mit der rezenten Parabraunerde entstanden sind, können diese in der KT z. T. durch einen später erodierten fossilen Boden aus Löß gebildet worden sein.

Die Tonanreicherungsbänder setzen sich im Schliffbild vorwiegend aus kantengerundeten Skelettbestandteilen mit 200 bis $1000 \mu$ Durchmesser zusammen. Unter den Mineralkörnern überwiegt Quarz. Die Quarzkörner werden von bei $+N$ doppelbrechenden Plasmasäumen und -bändern umgeben (s. Abb. 29). Meist wird der Verband zwischen den Mineralkörnern durch Braunlehmteilplasma hergestellt, z. T. sind kleinere Zwischenräume ganz mit Plasma ausgefüllt. Dadurch erhält das Bodenmaterial seine Bindigkeit. Das Braunlehmteilplasma ist in den einzelnen Schliffen verschieden eisenhaltig, so daß die Färbung von hellgelb bis dunkelrötlichbraun reicht. Bisweilen zeigt die Grundsubstanz schaligen Aufbau, beim Austrocknen zerfällt sie entlang den vorgezeichneten Bahnen der Absonderung zwiebelförmig.

1) Die Maßstabsfolien zu den Abbildungen wurden freundlicherweise von Dipl. agr. K. ZIMMERMANN, Institut $f$. Bodenkunde, Bonn, zur Verfügung gestellt. 


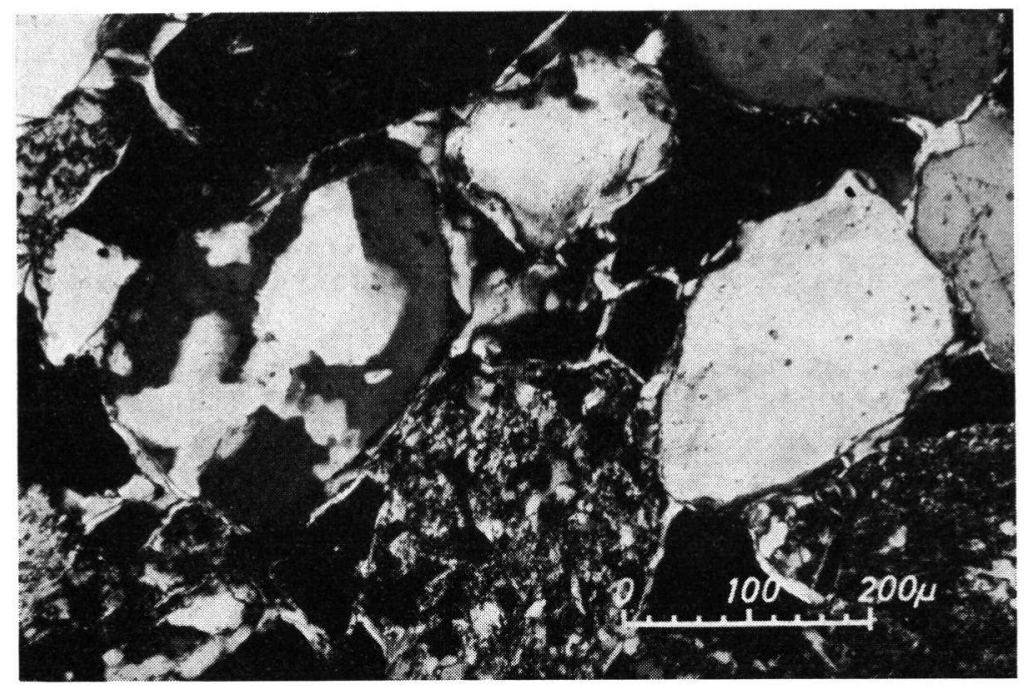

Abb. 29. Vergr. $125: 1$, N T, D B - Horizont, + N. Kantengerundete, fluviatile Skelettkörner mit doppelbrechenden, leuchtenden Plasmasäumen und Brücken.

Die Schliffbilder der NT und der KT unterscheiden sich nicht wesentlich. Die Skelettkörner der KT scheinen etwas dichter gelagert, die Plasmasäume und -brücken sind schwächer ausgebildet. Daher sind die Dichte und die Bindigkeit der Tonanreicherungsbänder der KT geringer als in der NT'. Lößlehm neigt offensichtlich weniger stark zur Durchschlämmung als Hochflutlehm.

Das Bodenmaterial setzt sich damit ausschließlich aus Bodenskelett und Braunlehmteilplasma zusammen. Es gehört nicht zu einem echten Verwitterungshorizont, sondern entstand durch Toneinschlämmung in frische, unverwitterte Kiese und Sande hinein. Das Braunlehmteilplasma unterscheidet sich nicht von dem in den Parabraunerden aus Löß, Sandlöß und Flugsand.

b. Untere Mittelterrasse und glaziale Schotter und Sande der Rißvereisung

Erst bei der uMT steht für die mikromorphologische Untersuchung Bodenmaterial aus echten Verwitterungshorizonten zur Verfügung. Vollständige Bodenprofile gibt es nicht. Ein nur schwach erodierter Boden ist am Egelsberg bei Krefeld (11) auf den glazialen Schottern und Sanden der Drenthe-Vereisung aufgeschlossen. Die übrigen Profile auf der uMT sind fast alle stärker erodiert; vor allem fehlt der stark verlehmte obere Teil des B-Horizonts.

Die Skelettkörner sind weiterhin kantengerundet mit einer durchschnittlichen Größe von 50 bis $800 \mu$. Randlich sind die Mineralkörner stark angewittert, zwischen den großen Körnern liegen in einer Braunlehmteilplasma-Grundmasse kleine Mineralstückchen; Quarz überwiegt.

Im Gegensatz zu den jüngeren Terrassen beschränkt sich das Fließplasma nicht mehr nur auf Hüllen- und Brückenbildung um und zwischen den Mineralkörnern. Strangartig umfließt nun Braunlehmteilplasma die Skelettkörner. An sehr unregelmäßig verlaufenden Fließbahnen und an der starken Zerstückelung des Plasmas ist eine intensive Durchknetung des Bodens zu erkennen (s. Abb. 30). Konkretionsartige Bildungen fehlen. Dafür ist eine wenig häufige Bleichung des Braunlehmteilplasmas zu Graulehmteilolasma als Merkmal einer in dem dichten Material wirksamen Staunässe zu werten. 


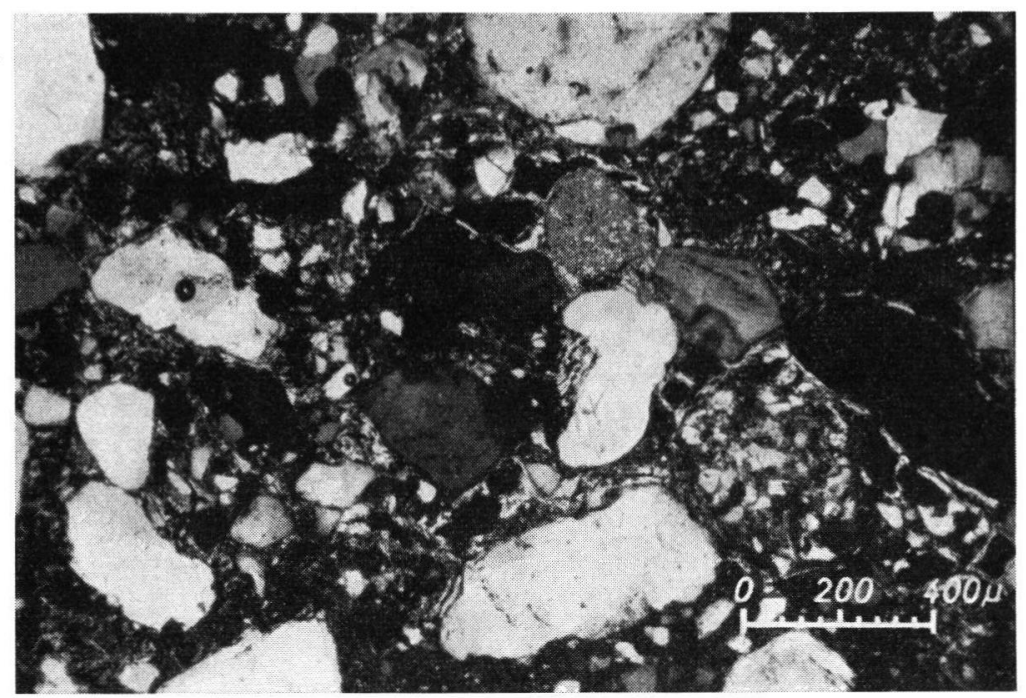

Abb. 30. Vergr. 50:1, u M T, f B - H o rizo n t, +N. Große, kantengerundete, und kleine, splittrige Mineralkörner in einer strähnigen, dichten und verwürgten Grundmasse aus doppelbrechendem Braunlehmteilplasma eingebettet.

Die Intensität der Verlehmung nimmt nach unten schnell ab. Im unteren Teil des BHorizonts gleicht das Schliffbild wieder dem der N'T und der KT. Braunlehmteilplasma bildet nur noch Plasmasäume und schwache Brücken zwischen den Mineralkörnern.

Die mächtigen Braunlehmteilplasmastränge, in die das reichlich vorhandene Bodenskelett eingebettet ist, sind ein typisches Merkmal der Braunlehme. Die von W. L. Kubı̈̈nA (1953) beschriebenen randscharfen Konkretionen fehlen.

c. Obere Mittelterrasse und $\mathrm{H}$ a u ptterrasse

Das Schliffbild der fossilen Böden auf der oMT und der H'T ist ähnlich dem der uMT. Die stark verlehmte Zone im oberen Teil des B-Horizonts ist jedoch weitaus mächtiger

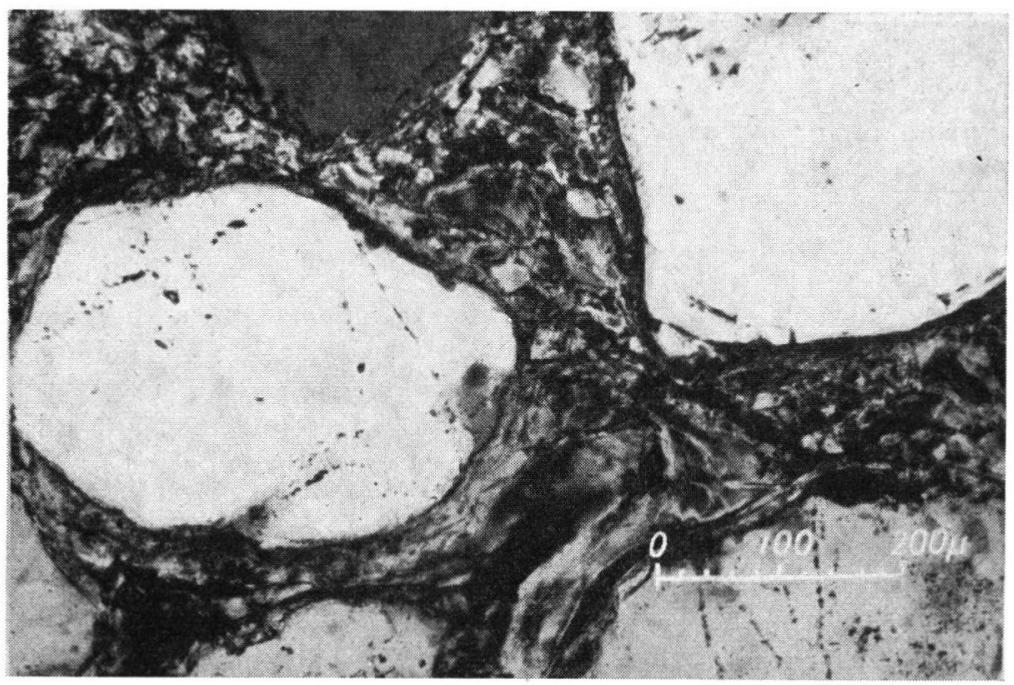

Abb. 31. Vergr. $125: 1, \mathrm{HT}$, f B - Hori 7 o $\mathrm{t},+\mathrm{N}$. Kantengerundete, fluviatile Mineralkörner in dichtem, zerknetetem Braunlehmteilplasma eingebettet. 
als bei der uMT. Daher wird auch im Schliffbild meist trotz der starken Erosion noch die verdichtete Zone beobachtet.

Die Skelettkörner sind rundlich und verschieden groß, z. T. sind sie zerbrochen und durch Verwitterung randlich angeätzt. Ein sehr strähniges, zerbrochenes und zerknetetes Braunlehmteilplasma mit unterschiedlichem Gehalt an Eisen (s. Abb. 31) umkleidet die Mineralkörner und verleiht damit dem Boden die große Dichte. Mitunter ist das Plasma schalig ausgebildet. Nur ganz vereinzelt finden sich konkretionsartige Bildungen mit unscharfen und zerrissenen Rändern, die einen Staunässeeinfluß anzeigen.

Die sekundär vergleyten braunlehmartigen Interglazialböden der HT und der oMT unterscheiden sich im Schliffbild deutlich von den normalen Bodenbildungen. Die kantengerundeten Mineralkörner sind hier in einer dunkelbraunen, opaken Grundmasse eingebettet, die nur in den Randpartien einiger Leitbahnen Doppelbrechung zeigt und rötlichgelb aufleuchtet. Es zeigt sich, daß hier Braunlehmteilplasma sekundär mit Eisen- und Manganverbindungen angereichert worden ist, so daß die Grundmasse dunkelbraun bis schwarz und opak wird. Diese Anreicherung führt schließlich bankweise zu einer steinähnlichen Verfestigung des Bodenmaterials.

\section{Schlußfolgerungen}

\section{Die stratigraphische Gliederung der Lößprofile}

Eine stratigraphische Gliederung von Lößprofilen in einem kleinen Arbeitsgebiet ist mit vielen Fehlerquellen verbunden. Die fossilen Böden, C ${ }^{14}$-Bestimmungen, Artefaktenfunde und der Vergleich mit anderen Lößprovinzen geben jedoch Daten, die selbst eine Gliederung in diesem engen Gebiet erlauben.

Die uMT, deren Drenthe-Alter durch ihre Verknüpfung mit den Endmoränen des nordischen Inlandeises als bewiesen gilt, ist für eine stratigraphische Gliederung der Lösse besonders wichtig. Wie bei der bodenkundlichen Beschreibung dargelegt wurde, findet sich auf der uMT die kräftige Bodenbildung des sogenannten „braunlehmartigen gelblichroten Interglazialbodens", die in ähnlicher Ausbildung aus Löß im Profil Wegberg stattgefunden hat. Damit erweist sich diese Bodenbildung jünger als die Drenthe-Vereisung, so daß wir sie am ehesten in die letzte nachgewiesene echte Interglazialzeit, d. h. in die EemWarmzeit zu stellen geneigt sein könnten.

Nun mïssen wir auch mit einer kräftigen Bodenbildung während der Ohe-Warmzeit (nach K. PiCARD Treenewärmeschwankung) rechnen, die zwischen dem Drenthe-Stadium und dem Warthe-Stadium liegt. Die Ohe-Warmzeit soll nach G. von Der Brelie (1955) den Charakter eines Interglazials gehabt haben. Nach E. Mückenhausen (1939), K. Picard (1960) und E. H. Stremme (1960) sollen während der Ohe-Warmzeit (Treenewärmeschwankung) stark gebleichte Böden entstanden sein, die eine sehr lange Bildungszeit mit wahrscheinlich wärmerem Klima als dem der Gegenwart verlangen. Die Böden aus dem Material des Warthe-Stadiums sollen denen aus dem Material der Weichsel-Vereisung näher stehen. So wird die Bildung des braunlehmartigen gelblichroten Bodens auf der uMT (Frechener Bodenbildung) und aus Löß (Wegberger Bodenbildung) mit H. REMY (1960b) in die noch etwas umstrittene Drenthe/Warthe-Warmzeit gestellt.

Aus diesen Erwägungen heraus müssen wir alle Lösse im Hangenden der Wegberger Bodenbildung und alle mit ihnen parallelisierten Bildungen der übrigen Gruben in die Warthe- und Würm-Eiszeit stellen. Uber dem Wegberger Boden finden sich zwei Parabraunerde-Pseudogleye $\left(\mathrm{f}_{2}\right.$ und $\mathrm{f}_{3}$ ), die in Erkelenz beide als Parabraunerden ausgebildet sind (s. Abb. 25, 26). Zwei Parabraunerden folgen ebenfalls im unteren Teil des Profils der Ziegeleigrube Weglau bei Koblenz-Metternich (vgl. H. REMY \& W. PAAs 1959, H. REMY 1960b) über der Frechener Bodenbildung aus Schottern der uMT der Mosel. 
Die Bildung der jüngeren Parabraunerde (Erkelenzer Bodenbildung) war vor mindestens 48000 Jahren abgeschlossen, wie $\mathrm{C}^{14}$-Bestimmungen an Humusproben aus A-Horizonten der Erkelenzer Bodenbildung zeigen (Erkelenz: Gro-2675: 48500 1600 Jahre und Brühl nach freundlicher Mitteilung von H. REMY: Gro-2677:50000 \pm 2000 Jahre). Die $\mathrm{C}^{14}$-Bestimmungen, die älter sind als 30000 Jahre, müssen als Minimalwerte aufgefaßt werden, so daß das wirkliche Alter der Humusproben sicherlich größer ist. Die Erkelenzer Bodenbildung ist die letzte kräftige Bodenbildung in den rheinischen Lößprofilen.

Ahnliche Verhältnisse finden wir nach K. Brunnacker (1957) und J. FinK (1960) bei der Verlehmungszone des Linzer Komplexes im österreichischen und bayerischen Alpenvorland (=Stillfried A, = Oberfellabrunn der trockenen Lößlandschaft in Niederösterreich), wo es zur Ausbildung ähnlicher Bodentypen kam. Die Humuszonen dieses Komplexes besitzen ein vergleichbares Alter. So hat die Senftenberger Humuskohle oberhalb der Linzer Verlehmungszone ein Alter von mehr als 54000 Jahren; die Humuszonen des Oberfellabrunner Komplexes sind gleichfalls in einem Zeitraum entstanden, der vor 54000 Jahren zu Ende ging. Damit können wir mit großer Wahrscheinlichkeit die Erkelenzer Bodenbildung mit der von Stillfried A (= Linz) gleichsetzen.

Im österreichischen wie auch im bayrischen Alpenvorland findet sich auf der rißeiszeitlichen Hochterrasse stets nur e in e kräftige Bodenbildung, die gleichalt ist mit der Stillfrieder Verlehmungszone. Diese letzte, kräftige fossile Bodenbildung vertritt daher in den Periglazialgebieten das Riß/Würm- (=Eem) Interglazial (J. Fink 1960, K. BRunNACKER 1957). Damit ist die Erkelenzer Bodenbildung wahrscheinlich während der EemWarmzeit entstanden. Es folgt daraus, daß die Rheindahlener Bodenbildung (ältere Parabraunerde), die eine viel schwächere Verlehmung und Profilentwicklung aufweist, während einer Wärmeschwankung in der Warthe-Kaltzeit entstanden sein muß.

H. REMY (1960b) parallelisiert die Wegberger Bodenbildung gleichfalls mit der Drenthe/Warthe-Warmzeit, die Rheindahlener Bodenbildung sieht er jedoch als altersgleich an mit der Eem-Warmzeit, während der Erkelenzer Boden schon zum Altwürm gerechnet wird.

Wiederum eine andere Gliederung würde sich ergeben aus einem Vergleich mit der belgischen und nordfranzösischen Gliederung nach R. TAvernier \& J. DE Heinzelin (1957). Danach wäre die Wegberger Bodenbildung gleichalt mit der Eem-Warmzeit. Die Erkelenzer Bodenbildung hätte sich aus einem Altwürmlöß entwickelt, und der Rheindahlener Boden würde das Altwürm noch einmal in zwei Abschnitte gliedern.

Für die weniger ausgeprägte Krefelder, Frimmersdorfer und Brühler Bodenbildung im Hangenden des Erkelenzer Bodens gibt es keine sicheren stratigraphischen Hinweise. Möglicherweise sind diese Böden gleichalt mit dem Paudorfer Boden in Ósterreich.

Der sehr mächtige, einheitliche jüngste Löß oberhalb des Frimmersdorfer Bodens und des Naßbodens ist wie in Österreich und Süddeutschland sicherlich während des Maximums der Weichselvereisung (25000 bis 17000 Jahre v.h.) angeweht worden.

\section{Der Ablauf des Jungpleistozäns im Niederrheingebiet auf Grund der Lößgliederung}

Folgender Ablauf des Jungpleistozäns im Niederrheingebiet ergibt sich (s. Abb. 32): Nur wenige Angaben sind über den Drenthe-Löß zu machen; das Material ist sehr sandig und ganz verlehmt. Eine weitere Untergliederung der Drenthe-Ablagerungen auf Grund von Bodenbildungen ist bisher in dem hier behandelten Gebiet nicht möglich. Der Drenthe-Löß ist während der Drenthe/Warthe-Warmzeit zu einem braunlehmartigen gelblichroten Boden verwittert. Diese Wegberger Bodenbildung mit ihrer kräftigen Verlehmung und Färbung deutet auf Klimabedingungen hin, die während späterer Perioden in diesem Raum nicht mehr erreicht wurden. Wahrscheinlich hat ein warmes und feuchtes Klima 
geherrscht. Die starke Pseudovergleyung dieses Bodens ist ein sekundäres Merkmal, das später während feuchter Zeiten entstanden ist.

Die Warthe- und Weichsel-Eiszeit sind durch Klimaschwankungen in Abschnitte gegliedert. Die Schwankungen prägen sich in dem milden und feuchten Klima des Niederrheingebiets ungleich stärker in den Lößprofilen aus als in anderen mehr kontinentalen Lößprovinzen. So sind hier Klimaschwankungen kleineren Ausmaßes, die sich in trockenen Gebieten gar nicht erst ausprägen, durch Bodenbildungen nachzuweisen. Mit der Klimaverschlechterung zu Beginn der Wartheeiszeit setzte eine kräftige Solifluktion ein, der der interglaziale Boden zum größten Teil zum Opfer fiel. Nur in besonders günstigen Lagen hat sich Lößlehm erhalten können. Zum Bodenfließen kommen in weiten Gebieten Kryoturbationen hinzu, die typisch sind für den Zeitraum zwischen Bodenbildung und folgendem Lößabsatz.

Über der Fließerde folgt mit scharfer, ungestörter Grenze ein stets entkalkter älterer Warthe-Löß, der in einem kalten und trockenen Klima gebildet wurde. Die Rheindahlener Bodenbildung aus diesem Löß ist in keinem Fall ganz erhalten; meist tritt im oberen Teil ein ca. $50 \mathrm{~cm}$ mächtiger kräftigbrauner Horizont auf mit einem scharfkantigen Polyedergefüge und typischen Tonhäutchen auf den Gefügeelementen. Diese Merkmale weisen den Boden als Parabraunerde aus, die in einem feuchten und mäßig warmen Klima entstanden ist. Auf den feuchten Charakter dieser Bodenbildung deutet ebenfalls die häufig beobachtete Pseudovergleyung hin. Die Intensität der Bodenbildung läßt auf eine Wiederbewaldung in diesem Gebiet schließen. Der j. Warthe-Löß ist im Niederrheingebiet ziemlich einheitlich ausgebildet. Feuchtere Abschnitte zeichnen sich durch das Artefakte führende, schichtige Material der Ziegeleigrube Dreesen in Rheindahlen ab. Der EemBoden aus diesem Löß, die Erkelenzer Bodenbildung, wiederum eine Parabraunerde, ist in einigen Profilen noch ganz erhalten. Er zeigt eine sehr klare Horizontgliederung mit einem vom $\mathrm{A}_{3}$-Horizont sehr scharf abgesetzten Textur-B-Horizont. Das Gefüge des B-Horizonts ist meist bröckelig bis kantengerundet-kleinpolyedrisch. Dadurch unterscheidet es sich neben einer etwas helleren Färbung deutlich von der älteren Parabraunerde. Tondurchschlämmung, häufige Pseudovergleyung und scharfe Horizontgliederung weisen für die Bildung des Erkelenzer Bodens ebenfalls ein feuchtes und mäßig warmes Klima nach. Gleichzeitig hat im Niederrheingebiet der höchste nachweisbare Grundwasserstand seit der Eem-Warmzeit geherrscht. Subtypen von Parabraunerde und Gley und echte Gleye konnten nachgewiesen werden. Der Boden weist eine größere Profilentwicklung und eine kräftigere Verlehmung als der Rheindahlener Boden auf, so daß wir erst recht für die Zeit dieser Bodenbildung, die intensiver als die heutige war, eine Wiederbewaldung des Niederrheingebiets annehmen müssen.

Der Altere Weichsel-Löß ist im nördlichen Arbeitsgebiet meist ganz geschichtet und besitzt bisweilen an der Basis einen Geröllhorizont. In seiner Ausbildung entspricht er dem von F. Bordes (1954) beschriebenen limon à doublets. Im Tagebau FrimmersdorfWest treten in diesem sehr mächtigen Weichsel-Löß in mehrfacher Wiederholung kalkhaltige Braunerden und Naßböden auf. Seitlich verlieren sich diese Böden in schichtiges Material, das schließlich sogar die Frimmersdorfer Bodenbildung, die sich aus diesem Löß entwickelt hat, erfaßt. Dann ist die Grenze Alterer/Jüngerer Weichsel-Löß nur noch durch den Fazieswechsel zu erkennen. Daraus ergibt sich für die frühe Weichsel-Eiszeit eine Zeit sehr wechselnder Klimaverhältnisse, während der Bodenfließen, Lößbildung und Bildung von kalkhaltigen Braunerden und Naßböden in mehrfacher Wiederholung aufeinander folgten. Im ganzen gesehen haben keine ausgesprochen extrem kaltzeitlichen Klimabedingungen geherrscht. Große Lößmächtigkeiten haben sich nur in Hanglagen bilden und erhalten können; in ebener Lage ist der Altere Weichsel-Löß meist viel geringmächtiger.

Im südlichen Teil des Arbeitsgebiets ist die ausgeprägte Schichtung des Alteren Weichsel-Lösses nicht vorhanden; das Material ist nur noch durch sandigere Einlagerungen 


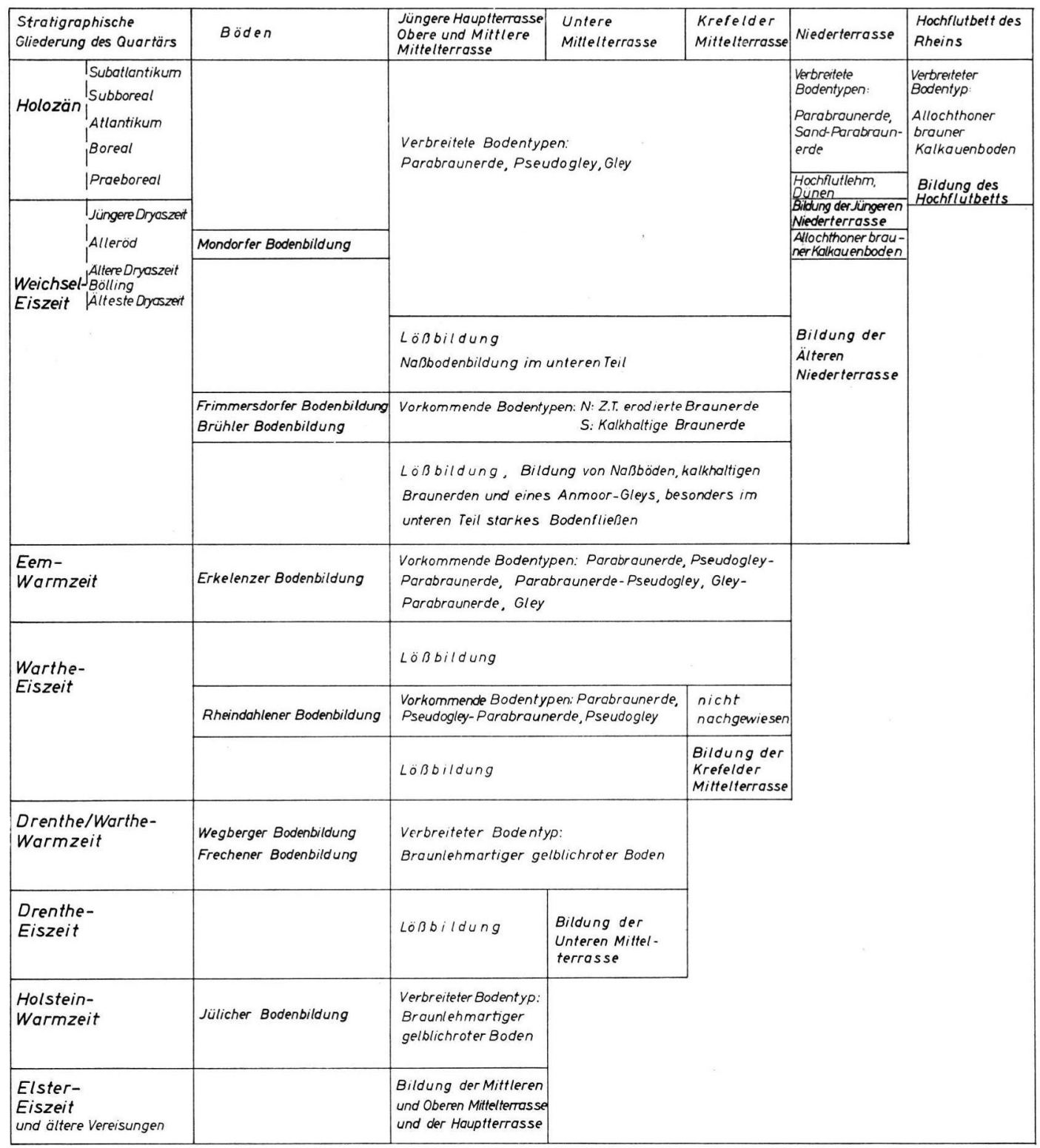

Abb. 32. Stratigraphische Gliederung der Terrassen im Niederrheingebiet mit Hilfe ihrer Verwitterungsdecken und Deckschichten.

schwach gestreift. Im Aufschluß Brühl N (s. Abb. 23) läßt sich dieser Löß durch eine kalkhaltige Braunerde nur noch einmal untergliedern. Die Klimaschwankungen haben sich damit in der etwas trockeneren Landschaft von Bonn bis Köln nicht so stark ausgeprägt wie im nördlichen Niederrheingebiet.

Die Abgrenzung einer feuchteren und einer trockeneren Landschaft in der niederrheinischen Bucht zeigt sich auch in dem Boden auf dem älteren Weichsel-Löß. Dieser ist im Norden in normaler, ebener Lage durch Solifluktion und Winderosion mehr oder 
weniger erodiert, so daß hier die typologische Ansprache nicht mit Sicherheit möglich ist. Mit Vorbehalt wird er als eine Braunerde angesprochen (Frimmersdorfer Boden).

Im südlichen Arbeitsgebiet ist der Boden (Brühler Boden) noch nicht entkalkt, hier prägt er sich nur durch eine schwache Verlehmung und Verbraunung aus, d. h. als eine geringmächtige kalkhaltige Braunerde.

Das jüngere Weichsel-Stadial hegann mit Bodenfließen; Geröllhorizonte treten etwas seltener auf und erreichen eine geringere Mächtigkeit. So folgt über der Frimmersdorfer Bodenbildung meist ein sehr homogener jüngster Löß, der im zentralen Lößgebiet Mächtigkeiten von $5 \mathrm{~m}$ und mehr erreichen kann und im unteren Teil einen Naßboden enthält. Fast während der ganzen Lößbildung muß so ein sehr gleichbleibend kaltes und trockenes Klima geherrscht haben; die Lößfolge zeigt im zentralen Gebiet keine weitere Gliederung durch Bodenbildungen oder Fließerden. Lediglich während der Bildung des unteren Teiles haben zeitweise feuchtere Klimabedingungen geherrscht, wie der Naßboden und die starken Würgeerscheinungen an der Basis zeigen.

In den Randgebieten der Lößverbreitung kam es nach der Bildung eines geringmächtigen Lösses und des Naßbodens durch sehr starke Winde zu einer zeitweisen Unterbrechung der Lößsedimentation, stellenweise zu einer kräftigen Winderosion, der meist der Naßboden und Teile der Frimmersdorfer Bodenbildung zum Opfer fielen. Selbst bis zu $1 \mathrm{~cm}$ Durchmesser große Gerölle wurden auf der Oberfläche bewegt. Nach der Bildung einer Steinsohle wurden schließlich wieder Flugsand und mit abnehmender Windstärke Sandlöß und Löß angeweht. Im Grenzgebiet der Lößverbreitung wurden nur Flugsand und Sandlöß abgesetzt.

Im Spätglazial und Holozän verwitterte der jüngste Löß im Niederrheingebiet unter normalen Bedingungen zu einer Parabraunerde. Die Mächtigkeit dieses Bodens ist im südlichen Teil des Arbeitsgebiets im Durchschnitt geringer als im nördlichen. Die braune Streifung in dem Sandlöß und Flugsand ist bei der Bodenbildung entstanden: Tonsubstanz wurde aus dem Oberboden ( $\mathrm{A}_{1}$ - und $\mathrm{A}_{3}$-Horizont) nach unten durchgeschlämmt und in braunen Tonanreicherungsbändern (B-Horizont) wieder abgesetzt. In feinem Lößmaterial hat sich der B-Horizont nicht aufgelöst, sondern hat einen einheitlichen B-Horizont mit den typischen Tonhäutchen auf den Gefügeelementen gebildet.

\section{Vergleich der Lösse im Niederrheingebiet mit den Lössen Nordfrankreichs und Belgiens}

Enge Beziehungen verbinden das Niederrheingebiet mit Nordfrankreich und Belgien. Bei einem ähnlichen Klima sind hier gleiche Bodentypen entstanden.

Der Wegberger Bodenbildung entspricht wahrscheinlich in Frankreich der sogenannte "limon rouge fendillé", der in Belgien dem „sol de Rocourt“ entspricht. Diese Bodenbildungen werden dort jedoch in das Eem verlegt (R. TAvernier \& J. DE HEInzelin 1957). Jeder folgenden Periode der Lößbildung ging eine Solifluktion voraus, die einen Geröllhorizont („caillouti") bildet. Die Artefakte finden sich meist in diesen Fließerden.

Die Industrie des "moustérien de tradition acheuléenne" findet sich in den basalen cailloutis des "loess récent I“, der stellenweise im unteren Teil humose Einlagerungen besitzt. Sehr häufig zeigt der "loess récent I“ an der Oberkante eine bis $2 \mathrm{~m}$ mächtige ausgesprochene Bodenprofilentwicklung. Die Oberfläche der Gefügeelemente weist typische Tonhäutchen auf. Damit zeigt dieser Boden, der „sol de Clypot“, eine ähnliche Ausbildung wie die Rheindahlener Bodenbildung in unserem Gebiet.

Die folgenden „cailloutis" des "loes récent II" führen Artefakte des oberen Moustiers (F. Bordes 1954). Stellenweise treten diese auch im unteren Teil des Lösses in humosen Einlagerungen auf. Selten ist der Boden auf dem „loes récent II“ noch erhalten; wenn er erhalten ist, zeigt er sehr deutlich den Charakter eines „sol hydromorphe à horizon B 
textural bien développé“ (R. Tavernier \& J. DE Heinzelin 1957). Damit weist dieser Boden, der „sol de Kesselt“, gleiche Merkmale auf wie die Erkelenzer Bodenbildung des Niederrheingebiets. In den überlagernden cailloutis findet sich eine Chatelperron-Industrie (Périgord O).

Der "loess récent III" tritt in Nordfrankreich und Belgien in zwei verschiedenen Fazies auf: 1. als ungeschichteter, pulvriger Löß (type Brabantien), der auf das Trockengebiet beschränkt ist, und 2. als geschichteter Löß (limon à doublets), der in den nördlichen meernahen Regionen verbreitet ist und stellenweise durch einen „caillouti“ zweigeteilt ist. Im mittleren Teil des "loess récent III“ findet sich das Perigord III und im oberen Teil, schon in der rezenten Verlehmungszone, der "terre à brique“, das Perigord IV (=Gravette) und das Protosolutré.

Die Altersbestimmung für das Périgord IV (spätes Aurignac mit Gravette-Spitzen) des Abri Pataud in Les Eyzies, Dordogne, ergab ein Alter von 24000 Jahren (RuBiN \& SuEss 1955). Damit ist das Gravette in Frankreich gleichalt mit dem österreichischen, und der Altere Weichsel-Löß im Niederrheingebiet und in Osterreich vertritt fast den ganzen „loess récent III“, während der Jüngere Weichsel-Löß in Nordfrankreich nicht oder nur in ganz geringer Mächtigkeit vertreten ist.

Diese Deutung wird gestützt durch eine Beobachtung von R. TAvernier \& J. DE HEINZELIN (1957): „Dans plusieurs affleurements dans la région sablo-limoneuse on trouve des dépôts sableux, parfois épais de plusieurs mètres, présentant un caractère éolien et des indices de climat froid, qui sont situés entre l'horizon Allerød et des formations qui, par leur position et leur facies, semblent appartenir au Limon Récent III. Sous ces dépôts sableux, la partie supérieure des formations du Limon Recent III présente parfois une lehmification qui in lique une pédogenèse plus importante que celle qui correspond à l'oscillation Allerød."

$\mathrm{Da}$ die Bölling-Schwankung nur eine unbedeutende Verlehmung hervorgerufen haben kann, ist in dieser begrabenen Bodenbildung auf dem „loess récent III“ die Frimmersdorfer Bodenbildung zu sehen, und der Jüngere Weichsel-Löß ist so wahrscheinlich in dem beschriebenen Gebiet durch lehmig-sandige Ablagerungen vertreten.

\section{Stratigraphische Gliederung der Terrassen im Niederrheingebiet mit Hilfe ihrer Böden und Deckschichten}

Im Anschluß an die stratigraphische Gliederung der Deckschichten und den bodenkundlichen Vergleich der Terrassen im Niederrheingebiet soll nun eine Einordnung der Terrassen in die allgemeine Quartärgliederung versucht werden. Während die bodenkundliche Methode bei den jüngeren Terrassen noch eine genauere Altersbestimmung erlaubt, sind Schlußfolgerungen für die älteren Stufen nur in allgemeinerem Rahmen möglich. Das Ergebnis ist in Abb. 32 zusammengefaßt.

\section{Das Hochflutbett des Rheins}

Nach der Bildung der Niederterrasse setzte zu Beginn des Holozäns die Ausräumung und damit die Anlage des Hochflutbetts des Rheins ein. Zu Beginn des Boreals hatte nach H. Nietsch $(1940,1953)$ bei Köln schon die Verlandung der zugehörigen, in die Oberfläche der Niederterrasse eingesenkten Rinnen begonnen. Der Absatz der Hochflutlehme und Dünen auf der Niederterrasse steht nach H. BREDDIN (1926) mit der Bildung des Hochflutbetts in direkter zeitlicher Beziehung. Stellenweise überlagern die Dünensande die Hochflutbildungen; meist gehen jedoch beide Bildungen ineinander über.

Der typische Boden des Hochflutbetts ist der allochthone braune Kalkauenboden, der periodisch bei Rheinhochwasser aufgekalkt wird unter gleichzeitigem Absatz von rezentem A uenlehm. Dieser Boden zeigt damit, daß heute noch im Hochflutbett bei Hochflut eine 
geringfügige Sedimentation stattfindet. In der übrigen Zeit, während der der Rhein sich auf sein Bett zurückgezogen hat, wird nicht mehr sedimentiert.

Im Hochflutbett hat der Rhein, wie die verlandeten Altwasserrinnen zeigen, seit dem frühen Boreal immer wieder bis in jüngste Zeit seinen Lauf geändert (A. STEEger 1952).

\section{Die Niederterrasse}

Die morphologisch meist einheitliche NT des Niederrheingebiets setzt sich aus zwei Schotterkörpern zusammen, der äNT und der jNT.

a) Die Jüngere $\mathrm{Niederterrasse}$

Das Alter dieser jNT läßt sich recht genau festlegen. Im Profil Mondorf (32) liegt sie als geringmächtige, bimsführende Lage über dem allochthonen braunen Kalkauenboden des Alleröds, im Profil Beuel (31) über frostgestörten Kiesen und Sanden der äNT. Mit dem Praeboreal war die Aufschotterung schon abgeschlossen; denn schon mindestens im Boreal begann die Verlandung der Altwasserrinnen auf der Terrasse (H. NiEtsch 1940). Diese Beobachtungen verlegen die Bildungszeit der jNT eindeutig in die Jüngere Dryaszeit.

Die Erosion vor Ablagerung der Laacher Bims führenden Schotter ist nicht sicher festzulegen. Wahrscheinlich hat sie aber schon zu Beginn des Alleröds stattgefunden; denn der allerödzeitliche Brohltaltrass findet bei seiner Bildung schon ein tief unter das Niveau der äNT erodiertes Rheinbett vor (W. Ahrens 1930).

b) Die Ältere Niederterrasse

Die Ausrämung der KT und der Beginn der Aufschotterung der äNT sind im Arbeitsgebiet mit bodenkundlichen Methoden nicht festzulegen. Aus der Einschaltung von vulkanischen Mineralien der Bimseruptionen schließen J. FrecheN \& G. vaN DEN Boom (1959), daß die älteren Niederterrassenschotter aus mehreren übereinanderliegenden Teilschotterdecken bestehen, die im Würm II und III, möglicherweise auch schon im Würm I gebildet wurden.

Das Ende der Schotterbildung der äNT wird festgelegt durch die Bildung des allochthonen braunen Kalkauenbodens im Profil Mondorf (32), der auf Grund seiner starken Bimsführung in das Alleröd gestellt wird. Damit bildet die Altere Dryaszeit die obere Grenze für die Ablagerung der Älteren Niederterrassenschotter.

3. Die Krefelder Terrasse und die Untere Mittelterrasse

Die KT wurde ursprünglich als eine Mittelterrasse angesehen (G. FLIEGEL 1910); sie sollte also während der vorletzten Vereisung entstanden sein. Während F. WILDSChrex (1929) die KT ebenfalls noch als gleichalt mit der vorletzten Vereisung auffaßt, erklärt A. SteEger (1925) sie als jünger, weil sie auch noch östlich der Stauchmoränen entwickelt ist. H. BreDDIN (1929) kommt auf Grund seiner Untersuchungen bei Straelen zu einer ähnlichen Folgerung; er bezeichnet die KT als Oberstufe der NT und stellt sie in die letzte Vereisung. A. SteEger betont noch 1952, daß der Begriff „Krefelder Terrasse“ rein morphologisch aufzufassen sei. Auf Grund von bodenkundlichen Untersuchungen stellt E. Mückenhausen (1954) die Bildung der "Jüngeren Mittelterrasse“ (KT) ebenfalls noch in das Würm.

In neuerer Zeit ist das rißeiszeitliche Alter der $\mathrm{KT}$ wieder stärker betont worden. So wird sie von W. Quitzow (1956) in das Warthe-Stadium gestellt; K. N. Thome (1958, 1959) sieht in ihr überhaupt nur eine Erosionsterrasse, herausgeschnitten aus der uMT und entstanden bei dem staffelweisen Eisrückzug aus dem Niederrheintal nach dem Drenthevorstoß. 
Die uMT und die glazialen Schotter und Sande der Rißvereisung sind gleichalt mit dem Maximalvorstoß der Norddeutschen Inlandvereisung, dem Drenthevorstoß der SaaleVereisung (vgl. A. Steeger 1913, 1925, W. Löscher 1922, H. G. Steinmann 1925, J. D. DE Nota 1956).

Wie oben gezeigt wurde, ist die uMT zu einem braunlehmartigen gelblichroten Interglazialboden verwittert, der Frechener Bodenbildung. Dieser Boden, der während der Drenthe/Warthe-Warmzeit gebildet wurde, konnte auf der KT in keinem Aufschluß beobachtet werden. So liegt der Schluß nahe, daß die KT jünger als die Drenthe/WartheWarmzeit ist. Andererseits wurde bereits in einem jüngeren Warthe-Abschnitt über der KT ein jüngerer Warthe-Löß abgesetzt. Als Bildungszeit für die Aufschotterung ergibt sich damit ein älterer Warthe-Abschnitt.

Mit großer Wahrscheinlichkeit müssen wir die KT auch dann in die Warthe-Eiszeit stellen, wenn wir mit H. REMy (1960b) die Erkelenzer Bodenbildung in das Altwürm und die Rheindahlener Bodenbildung in das Eem stellen würden. Dann läge auf der KT, die wie die übrigen Terrassen des Niederrheingebiets sicherlich glazialklimatischer Entstehung ist, der Altwürmlöß. Wenn wir aber die Wegberger und die Frechener Bodenbildung in Anlehnung an die belgische und nordfranzösische Lößgliederung in die Eem-Warmzeit stellen würden, dann läge der Schluß nahe, daß die KT jünger als die Eem-Warmzeit und zu Beginn des Altwürms entstanden wäre.

Diese Ausführungen mögen zeigen, wie die stratigraphische Stellung gerade der KT von der Gliederung und der stratigraphischen Einstufung der Deckschichten abhängig ist. Daher ist eine klare und eindeutige Lösung der Altersfrage bei der KT mit Hilfe bodenkundlicher Methoden nur möglich im Rahmen einer endgültigen Klärung der Lößstratigraphie. Auf Grund der hier erarbeiteten Lößgliederung erweist sich die KT als eine echte Mittelterrasse.

\section{Die Obere Mittelterrasse und die Jüngere Hauptterrasse}

Die Kiese und Sande der HT sowie der oMT und uMT sind zu einem braunlehmartigen gelblichroten Interglazialboden verwittert. Die Bodenbildung auf den beiden älteren Stufen ist aber im Vergleich zu der drenthezeitlichen jüngeren Stufe sehr viel kräftiger. Die Verwitterung der uMT hat wahrscheinlich im Ohe-Interglazial stattgefunden. Die ungleich stärkere Bodenbildung der beiden älteren Stufen geht mit großer Wahrscheinlichkeit auf eine Summierung des Effektes älterer Interglazialzeiten zurück.

Die Aufschotterung der oMT wird heute allgemein in die frühe Mindeleiszeit, die der jHT in die Günzeiszeit gestellt. So hat die oMT neben der Verwitterung des Ohe-Interglazials noch die der Holstein-Warmzeit, die jHT dazu die der Cromer-Warmzeit erlebt.

Auf der jHT konnte in den Deckschichten nur in zwei Profilen Drenthelöß nachgewiesen werden. In allen übrigen Profilen ist nur noch ein mehr oder weniger vollständiges Würmlößprofil zu beachten. Die älteren Lösse sind offenbar durch starke Solifluktion, Abspülung usw. weitgehend abgetragen worden.

\section{F. Angeführte Schriften}

Ahrens, W.: Die Trennung der "Niederterrasse“ am Mittel- und Niederrhein in einen diluvialen und einen alluvialen Teil auf Grund der Geröllführung. - Z. deutsch. geol. Ges. 82, S. 129-141, Berlin 1930.

Bordes, F.: Les limons quaternaires du Bassin de la Seine. - Arch. Inst. Paléont. Humaine, Mém. 26, Paris 1954.

BRANDTNER, F.: Jungpleistozäner Löß und fossile Böden in Niederösterreich. - Eisz. u. Geg. 4/5, S. 49-82, Ơhringen 1954. - - Lößstratigraphie und palaeolithische Kulturabfolge in Niederösterreich und den angrenzenden Gebieten. - Eisz. u. Geg. 7, S. 127-175, OOhringen 1956. 
Breddin, H.: Löß, Flugsand und Niederterrasse am Niederrhein. - Jb. preuß. geol. L.-A. 46 (1925), S. 635-662, Berlin 1926. - - Uber Flußterrassen, diluviale und aliuviale Bodenbewegungen im westlichen Niederrheingebiet. - Jb. preuß. geol. L.-A. 50 (1929), S. 806845, Berlin 1930.

v. D. Brelie, G.: Die pollenstratigraphische Gliederung des Pleistozäns in Nordwestdeutschland. 2. Die Pollenstratigraphie im jüngeren Pleistozän. - Eisz. u. Geg. 6, S. 25-38, Ơhringen 1955.

Brelie, G. v. D., Kilpper, K. \& Teichmüller, R.: Das Pleistozän-Profil von Frimmersdorf an der Erft. - Fortschr. Geol. Rheinld. u. Westf. 4, S. 179-196, Krefeld 1959.

v. D. Brelie, G. u. Rein, U.: Pollenanalytische Untersuchungen zur Gliederung des Pleistozäns am linken Niederrhein. - Geologie en Mijnbow 18, S. 423-425, 1956.

Brunnacker, K.: Regionale Bodendifferenzierungen während der Würmeizeit. - Eisz. u. Geg. 7, S. 43-48, Ơhringen 1956.

FINK, J.: Zur Korrelation der Terrassen und Lösse in Ósterreich. - Eisz. u. Geg. 7, S. 49-77, Ohringen 1956. - - Leitlinien einer österreichischen Quartärstratigraphie. - Mitteilungen d. Geol. Ges. 53, S. 249-266, Wien 1960.

Firbas, F.: Das absolute Alter der jüngsten vulkanischen Eruptionen im Bereich des Laacher Sees. - Naturwiss. 40, S. 54-55, Berlin 1953.

Frechen, J.: Die Herkunft der spätglazialen Bimstuffe in mittel- und süddeutschen Mooren. Geol. Jb. 67, S. 209-230, Hannover 1952. - - Die Tuffe des Laacher Vulkangebietes als quartärgeologische Leitgesteine und Zeitmarken. - Fortschr. Geol. Rheinld. u. Westf. 4, S. 363-370, Krefeld 1959.

Frechen, J. \& v. D. Boom, G.: Die sedimentpetrographische Horizontierung der pleistozänen Terrassenschotter im Mittelrheingebiet. - Fortschr. Geol. Rheinld. u. Westf. 4, S. 89-125, Krefeld 1959.

Frechen, J. \& Rosauer, E.: Aufbau und Gliederung des Würm-Löß-Profiles von Kärlich. - Fortschr. Geol. Rheinld. u. Westf. 4, S. 267-282, Krefeld 1959.

Freising, H.: Neue Ergebnisse der Lößforschung im nördlichen Württemberg. - Jh. geol. Abt. württ. statist. L. A. 1, S. 54-59, Stuttgart 1951.

Gross, H.: Die bisherigen Ergebnisse von C14-Messungen und palaeontologischen Untersuchungen für die Gliederung und Chronologie des Jungpleistozäns in Mitteieuropa und den Nachbargebieten. - Eisz. u. Geg. 9, S. 155-187, Öhringen 1958.

DE Jong, J. D.: Sedimentpetrographische Untersuchungen in Terrassenschottern im Gebiet zwischen Krefeld und Kleve. - Geologie en Mijnbow, 18, S. 389-394, 1956.

Jungbluth, F. A.: Die Terrassen des Rheins von Andernach bis Bonn. - Verh. naturhist. Ver. Rheinl. Westf. 73, (1916), S. 1-103, Bonn 1917.

Kaiser, E.: Die Ausbildung des Rheintals zwischen Neuwieder Becken und Bonn-Kölner Bucht. Verh. 14. deutsch. Geographentag Cöln 1903, S. 206-215, Berlin 1903. - - Die Entstehung des Rheintals. - Verh. Gesellschaft deutscher Naturforscher und Arzte, Vortrag in Cöln 1908.

KubıËNA, W. L.: Bestimmungsbuch und Systematik der Böden Europas. - Stuttgart 1953. - -Zur Mikromorpho'ogie, Systematik und Entwicklung der rezenten und fossilen Lößböden. Eisz. u. Geg. 7, S. 102-112, Öhringen 1956.

LaAtsch, W.: Dynamik der mitteleuropäischen Mineralböden. - Dresden und Leipzig 1954.

I.̈sCHER, W.: Ruhrdiluvium und Eiszeitbildungen. - Glückauf 58, S. 229-231, Essen 1922.

Maarleveld, G. C.: Ergebnisse von Kiesanalysen im Niederrheingebiet. - Geologie en Mijnbow 18, S. 411-415, 1956.

Monreal, W.: Schwermineral- und Gerölluntersuchungen in den Flußterrassen östlich und westlich des Viersener Höhenzuges am linken Niederrheingebiet. - Decheniana 111, H. 2, S. 103-139, Bonn 1959.

Mǘckenhausen, E.: Die Böden des Warthestadiums in Nordhannover im Vergleich zum westlichen Alt- und zum östlichen Jungdiluvium. - Abh. nat. Ver. Bremen 31, S. 334-346, Bremen 1939. - - Über gleyartige Böden im Rheinland. - Z. f. Pflanzenernährung, Düngung, Bodenkunde 50 (95), S. 113-134, 1950. - - Fossile Böden im nördlichen Rheinland. Z. f. Pflanzenernährung, Düngung, Bodenkunde 65 (110), S. 81-103, 1954. - - Die wichtigsten Böden der Bundesrepublik Deutschland. - Wiss. Schriftenreihe des AID, XIV, Bad Godesberg 1957. - - Die stratigraphische Gliederung des Lößkomplexes von Kärlich im Neuwieder Becken. - Fortschr. Geol. Rheinld. u. Westf. 4, S. 283-300, Krefeld 1959.

Mückenhausen, E. \& Wortmann, H.: Erläuterungen zur Bodenübersichtskarte von NordrheinWestfalen. - Geologisches Landesamt Nordrhein-Westfalen 1958. 
NARR, K. J.: Alt- und mittelpalaeolithische Funde aus rheinischen Freilandstationen. - Bonner Jahrbücher 151, S. 5-51, Bonn 1951.

NiETsCi, H.: Pollenanalytische Untersuchung auf der Niederterrasse bei Köln. - Z. deutsch. geol. Ges. 92, S. 350-364, Berlin 1940. - Zur spät- und nacheiszeitlichen Entwicklung einiger Flußtäler im nordwestlichen Deutschland. - Z. deutsch, geol. Ges. 104, S. 29-40, Hannover 1953.

PAAs, W.: Erläuterungen der bodenkundlichen Aufnahme an der Trasse der Nord-West-Ơlleitung zwischen Ratingen und Rheindorf bei Leverkusen. - Nicht veröffentlicht; im Archiv des geologischen Landesamts in Krefeld, 1959.

Picard, K.: Zur Untergliederung der Saalevereisung im Westen Schleswig-Holsteins. - Z. deutsch. geol. Ges. 112, 2. Teil, S. 316-325, Hannover 1960.

QuaAs, A.: Löß und lößähnliche Bildungen am Niederrhein. - Neues Jb. für Min. etc. 44, S. 274342, Stuttgart 1921.

Qurtzow, H. W.: Die Terrassengliederung im niederrheinischen Tieflande. - Geologie en Mijnbow 18, S. 357-373, 1956.

Remy, H.: Zur Gliederung des Lösses bei Kärlich und Bröhl am unteren Mittelrhein mit besonderer Berücksichtigung der Faunen. - Fortschr. Geol. Rheinld. u. Westf. 4, S. 323-330, Krefeld. - - Die zeitliche Stellung der Rodderbergtuffe im rheinischen Löß. - Decheniana 112, S. 271-278, Bonn 1960 (1960a). - - Der Löß am unteren Mittel- und Niederrhein. Eisz. u. Geg. 11, S. 107-120, OOhringen 1960 (1960b).

Remy, H. \& PaAs, W.: Die Lößprofile von Koblenz-Metternich und Moselweiß. - Fortschr. Geol. Rheinld. u. Westf. 4, S. 331-336. Krefeld 1959.

Scheffer, F. \& Schachtschabel, P.: Lehrbuch der Agrikulturchemie und Bodenkunde, I. Teil: Bodenkunde. - Stuttgart 1960.

ऽ Снönhals, E.: Ưber fossile Böden im nichtvereisten Gebiet. - Eisz. u. Geg. 1, S. 109-130, Ơhringen 1951.

Corls and Men, Yearbook of Agriculture. - Washington 1938.

Steeger, A.: Beziehungen zwischen Terrassenbildung und Glazialdiluvium im nördlichen niederrheinischen Tieflande. - Abh. d. Ver. f. naturw. Erforschung d. Niederrheins, S. 137163. Krefeld 1913. - - Das glaziale Diluvium des niederrheinischen Tieflandes. - Beitrag I-VIII. - Ber. Versamml. niederrhein. geol. Ver. 1923, S. 1-46, Bonn 1925, Beitrag VIII: 1925, S. 48-60. Bonn 1926. - - Diluviale Bodenfrosterscheinungen am Niederrhein. Geol. Rdsch. 34, S. 520-538, Stuttgart 1944. - - 100 Jahre Eiszeitforschung am Niederrhein. - Der Niederrhein 19, S. 57-63, Krefeld 1952. - - Weitere Beobachtungen über das Vorkommen von Bimsstein in den jüngsten Rheinterrassen des unteren Niederrheins. Geol. Jb. 69, S. 387-390, Hannover 1954.

Sternmann. G.: Über das Diluvium am Rodderberge. - S.-Ber. naturh. Verh. Rheinl. u. Westf. f. 1906 A, S. 21-33, Bonn 1907. - - Die diluvialen Ruhrterrassen und ihre Beziehungen zur Vereisung. - Ber. Vers. niederrhein. geol. Ver. (1924), S. 29-45, Bonn 1925.

Stremme, H. E.: Bodenbildung auf Geschiebelehmen verschiedenen Alters in Schleswig-Holstein. Z. deutsch. geol. Ges. 112, 2. Teil, S. 299-308, Hannover 1960.

Tavenier, R.. \& Heinzelin, J. DE: Chronologie du Pléistocène Superieur, plus particulièrement en Belgique. - Geologie en Mijnbow 19, S. 306-309, 1957.

Thome, K. N.: Die Begegnung des nordischen Inlandeises mit dem Rhein. - Geol. Jb. 76, S. 261308, Hannover 1958. - - Eisvorstoß und Flußregime an Niederrhein und Zuider See im Jungpleistozän. - Fortschr. Geol. Rheinld. u. Westf. 4, S. 197-246, Krefeld 1959.

VINKEN, R.: Sedimentpetrographische Untersuchung der Rheinterrassen der östlichen Niederrheinischen Bucht. - Fortschr. Geol. Rheinld. u. Westf. 4, S. 127-170, Krefeld 1959.

Wilckens, O.: Materialien und Beiträge zur Geologie und Palaeontologie der Umgegend von Bonn VIII. Leuzitphonolithuffe in der Hochterrasse von Leubsdorf bei Linz am Rhein. - Ber. d. niederrhein. geol. Ver. (1930/31), 24/25, S. 75-77, 1932.

Wildschrey, Ed.: Das niederrheinische Diluvium. - Ber. d. niederrhein. geol. Ver. (1924), S. 45-68, Bonn 1925.

W'oldstedt, P.: Probleme der Terrassenbildung. - Eisz. u. Geg. 2, S. 36-44, OOhringen, 1952 (1952a). - - Die Stellung des Niederrheingebietes im Rahmen des europäischen Quartärs. - Der Niederrhein 19, S. 55-56, 1952 (1952b). - - Saaleeiszeit, Warthestadium und Weichseleiszeit in Norddeutschland. - Eisz. u. Geg. 4/5, S. 34-48, OOhringen 1954. - - Über die Gliederung des Würmeiszeit und die Stellung der Lösse in ihr. - Eisz. u. Geg. 7, S. 7886, OOhringen 1956. - - Das Eiszeitalter, Band I und II, Stuttgart 1954 und 1958. - Die Letzte Eiszeit in Nordamerika und Europa. - Eisz. u. Geg. 11, S. 148-165, Öhringen 1960.

WunstoRF, W.: Uber Löß und Schotterlehm im niederrheinischen Tiefland. - Verh. naturh. Vẹr. d. preuß. Rheinl. u. Westf. 69 (1912), S. 293-340, Bonn 1913, 
ZimmermanN II, E.: Löß und Decksand am Südrande der Niederrheinischen Bucht. - Jb. preuß. geol. L.-A. (1918), S. 155-179, Berlin 1920.

Zimmermann, K.: Zum Problem der maßstabsgerechten Abbildung speziell von Bodendünnschliffen. - Zeiss-Mitteilungen 1, 10. Heft, S. 363-376, 1959.

ZonNeveld, J. I. S.: Schwermineralgesellschaften in niederrheinischen Terrassensedimenten. Geologie en Mijnbow 18, S. 395-401, 1956.

Brunnacker, K.: Die Geschichte der Böden im jüngeren Pleistozän in Bayern. - Geol. Bavarica, Nr. 34, S. 1-95, München 1957.

KaIsER, K.: Gliederung und Formenschatz des Pliozäns und Quartärs am Mittel- und Niederrhein sowie in den angrenzenden Niederlanden unter besonderer Berücksichtigung der Rheinterrassen. - Köln und die Rheinlande, Festschrift zum XXXIII. Deutschen Geographentag vom 22. bis 26. Mai 1961 in Köln, Wiesbaden 1961.

Manuskr. eingeg. 5. 6. 1961.

Anschrift des Verf.: Diplom-Geol. Dr. W. Paas, Institut f. Bodenkunde der Universität, Bonı, Nußallee 13. 